University of South Carolina

Scholar Commons

Theses and Dissertations

Spring 2019

Plasma Surface Functionalization of AFP Manufactured

Composites for Improved Adhesive Bond Performance

Ibrahim Sarikaya

Follow this and additional works at: https://scholarcommons.sc.edu/etd

Part of the Mechanical Engineering Commons

Recommended Citation

Sarikaya, I.(2019). Plasma Surface Functionalization of AFP Manufactured Composites for Improved Adhesive Bond Performance. (Master's thesis). Retrieved from https://scholarcommons.sc.edu/etd/5158

This Open Access Thesis is brought to you by Scholar Commons. It has been accepted for inclusion in Theses and Dissertations by an authorized administrator of Scholar Commons. For more information, please contact digres@mailbox.sc.edu. 


\title{
PLASMA SURFACE FUNCTIONALIZATION OF AFP MANUFACTURED COMPOSITES FOR IMPROVED ADHESIVE BOND PERFORMANCE
}

\author{
by \\ Ibrahim Sarikaya \\ Bachelor of Engineering \\ Yildiz Technical University, 2011
}

Submitted in Partial Fulfillment of the Requirements

For the Degree of Master of Science in

Mechanical Engineering

College of Engineering and Computing

University of South Carolina

2019

Accepted by:

Ramy Harik, Director of Thesis

Tanvir Farouk, Reader

Cheryl L. Addy, Vice Provost and Dean of the Graduate School 
(C) Copyright by Ibrahim Sarikaya, 2019 All Rights Reserved. 


\section{ACKNOWLEDGMENTS}

I would like to express my deepest appreciation for his aspiring guidance, invaluable friendly contribution during the research to my advisor, Dr. Ramy Harik, who supported me throughout my master degree. Also, I would like to thank my committee member, Dr. Tanvir Farouk, for his constructive suggestions and comments for the research. Furthermore, I would like to thank USC 2C26 student team at McNair Center for their help in the experimental work: Peter Gilday, Megan Ryan, Cody Shuman, Michael Haddad and Malik Tahiyat.

I would like to also thank NASA Langley Research Center and the Advanced Composite Consortium. This research was funded by NASA under Award Nos. NNL09AA00A and 80LARC17C0004. I would like to thank the 2C26 CRT partners: John Connell from NASA Langley Research Center for the great and instrumental support; Eileen Kutscha and Kay Blohowiak from The Boeing Company; Xiaomei Fang,

Gurbinder Sarao, and Wenping Zhao from UTC Aerospace. I would like to also thank for their support in this project from BTG Labs: Gilles Dillingham, and Derrick Merrell; and Plasmatreat: Josh Schlup; Solvay: Alejandro Rodriguez.

My acknowledgment would be incomplete without thanking my great friend Erdem Kantemur for his support, friendship and best Mediterranean foods from his restaurant from the beginning of my master degree until to the end. 
Last but not least, I would like to extend my deepest gratitude to my family members and friends for almost unbelievable supporting and encouraging me for the years, especially my parents. 


\begin{abstract}
High-performance composite structures not only require a reliable fabrication process when creating primary structures, but also a high fidelity and repeatable bonding process for the assembled components. During the assembly process, surface contaminants are a major concern as they have the potential to compromise the bond quality resulting in poor bond strength, low failure load, and undesirable failure modes of the adhesively bonded structures. This is further complicated by composite materials inherently possessing low surface energy and thus exhibiting low adhesive property. Therefore, detecting and removing contaminants on the pre-bond composite surface is an active research topic in pursuit of a safer operation of composite structures.

In this research, composite panels were fabricated with Hexcel IM7/8552 carbon fiber using an automated fiber placement (AFP) machine by IMT®. An atmospheric pressure air driven plasma discharge by Plasmatreat ${ }^{\circledR}$ was utilized to treat the surface of the composite material. Atmospheric Pressure Plasma Jet (APPJ) treatment effects of carbon fiber reinforced polymers (CFRPs) were investigated with surface characterization methods as well as with double cantilever beam (DCB) tests. A water contact angle (WCA) measurement for assessment of surface energy, X-ray photoelectron spectroscopy (XPS) to understand surface elemental composition, scanning electron microscopy (SEM) to observe surface morphological changes, and atomic force microscopy (AFM) to analyze surface topographical changing were used to determine the effects of the APPJ treatment. Two composite laminates were bonded with
\end{abstract}


Metlbond1515 3M, and DCB testing was performed to two groups of these bonded laminates to differentiate the bond performance between (1) pristine $\mathbf{P}$ and (2) treated $\mathbf{T}$ composite laminates. Mode I interlaminar fracture toughness was calculated for each test while failure modes were also assessed. A thorough test plan was conducted and experimental results were analyzed. The analysis demonstrated that APPJ treatment has a positive effect on the CFRP bonding effectiveness through the functionalization of the composite surface. 


\section{TABLE OF CONTENTS}

ACKNOWLEDGMENTS ............................................................................ iii

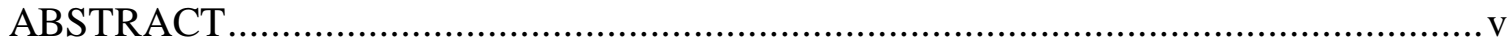

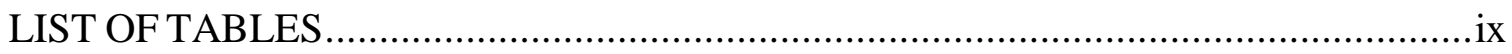

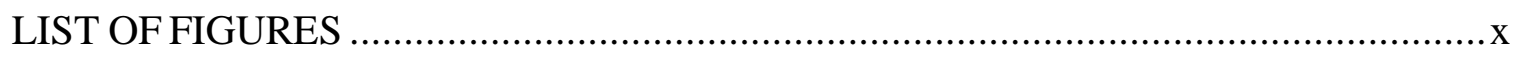

LIST OF SYMBOLS ...................................................................................

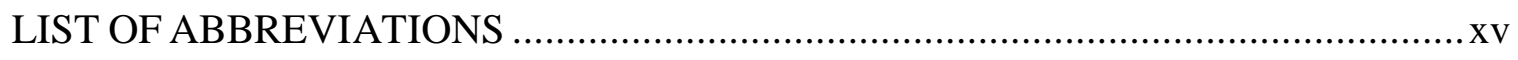

CHAPTER 1 INTRODUCTION..................................................................... 1

1.1 BACKGROUND ................................................................................. 1

1.2 PLASMA TREATMENT .............................................................. 2

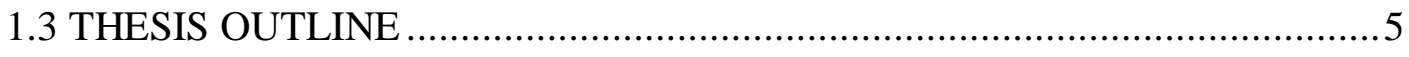

CHAPTER 2 LITERATURE REVIEW ............................................................. 7

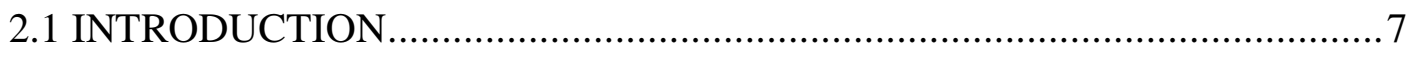

2.2 PLASMA SURFACE TREATMENT ....................................................

2.3 SURFACE CHARACTERIZATION................................................... 15

2.4 MODE I INTERLAMINAR FRACTURE TEST .....................................22

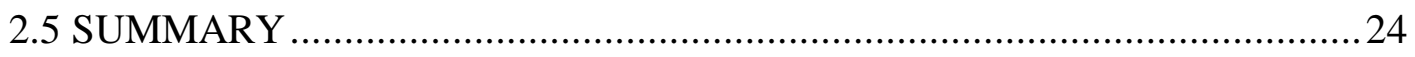

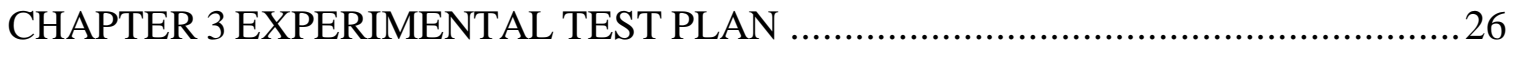

3.1 EXPERIMENTAL OVERVIEW ...................................................26

3.2 MATERIAL AND TEST COUPON PREPARATION .............................29

3.3 OPEN-AIR PLASMA TREATMENT ................................................. 38 


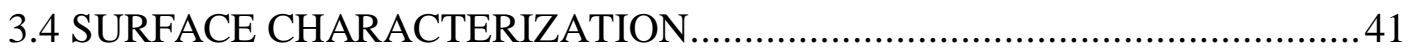

3.5 DOUBLE CANTILEVER BEAM (DCB) TEST ……………….................45

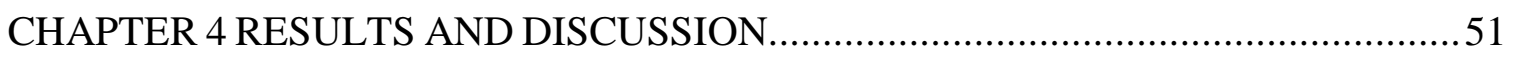

4.1 WATER CONTACT ANGLE (WCA) …………….................................51

4.2 SCANNING ELECTRON MICROSCOPY (SEM) ……………...................55

4.3 ATOMIC FORCE MICROSCOPY (AFM) …………………................58

4.4 X-RAY PHOTOELECTRON SPECTROSCOPY (XPS) ...............................61

4.5 DOUBLE CANTILEVER BEAM (DCB) TEST …………………..............67

CHAPTER 5 CONCLUSIONS AND FUTURE WORK ……………………............75

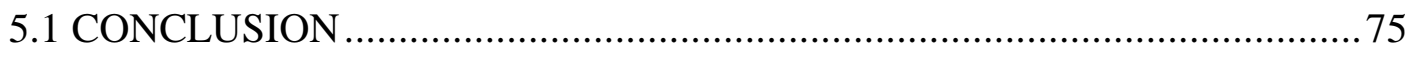

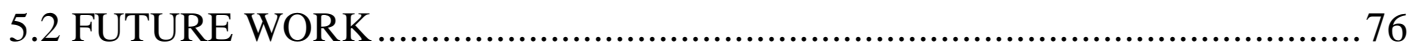

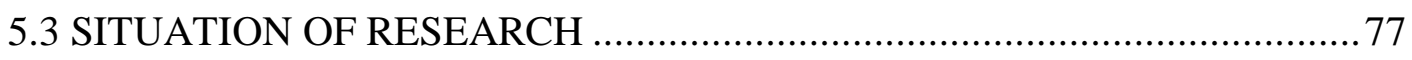

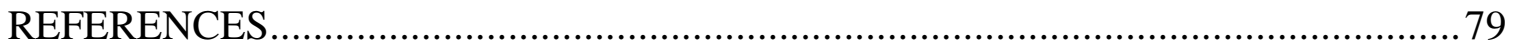

APPENDIX A STANDARDIZATION FLOWCHARTS .........................................90 


\section{LIST OF TABLES}

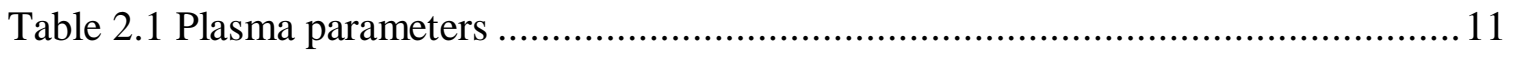

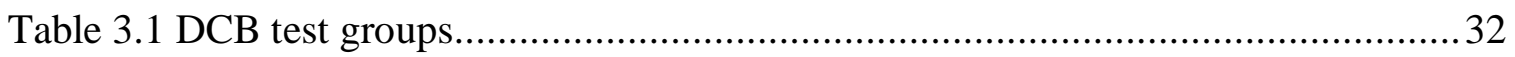

Table 3.2 DCB test number description and plasma process parameters......................33

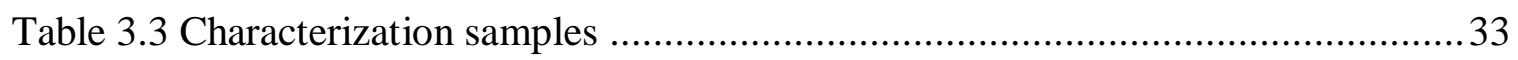

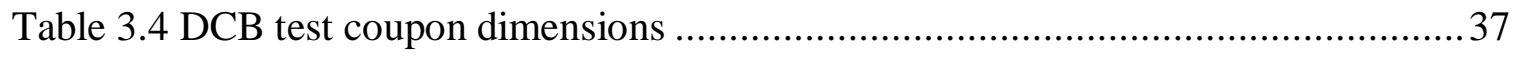

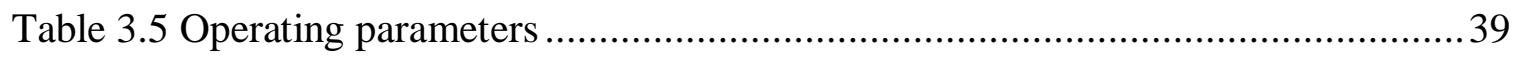

Table 4.1 Rms surface roughness for pristine and treated samples ..........................59

Table 4.2 XPS elemental composition of pristine and treated samples .........................62

Table 4.3 XPS contributions of Carbon chemical bonds/groups .............................. 65

Table 4.4 XPS contributions of Oxygen and Silicon chemical bonds/groups .................66 


\section{LIST OF FIGURES}

Figure 2.1 Plasma treatment system.......................................................... 11

Figure 2.2 Vacuum plasma system .............................................................. 12

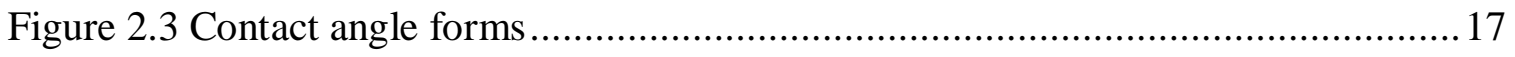

Figure 3.1 Pristine P DCB test and characterization diagram ..................................2 27

Figure 3.2 Treated T DCB test and characterization diagram ..................................28

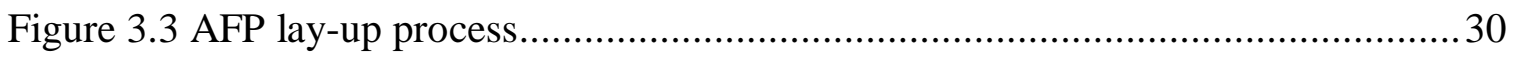

Figure 3.4 Cure cycle of Hexcel IM7/8552 [109] .............................................. 31

Figure 3.5 Composite panel dimension ..................................................... 31

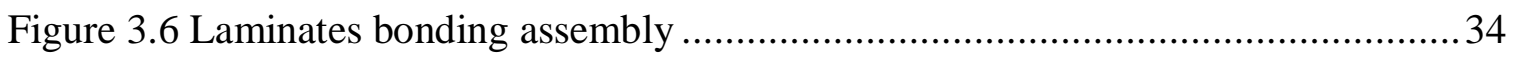

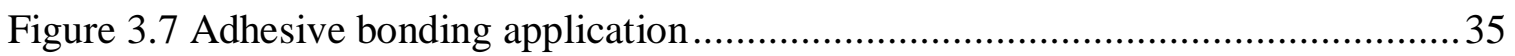

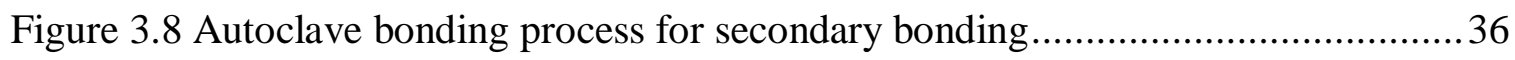

Figure 3.9 Drawing outline and cutting coupons ............................................ 36

Figure 3.10 Clamping piano hinge while J-B Weld cures...................................... 37

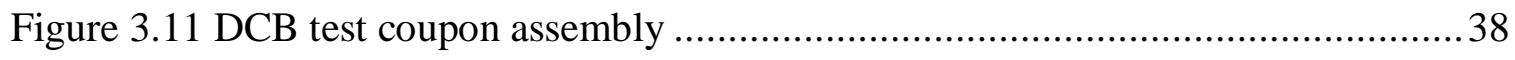

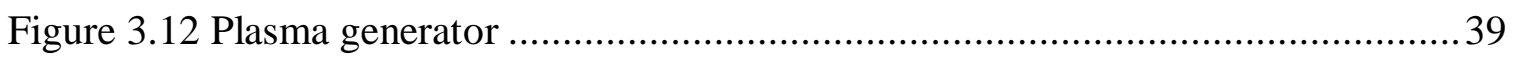

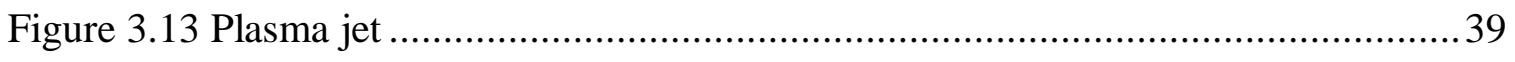

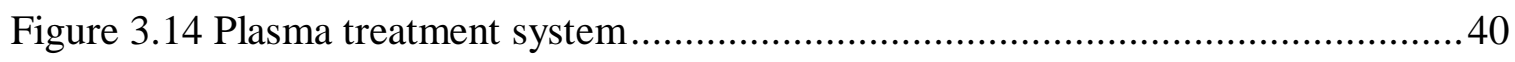

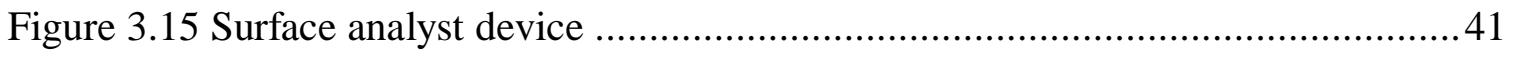

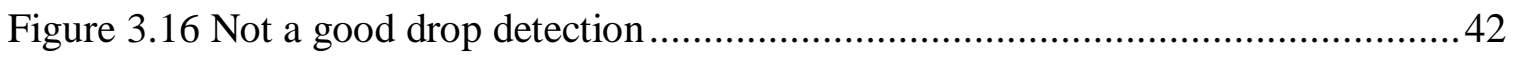

Figure 3.17 Well defined drop detection ..................................................... 42

Figure 3.18 Tescan Vega SBU variable pressure SEM.........................................43 
Figure 3.19 Kratos Axis Ultra XPS.

Figure 3.20 DCB test schematic 45

Figure 3.21 DCB test setup. .46

Figure 3.22 DCB test coupon marked....... 47

Figure 3.23 Delamination resistance curve (R curve) [39]

Figure 3.24 DCB failure modes a) Adhesive failure b) Cohesive failure c) Thin layer cohesive failure d) Adhesion promoter to substrate e) Adhesive to adhesion promoter...50

Figure 4.1 WCA for pristine and treated samples ...........................................52

Figure 4.2 WCA for pristine and treated samples (S1,V1-2-3, and D1)......................53

Figure 4.3 WCA for pristine and treated samples (S2,V1-2-3, and D1) ......................54

Figure 4.4 WCA for pristine and treated samples (S3,V1-2-3, and D1) .....................54

Figure 4.5 WCA for pristine and treated samples (S1-3,V2, and D0) ........................55

Figure 4.6 Sample 1 SEM images a) Pristine M:1000x b) Pristine M:5000x ................56

Figure 4.7 Sample 2 SEM images a) Pristine M:1000x b) Pristine M:5000x ................56

Figure 4.8 Sample 3 SEM images a) Pristine M:1000x b) Pristine M:5000x .................57

Figure 4.9 Sample 4 SEM images a) Pristine M:1000x b) Pristine M:5000x ................57

Figure 4.10 Sample 5 SEM images a) Pristine M:1000x b) Pristine M:5000x ...............58

Figure 4.11 Sample 1 3D images a) Pristine b) Treated (S1, D1) ..............................59

Figure 4.12 Sample 2 3D images a) Pristine b) Treated (S2, D1) .............................60

Figure 4.13 Sample 3 3D images a) Pristine b) Treated (S3, D1) ...............................60

Figure 4.14 Sample 4 3D images a) Pristine b) Treated (S1, D0) ..............................60

Figure 4.15 Sample 5 3D images a) Pristine b) Treated (S3, D0) ...............................61

Figure 4.16 Sample 1 Carbon (C1s) deconvolution of pristine and treated ...................64

Figure 4.17 Sample 1 Oxygen (O1s) deconvolution of pristine and treated ..................64

Figure 4.18 Sample 1 Silicon (Si2p) deconvolution of pristine and treated...................65

Figure 4.19 Load-displacement curves of P.001-005, T.S1V2D1, and T.S3V2D1.........67 
Figure 4.20 Load-displacement curves of P.006-010, T.S1V2D0, and T.S3V2D0.........68

Figure 4.21 GIP results for pristine and treated DCB tests .....................................6 69

Figure 4.22 Mode I delamination resistance curve (R curve) of pristine tests ................70

Figure 4.23 Mode I delamination resistance curve (R curve) (T.S1V2D0-T.S3V2D0) ...71

Figure 4.24 Mode I delamination resistance curve (R curve) (T.S1V1D1-T.S1V2D1-

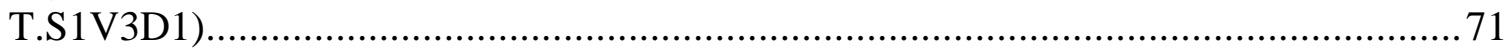

Figure 4.25 Mode I delamination resistance curve (R curve) (T.S2V1D1-T.S2V2D1-

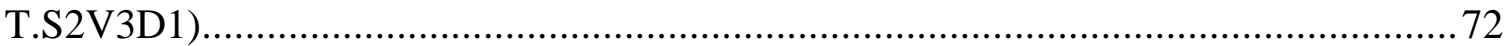

Figure 4.26 Mode I delamination resistance curve (R curve) (T.S3V1D1-T.S3V2D1-

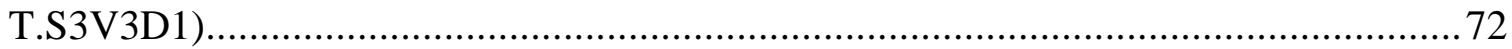

Figure 4.27 Failure modes (a) Pristine (b) T.S1V1D1 (c) T.S2V1D1 .........................73

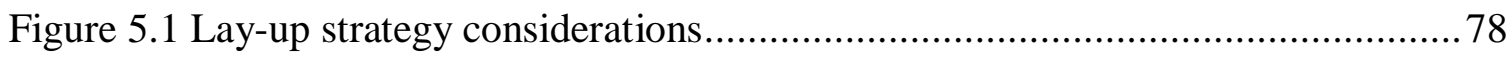

Figure A.1 AFP composite manufacturing flowchart ....................................... 90

Figure A.2 Autoclave cure cycle flowchart .................................................. 91

Figure A.3 Bonding laminate flowchart .................................................... 92

Figure A.4 Hinge bonding test flowchart .................................................... 93

Figure A.5 Atmospheric pressure plasma treatment flowchart ..............................94

Figure A.6 Water contact angle measurement flowchart .................................... 95

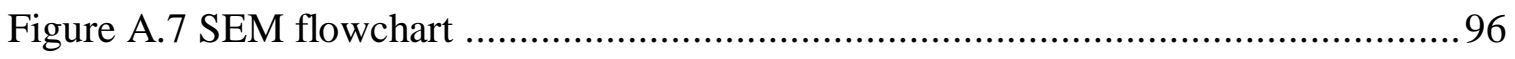

Figure A.8 Double cantilever beam test flowchart .......................................... 97 


\section{LIST OF SYMBOLS}

a Delamination (propagation) length

$a_{o} \quad$ Initial crack length

$A_{1} \quad$ Slope of the plot of a/b versus $\mathrm{C}^{1 / 3}$

$b \quad$ Width of DCB test coupon

c Compliance

E Area under the load-displacement curve

$G_{I C} \quad$ Mode I interlaminar fracture toughness (Mode I strain release rate)

$G_{I P} \quad$ Fracture toughness according to area method

$h \quad$ Thickness of DCB test coupon

H Contact angle hysteresis

$L \quad$ Length of DCB test coupon

$n \quad$ Slope of the plot of Log C versus Log a

$P \quad$ Applied load

Rms Root mean square roughness

$R_{a} \quad$ Surface average roughness

$\theta_{a} \quad$ Advancing angle

$\theta_{\mathrm{r}} \quad$ Receding angle

$\theta \quad$ Water contact angle

$\gamma_{s v} \quad$ Solid-vapor interfacial tension 
$\gamma_{s} \quad$ Solid tension (Surface energy of the solid)

$\pi_{S} \quad$ Spreading pressure of the liquid

$\gamma_{l v} \quad$ Liquid-vapor interfacial tension

$\gamma_{s l} \quad$ Solid-liquid interfacial tension

$\gamma_{l} \quad$ Surface tension of the test liquid

$\gamma_{\mathrm{S}}^{\mathrm{D}} \quad$ Polar component

$\gamma_{\mathrm{S}}^{\mathrm{P}} \quad$ Dispersive component

$\gamma_{l}^{\mathrm{D}} \quad$ Polar component of the liquid

$\gamma_{l}^{\mathrm{P}} \quad$ Dispersive component of the liquid

$\delta \quad$ Load point deflection

$\Delta \quad$ Effective delamination extension to correct for rotation of DCB arms at delamination front 


\section{LIST OF ABBREVIATIONS}

$3 \mathrm{D}$

Three-dimensional

$\mathrm{AFM}$ Atomic force microscope

AFP Automated fiber placement

APP Atmospheric pressure plasma

APPJ Atmospheric pressure plasma jet

CC Compliance calibration

$\mathrm{CF}$ Carbon fiber CFRP Carbon fiber reinforced polymer

DBD. Dielectric barrier discharge

DCB Double cantilever beam

FTIR Fourier transform infrared spectroscopy

GB Grit blasting

IM Intermediate Modulus

MBT Modified beam theory MCC Modified compliance calibration

$\mathrm{RF}$ Radio frequency

RMS Root mean square SEM Scanning electron microscopy WCA Water contact angle XPS X-ray photoelectron spectroscopy 


\section{CHAPTER 1}

\section{INTRODUCTION}

\subsection{BACKGROUND}

In today's aerospace industry, carbon fiber reinforced polymers (CFRPs) have become a major alternative material, used instead of metals in manufacturing, due to their exceptional properties. For instance, composite materials have been used around 50\% in the Boeing 787 Dreamliner. Their advantages over metals are specific strength, stiffness, low density and high fatigue endurance [1-4]. Mechanical fastenings like rivets, fasteners, or bolts may be used as a joining method of composites; however, they have many disadvantages such as increased weight, high fabrication cost, and increased stress concentrations [5].

In recent times, adhesive bonding of composites is a preferred method for its advantageous assembly process which includes improving the structural performance of bonded composites, reducing weight, cost-effectiveness, and eliminating the associated disadvantages aforementioned [6]. In spite of these numerous advantages of bonding, CFRPs possess inert surfaces, and when used without an appropriate surface treatment, produces bonds with poor adhesion properties $[7,8]$ and low interlaminar shear strength [9]. Therefore, surface contaminants like silicon prevent a strong bond quality. Treatments and surface preparation can increase the roughness, surface energy, and surface functional groups of the CFRP, which tends to increase the surface's wettability, 
which relates to the enhancement of bond strength $[9,10]$. Furthermore, ensuring a contamination-free surface is an extremely critical factor for strong bonding.

Conventional methods to prepare the bonding surface of composites utilize either mechanical roughening or peel ply techniques. However, abrasion techniques have shown to impart inconsistency in surface preparation; in addition, byproducts from these techniques do not completely qualify as environmentally benign [11]. Solvent wipes are also used as a contaminant removal technique but in most cases have not been shown to be as effective as abrasion [11].

Other mechanical treatments such as sanding and grit blasting (GB) do create chemically active sites, that either get oxidized by free radicals to form reactive functional groups, or directly react with adhesives, which ultimately strengthens the bond [12]. In spite of the efficiency of the abrasion techniques, there always remains an opportunity for alternative methods to increase the surface area of active sites.

\subsection{PLASMA TREATMENT}

Plasma treatment is a non-contacting, environmentally benign method by requiring minimal operator intervention [11]. This method potentially overcomes many of the practical limitations of conventional surface preparation methods, while maintaining bonding efficacy and providing consistency [11]. Plasma treatment modifies the surface morphology via the creation of free radicals and ions, specific to the gas conditions used, which further reacts with the composite surface [13, 14]. Plasma treatment modifying composite surface properties for specific applications has been extensively studied $[8,12,15-21]$; in most instances, an increase in surface energy of the substrate is reported, preferentially denoted by a decrease in WCA, which enhances 
wettability characteristics without changing its bulk properties [7, 10, 22-24].

Plasma treatment has been previously studied to strengthen interfacial bond strength between fiber and resin. It has been attributed the following potential properties: remove contaminants, increase surface roughness, increase surface energy and impart functional groups that promote chemical interactions between fiber and matrix resin [9].

Surface treatment with a 'dielectric barrier discharge' (DBD) has been studied on various polymer films $[25,26]$; subsequent surface chemical characterization through $\mathrm{X}$ ray photoelectron spectroscopy (XPS) revealed that DBD treatment has resulted in an increase in oxygen content in the polymers. Furthermore, the WCA has also been reported to decrease significantly, indicating an increase in the wettability and thus surface energy [8, 20, 25-28]. Scanning electron microscopy (SEM) did not reveal any significant physical damage after the treatment period [25, 26, 29, 30].

Application of an APPJ on polymer films has been reported to have enhanced adhesive bonding ability resulting from the formation of oxygen-containing functional groups $[9,31,32]$. The inspiration that APPJ can be used to remove low molecular weight contaminants [11] from composite surfaces stemmed from the fact that APPJ is reported to remove organic contaminants from metal surfaces [14].

In most research involving surface preparation by plasma, APPJ is chosen over other plasma sources, namely, 'low-pressure discharges,' 'arc and plasma torch,' 'corona,' and 'DBD'. This is due to its following properties of a relatively low breakdown voltage of the plasma discharge $(0.05-0.2 \mathrm{kV})$, a high concentration of charged species $\left(10^{11}-10^{12} \mathrm{~cm}^{-3}\right)$ [12], ability to treat the large surface area and sufficient electron energy for dissociating molecules at a low neutral gas temperature [33]. 
In composite systems, application of APPJ has been reported to enhance lap shear bond strength [11]. In the work done by Encinas et al [7], two composites, created with glass and carbon fiber reinforced toughened epoxy resins used in the construction of airplane structures, have been subjected to different surface treatments in order to achieve robust adhesive joints. The investigation focused on the application of the solvent wipe, abrasion, GB, and APPJ treatment. Results from double cantilever beam (DCB) tests showed that the most effective method in terms of fracture toughness was the combination of fluorine (a possible contaminant) removal by GB followed by surface activation achieved by APPJ. In the work done by Lee, H. et al [29], plasma treatment of the surface of recycled CF was investigated; it was concluded that even the shortest treatment time generated oxygenated functional groups. This resulted in better adhesion between the $\mathrm{CF}$ and the polymer matrix with the formation of polar groups on the surface after plasma treatment $[7,11,34,35]$. In the same paper, it was also reported that CFRP produced from the treated recycled CF may attain physicochemical properties comparable to those of fresh CFRP; an increase in oxygen-containing functional groups in CF after plasma treatment was also reported $[9,36]$.

Despite existing literature, there are relatively limited reports on APPJ treatment on CFRP manufactured by AFP machines, as well as their optimal APPJ process parameters. Previous research has shown that APPJ treatment of surfaces can increase the oxygen content of the surface, confirmed by XPS measurements; this ultimately leads to increased surface energy denoted by a decrease in WCA.

In this research, we propose an investigation into the effects of plasma treating composite specimens manufactured by an AFP machine. To analyze the change in 
morphology resulting from the plasma treatment, characterization methods, namely, WCA, SEM, and XPS were adopted. The DCB test method was employed to measure Mode I (opening mode) interlaminar fracture toughness of the unidirectional ([0] $]_{\mathrm{n}}$ CFRP composites [37-42], and to assess the bonding effectiveness for each group of test coupons.

\subsection{THESIS OUTLINE}

This thesis is organized as follows to understand the effect of APPJ treatment on CFRPs and the optimal plasma process parameters with characterization methods and Mode I interlaminar fracture toughness test:

Chapter 2 presents a literature review of plasma surface treatment with vacuum plasma systems and atmospheric pressure plasma systems. Then, surface characterization methods of composites are explained for chemical composition changes, contact angle measurement, and surface morphological and topographical changes. Lastly, double cantilever beam test is presented with calculations of Mode I interlaminar fracture toughness to investigate adhesive bond strength.

Chapter 3 develops the experimental test plan of the project: Fabrication of unidirectional composite panel, DCB test coupons and characterization samples, surface characterization methods, water contact angle, x-ray photoelectron spectroscopy, scanning overlap microscopy and atomic force microscopy, open-air atmospheric pressure plasma jet treatment application details, and finally, double cantilever beam test with calculation of fracture toughness.

Chapter 4 validates results of characterization methods of contact angle measurement, XPS, SEM and AFM, and double cantilever beam test. Fracture toughness 
values of $G_{I C}$ and $G_{I P}$, and failure modes of pristine $\mathbf{P}$ and treated $\mathbf{T}$ tests are compared.

Chapter 5 concludes the presented work with recommendations and presents future research opportunities. 


\section{CHAPTER 2}

\section{LITERATURE REVIEW}

This literature review chapter starts with an introduction by presenting adhesive bonding and plasma surface treatment applications in the context of the aerospace industry. Then, an overview of plasma surface treatment methods is presented with vacuum plasma systems and atmospheric pressure plasma systems in section 2 . Afterwards, surface characterization methods are explained: Contact angle measurement, surface energy measurement, surface chemical composition changes, and morphological and topographical changes. Finally, DCB test with calculation of Mode I interlaminar fracture toughness and failure modes is presented for adhesive bond strength of composites structures.

\subsection{INTRODUCTION}

Carbon fiber reinforced polymers (CFRPs) are used for a variety of applications in the aerospace, automotive, marine, and nuclear engineering industries due to their favorable mechanical properties. Some of these properties include high strength to weight ratio, a lower density, specific stiffness, corrosion resistance, fatigue endurance, material toughness, and damage tolerance $[9,28]$.

Due to these advantages, the efficient joining of composites is a crucial process to maintain the product structural integrity, with adhesive bonding being the preferred joining method. Adhesive bonding provides numerous advantages over mechanical 
fasteners with characteristics like weight reduction, improved damage tolerance [10], increased efficiency, lower fabrication cost [5] and reduced mechanical repair [7, 43-47]. Furthermore, the bonding process does not break the fibers like the drilling/riveting process, and thus it helps achieve load transfer uniformity.

The disadvantages of adhesive bonding include the chances of a weak adhesive quality and lower interlaminar shear strength [9] due to contaminants [48] on the surface of the composite combined with lack of adequate surface treatment. This promotes low surface energy, weak bonding, poor interfacial adhesion [9], and undesirable wettability properties [49]. These weaker properties are an obstacle for good performance bonding; therefore, to improve surface properties and mechanical strength, an efficient surface treatment technique needs to be implemented [10, 50, 51].

The proper surface treatment before bonding is a necessary process which aims to induce a rougher and more wettable surface $[52,53]$ while improving the fracture toughness and active sites [30] which lead to a satisfactory adhesive bond [54]. Abrasion/solvent cleaning [55], grit blasting, peel-ply, tear-ply, acid etching, chemical cleaning with a solvent [56], corona discharge treatment, plasma treatment and laser treatment [57] are very useful applications performed to enhance surface characteristics. However, some of these methods like hand sanding or grit blasting leave undesirable residual particles on the surface. This requires further cleaning with a solvent [57] and may cause damage to the surface by bringing about delamination.

Adhesion identifies as the condition where two different bodies are gripped together by close, interfacial contact with the end goal that work can be exchanged starting with one surface then onto the next [58] and it depends on the surface properties 
of the parts. Better adhesive bonding and improvement of adhesion [35] may be accomplished by removing contaminants from the composite surfaces which prevent for a strong bond.

Recently, plasma treatment is an extremely promising surface treatment method which is widely preferred due to the immense number of advantages associated with its process. These include getting rid of contaminants on a surface and increasing the surface energy, which is linked to increased adhesive strength, adhesion, and a higher interlaminar shear strength [7]. Plasma treatment brings about these favorable conditions for adhesive bonding and the durability of adhesive joints by cleaning on an atomic level $[10,59]$. The advantages of such treatment over alternative methods include its low cost and its environmentally benign qualities such as the absence of water, chemicals, and its lack of pollutants [60]. Furthermore, it modifies the surface of the material without changing many of its physical characteristics [61].

An overview of plasma surface treatment is first presented, while the characterization methods is forwarded in the subsequent sections: The WCA, surface chemical composition with XPS, and surface morphological and topographical changes with the SEM and AFM. In section 2.4, the double cantilever beam (DCB) test method and the computation of the interlaminar fracture toughness are presented. Finally, a summary of the plasma surface treatment of CFRPs is presented.

\subsection{PLASMA SURFACE TREATMENT}

Plasma is the fourth state of matter consisting of a gaseous mixture of ions, free radicals, electrons, and high-energy neutrals [24, 62, 63]; in other words, it is the result of an energized gas. Ionizing a gas molecule and reorganizing its structure by way of 
exposure to a strong electrical field promotes the creation of ions and free electrons which contributes to this energization.

The thermodynamic properties of solids, liquids, and gases allow for most energy to be carried in the form of heat or kinetic energy [64]. Plasma, however, holds energy which is created by separating electrons from the nuclei of a molecule inducing the creation of ions and free electrons. Creating these ions and free electrons is the reason plasma is highly energetic at relatively low-temperature [64].

Plasma reactions with a substrate occur through a direct transfer of energy from the plasma. When each state has enough energy, phase changes happen to result in an increase in energy. Materials can change from solid to liquid, or from liquid to gas, due to the energization of the molecules. As a result, plasma activates and energizes a surface, which is optimum for adhesive bonding [18]. It alters the surface properties, without affecting the bulk properties [9], and creates conditions which allow previously improbable reactions to occur. Surface activation takes place when free electrons in the plasma transfer to and from the material [62]. The ions present in the plasma result in the integration of radical sites up to the depth of a few $10 \mathrm{~nm}$ on the surface of the composite $[62,65]$.

Surface preparation with plasma maximizes the adhesive bond strength [57] by enhancing roughness [66] and changing its surface chemistry [30]. Kusano [35] states two main effects resulting from surface chemistry alteration: (1) Creation of free radicals on the surfaces by cutting $\mathrm{C}-\mathrm{C}$ and $\mathrm{C}-\mathrm{H}$ bonds, and (2) Functionalization classified by oxidation and nitration. A chain dispersion reaction on the surface of the material can occur with treatment resulting in cleaning, and ionic activation $[32,35]$. 
Plasma surface treatment is the preferred cleaning method for numerous materials such as composites, plastics, polymers, papers, films, glass, and even metals. This is due to its low cost, minimum environmental impact, and high performance [67]. Additionally, plasma treatment does not damage the treated surface, yet still gives a high-quality surface finish for the adhesive application when compared to traditional methods. These applications are easily automated and simple to set up for manufacturing purposes [20] with controllable process parameters such as distance from the plasma jet to the surface of the material, and the rate at which the material is passed over and treated. These parameters which are shown in Table 2.1 influence the wettability, roughness, and adhesion properties of the substrate [32]. Exposure time is especially crucial for the effects of plasma, activation of a material's surface energy, and alteration of surface chemistry.

Table 2.1 Plasma parameters

\begin{tabular}{ll}
\hline Nozzle-substrate distance & Feed gas \\
Treatment speed & Feed gas flow rate \\
Treatment overlap & Jet rotation \\
Working frequency & Output voltage \\
Power &
\end{tabular}

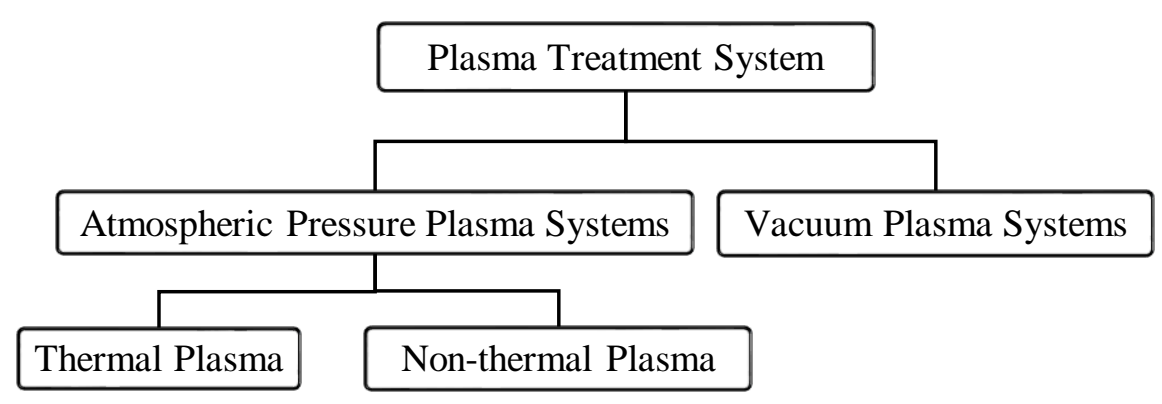

Figure 2.1 Plasma treatment system 
Two types of industrial plasma systems, both thermal and non-thermal $[68,69]$, which are shown in Figure 2.1, are discussed within the latter.

\subsubsection{Vacuum Plasma Systems}

Plasma treatment can be applied through a computer operated vacuum chamber with a pump. An electrically powered specific radio frequency (RF) or microwave (MW) electrode network, current alternating system, and gas management system are needed to maintain the effectiveness of the vacuum pump. After manually loading the substrate into the vacuum chamber for treatment, the pump purges the system of air and refills the chamber with an energized gas mixture. The substrate surface is cleaned while being exposed directly to the energetic ionized gas inside the chamber.

Vacuum plasma system, which is shown in Figure 2.2, allows for more control over regulated system variables, and a vacuum environment minimizes external processes that could interfere with the experiment. The vacuum chamber itself is a quarantined, controlled environment for the plasma processes such as deposition, sputtering, ion implantation or surface grafting [68].

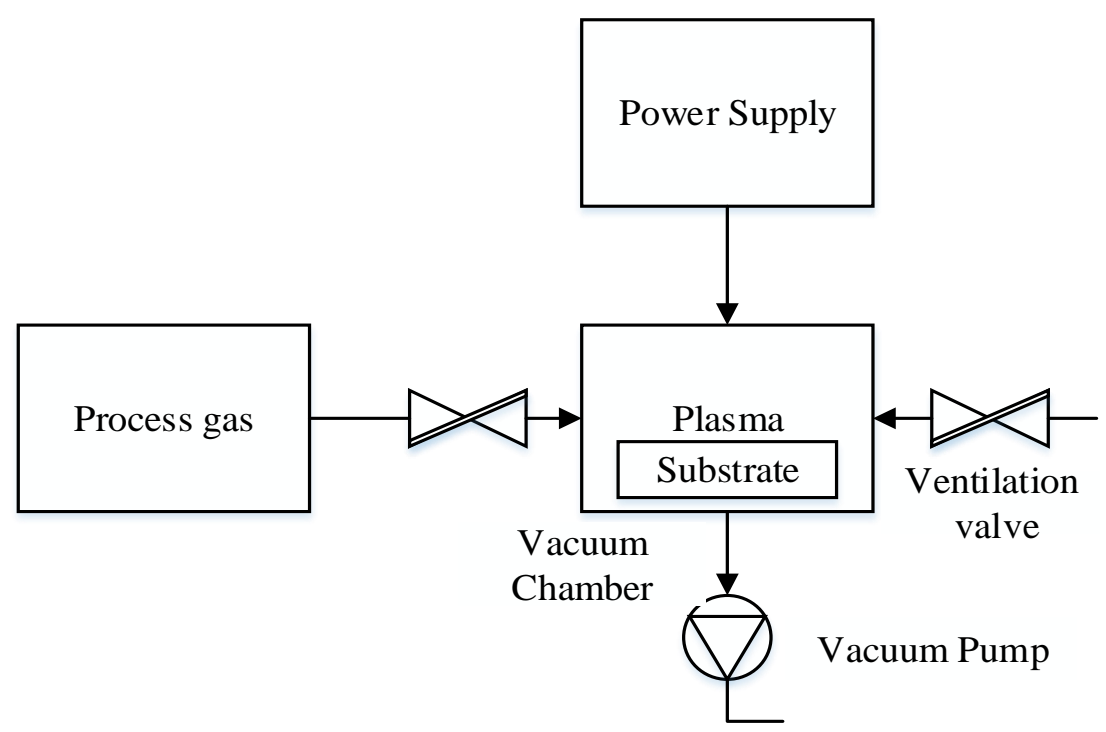

Figure 2.2 Vacuum plasma system 
The disadvantages of vacuum systems include the length of time to treat samples, the inability to continually automate the process, and the inability to uniformly treat all the surfaces [68]. It is also difficult to treat samples with complicated structures, particularly pieces with drilled holes or pockets. Additionally, vacuum systems are more costly, bulkier, and have limited treatment capabilities [64] when compared with an atmospheric pressure plasma (APP).

\subsubsection{Atmospheric Pressure Plasma (APP) Systems}

APP treatment is a simpler method which requires less equipment and is achieved by feeding gas into the plasma apparatus. This method requires minimal human expertise and is a non-contacting treatment which can be applied to any desired surface including complex shapes [11]. The ease of use makes it a notably investigated option in the aerospace industry [64].

A power supply and a plasma head require an APP system at atmospheric pressure. The plasma is created by an electrical discharge inside of the plasma head and is forced out of the head in the form of gas or air under controlled conditions. For this method, the whole surface is subject to gas and plasma discharge resulting in exposure to neutral reactive molecules, like oxygen, while being simultaneously activated by the reactive species in plasma [70]. APP can be applied using plasma jet, torch, dielectric barrier discharge (DBD), and radio frequency noble-gas discharge [69].

APP is classified as thermal (hot/high temperature) plasma if a large percentage of the molecules in the gas is ionized, or as non-thermal (cold/low-temperature) plasmas, if only a small percentage of the molecules are ionized $[63,69]$. 


\subsubsection{Thermal Plasma}

Thermal plasmas are made up of heavy particles and electrons whose temperature is in or near equilibrium relative to each other $[63,64,71,72]$. Their makeup consists of nearly fully ionized gas particles, where the electrons, ions, and neutral gases temperatures are at or near equilibrium: i.e. $\mathrm{T}_{\mathrm{e}} \approx \mathrm{T}_{\mathrm{i}} \approx \mathrm{T}_{\mathrm{g}}[63,69,72]$. These temperatures range from 5,000 $(1 \mathrm{eV}=11,600 \mathrm{~K}, 0.5 \mathrm{eV})$ to 50.000 degree $\mathrm{K}(50 \mathrm{eV})$ [63, 69, 72-75]. Due to this near equilibrium, the molecules in thermal plasma are complete or very near complete ionization.

Even though thermal plasmas usually operate at equilibrium, they are not always suitable for materials processing $[69,76]$ due to their high-temperature. Some thermal plasma applications are plasma spraying, plasma chemical vapor deposition, plasma waste destruction, and plasma metallurgy vb. Flames, arc discharges, and nuclear explosions are examples of thermal plasmas [64]. Arc discharges and high-temperature flames are attributed to the high electron densities in thermal plasmas [69].

Plasma reactive species are created by the electron's inelastic collision with a heavier particle while the elastic collisions between electrons and these heavier particles generate heat $[24,64]$. Electrons and neutral species frequently collide with a high rate and these collisions lead to thermal equilibrium [69].

\subsubsection{Non-thermal Plasma}

Nowadays, non-thermal plasmas called "non-equilibrium plasmas" or weakly ionized gas discharge are preferred for use due to their easier application capabilities at ambient atmospheric pressure and temperature [77]. Preferable qualities also include both (1) the absence of operating in thermodynamic equilibrium, and (2) being very capable of 
producing highly reactive neutral particles [78]. Thermal equilibrium cannot happen due to low concentrations of free electrons which mean fewer collisions between the electrons and neutral. There is a large difference in the electron temperature relative to the ion, and neutral temperature [21]. High energy electron-initiated reactions are still present in nonthermal plasma, and the presence of these electron-initiated reactions gives it the benefit of surface treatment without temperature related damage to the substrate [21].

Non-thermal plasmas exist in a state where less than $1 \%$ of the gas particles are ionized [79]. As a result, gas discharges operated at low pressures cannot obtain thermal equilibrium. Additionally, this obstacle may also appear when the gas temperature is less than the room temperature, and the electron temperature in the plasma may be around 0.1-5 eV while the neutral gas and ion temperatures are less [24, 63, 77]. This environment allows for the opportunity of a low-temperature chemical reaction [72].

Non-thermal plasmas have lower electron densities [24] leading to the advantage of no temperature damage/scarring; however, the non-thermal plasma gas has a much lower concentration of free electrons [69]. Thus, non-thermal plasmas are best used to treat thermally sensitive materials $[69,76,80]$.

\subsection{SURFACE CHARACTERIZATION}

Surface characterization is a vital process to figure out the plasma's effect on the surface. The latter may be characterized using several techniques in order to obtain images of the surface, its chemical composition, and its contact angle. Fourier transform infrared spectroscopy (FTIR), XPS, and time of flight secondary ion mass spectroscopy (TOF-SIMS) may be used to determine the composition of molecules on the surface at an average of $5 \mathrm{~nm}$ and $1 \mathrm{~nm}$ along the depth of the sample. In addition, SEM and AFM may 
be also used for morphological and topographical analyses.

\subsubsection{Water Contact Angle (WCA)}

Contact angle measurement is one of the easier ways to characterize a surface by analyzing around $1 \mathrm{~nm}$ or less in depth of the surface [35, 81-84]. The contact angle is the quantified interaction between a solid and a liquid [85] and is measured with a liquid droplet on the surface through the intersection of the liquid, solid, and the air.

Yuan et al [86] explains the difference between two different contact angles, namely static, when measured at a low speed, and dynamic when liquid-solid-gas contact line is in actual motion; the difference being that they are measured with different speed rates. The dynamic contact angle is equal or very close to the static angle at a low speed. The sessile drop method is used to calculate the static angle; however, the dynamic contact angle is determined by the advancing contact angle $\left(\theta_{a}\right)$ and the receding contact angle $\left(\theta_{r}\right)$. The advancing angle, bounded by a maximum, is the angle the liquid takes on when it is dropped on an unwetted solid surface; this is also known as expansion $[35,86$, 87]. In comparison, the receding angle is the minimum angle that occurs when the liquid is withdrawn from a previously wetted surface [35, 87]; this is also known as the contracting angle which helps to calculate an estimation of surface energy $[86,88]$. The difference between the advancing and the receding angle is defined by contact angle hysteresis $(H)$ :

$$
\mathrm{H}=\theta_{\mathrm{a}}-\theta_{\mathrm{r}}
$$

Solids of different compositions have different wetting properties and contact angles which are created when the liquid is resting on the solid. WCA determines the hydrophilic and hydrophobic properties of the surface, wettability (prompts for better 
adhesion or stronger bonding) [89], and how attracted the molecules of the liquid are to the surface of the composite. If the WCA is larger than $90^{\circ}$ then the substance is hydrophobic which indicates poor wettability, inadequate adhesion, and lower surface energy; if it is smaller than $90^{\circ}$, it is considered hydrophilic, which constitutes a higher wettability, better adhesiveness and higher surface energy $[9,49,90,91]$.

The contact angle $(\theta)$ between the drop and surface which is shown in Figure 2.3 has been described by Thomas Young [92] in 1805 as the intersection of gas, liquid and solid $[34,85]$. The Young-Dupré equation given in equation (2.2) shows the contact angle interfacial tension relationship and takes into account the linear correlation between the cosine of the WCA $(\cos \theta)$ and the polar component of surface energy $\left(\gamma_{s v}\right)$.

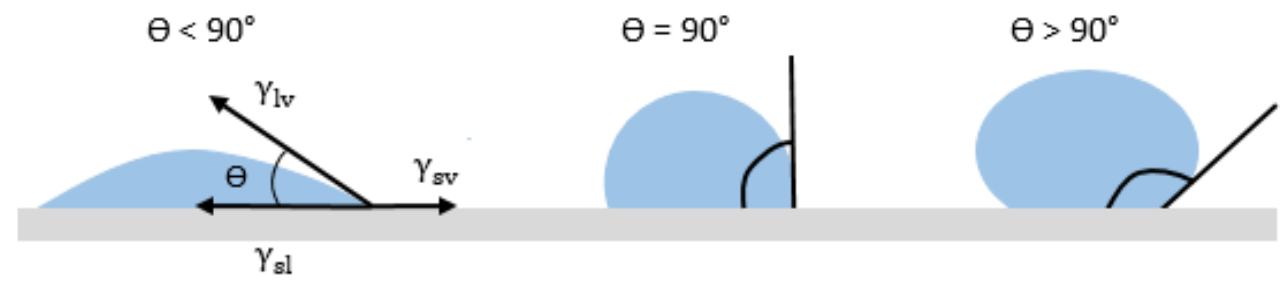

Figure 2.3 Contact angle forms

$$
\gamma_{\mathrm{sv}}=\gamma_{\mathrm{s}}-\pi_{\mathrm{s}}=\gamma_{\mathrm{lv}} \cos \theta+\gamma_{\mathrm{sl}}
$$

$\gamma_{s v}$ represents solid-vapor interfacial tension, $\pi_{s}$ represents the spreading pressure of the liquid reduction of solid surface energy coming from the interaction of the vapor with the wetting liquid, $\gamma_{s}$ represents solid tension, $\theta$ represents the contact angle between the liquid droplets and the charged surface, $\gamma_{l v}$ represents liquid-vapor interfacial tension, and $\gamma_{s l}$ represents solid-liquid interfacial tension. The $\pi_{s}$ can be rather large for high energy surfaces such as metals; however, for many low energy surfaces such as composite, the $\pi_{s}$ can be ignored [49]. If $\pi_{s}$ can be disregarded, solid tension $\left(\gamma_{s}\right)$ 
becomes equal to solid-vapor interfacial tension $\left(\gamma_{s v}\right)$ shown as:

$$
\gamma_{\mathrm{sv}}=\gamma_{\mathrm{lv}} \cos (\theta)+\gamma_{\mathrm{sl}}
$$

The contact angle $(\theta)$ and the liquid surface tension $\left(\gamma_{l v}\right)$ may be measured. However, it still requires two unmeasurable quantities $\left(\gamma_{s l}\right.$ and $\left.\gamma_{s v}\right)$. In order to calculate solid interfacial tension, the liquid contact angle must be measured with at least two different fluids (such as deionized water, ethylene glycol, methylene iodide, glycerol, diiodomethane, nitromethane, or 1,5-pentanediol) which have different balances of polar and dispersive components relative to their surface tension [7]. Therefore, the surface tension of liquids, which is used to measure the contact angle, should be more than a solid's surface tension [86].

\subsubsection{Ballistic Deposition}

Nowadays, an alternate technique is used to measure the contact angle, which is called the ballistic deposition method [52]. This method uses a jeweled nozzle to create the drop of liquid directly on the surface of the material. Strobel et al [88] reported that the ballistic deposition method is faster and more accurate than previously used techniques in measuring the receding contact angle, which is more important than the advancing angle when considering adhesion.

A portable contact angle measurement device called the Surface Analyst ${ }^{\mathrm{TM}}$ by BTG Labs ${ }^{\circledR}$ creates a liquid drop of known volume on the end of needlepoint or syringe. This droplet is dropped onto the material's surface from a fixed distance. Once the droplet has settled, the device determines its boundaries, and the contact angle is calculated with an average of the dropped diameter by the boundary measurement.

The microdroplet technique oscillates the growing larger droplet. The micro- 
droplets vibrate the large droplet at an increasing rate allowing the large droplet to spread to its equilibrium size, a $1.8 \mu \mathrm{L}$ drop. Much of the time dust particles and surface flaws serve as an impediment for the droplet forming to equilibrium size [52]. Dillingham et al [52] stated that this measurement method can result in a more comprehensive characterization of the wettability concerning surfaces which exhibit physical or chemical heterogeneity.

\subsubsection{Surface Energy Measurement}

The surface energy is a measurement of the density of free energy which is attributed to reactivity on the substrate surface. This is determined by the ions present on a surface, its hydrogen bonding, and van der Waals forces [71]. Surface energy may be calculated with the WCA between the composite and the liquid dropped on the surface. Surface energy directly correlates with, and can even be a good indicator of adhesive strength [49].

Contaminants on the surface of a substrate decrease its overall surface energy [48] by occupying various active sites which have the potential to host surface energy. Contamination on the surface leeches the habitat from potential surface energy by occupying these active sites. This leads to a reduction in adhesive strength when surface contamination is increased.

Surface energy cannot be directly measured; therefore, other measurement methods must be used to make this calculation through associative relationships [93]. In this case, surface energy shall be measured with the contact angle of various liquids (at least two) on the substrate surface. Measured values are used in the surface energy equation to calculate polar and dispersive or London components of the surface energy of 
the composite [71]. The polar function represents the hydrophilic/hydrophobic properties of the substrate, and the hydrophilic property increases substantially when a surface is plasma-treated.

Different methods may be used to accomplish this calculation; however, this explains the Owens-Wendt-Rable-Kaelble (OWRK) method [81, 94, 95] which does the calculation with contact angles:

$$
\frac{(1+\cos \theta) \cdot \gamma_{1}}{2 \sqrt{\gamma_{l}^{\mathrm{D}}}}=\sqrt{\gamma_{\mathrm{S}}^{\mathrm{P}}} \cdot \sqrt{\frac{\gamma_{\mathrm{l}}^{\mathrm{P}}}{\gamma_{\mathrm{l}}^{\mathrm{D}}}}+\sqrt{\gamma_{\mathrm{S}}^{\mathrm{D}}}
$$

We represent the surface tension of test liquid by $\gamma_{l}$ and the surface energy of the solid with $\gamma_{S}$. The superscripts $\mathrm{D}$ and $\mathrm{P}$ are used to differentiate between the dispersive and polar fractions. The angle $(\theta)$ represents the contact angle of the drop on the surface of the substrate. The total surface energy of the solid is calculated by the sum of $\gamma_{S}^{D}$ and $\gamma_{S}^{P}$

$$
\gamma_{S}=\gamma_{S}^{\mathrm{D}}+\gamma_{\mathrm{S}}^{\mathrm{P}}
$$

This method is the basic geometric mean method of Owens and Wendt which is an estimation of the polar and dispersive components; the calculation is dependent on the values of the WCA [88].

Plasma treatment is able to increase the polar component of the surface but has little to no effect on the dispersive component of surface energy [34]. Therefore, the cosine of the WCA is directly correlated with plasma treatment. Dillingham et al [12] stated that measurements indicate that APPJ treatment increased components of surface energy such as electron donating, electron accepting, and Lifschitz-van der Waals. An increase in electron donating strongly correlates with the strength of adhesion [12]. 
Surface energies are calculated and analyzed with many methods; however, these calculations do not encompass the chemical alterations which are happening on the surface [88].

\subsubsection{Surface Chemical Compositions (by XPS)}

XPS is one of the methods used to view changes in adhesion and wettability [61] by investigating the chemical modifications on the outermost surface layer of a composite by using a soft x-ray source. The XPS receives an emission of electrons from the surface and measures their energies in order to obtain binding energies. The XPS is a less sensitive method when compared to the contact angle measurement; typically, the XPS measures the chemistry of a surface to a depth of 5-10 nm [35]. However, it is unable to provide an overall characterization of the surface as it makes its analysis locally.

XPS analysis is used to help qualify the interaction between the adhesive and composite material. XPS detects the chemicals present on the surface which helps find the amount of oxidation; oxidation can be determined by the levels of carbon and oxygen found on the substrate surface after plasma treatment. Detecting chemicals on the sample surface is useful in determining which contaminants are present before and after plasma treatment. This is essential when qualifying experimental results and quantifying the effects of plasma treatment.

\subsubsection{Morphological and Topographical Changes (by SEM and AFM)}

The physical modifications of the composite surface and the strength of interaction between fibers and the matrix material may be investigated by SEM. It is used before and after treatment utilizing an electron beam of energy to take images of the surface. It is useful in comparing images for different surface preparation methods. 
SEM is a high definition microscope which can take quality images of both inorganic and organic material surfaces at a nanometer scale $[64,96]$. Surface images are created by exciting the surface secondary electrons with an electron beam $[64,97,98]$ which then captures emitted electrons at a depth of 50-500 angstroms from within a specimen's surface $[64,97,98]$. Although SEM features a multitude of various uses, its main purpose will be for the imaging of surfaces, which may yield useful morphological data [64].

Topographical changes with three-dimensional imaging capabilities such as the root mean square (rms) roughness, surface average roughness $\left(\mathrm{R}_{\mathrm{a}}\right)$ and total surface area to determine how APPJ affects the composite surfaces may be obtained by using AFM. APP treatment causes to increase surface roughness, which increases the hydrophilicity of surfaces, without influencing the bulk properties [99-101].

\subsection{MODE I INTERLAMINAR FRACTURE TEST}

The double cantilever beam (DCB) test is a method used to analyze adhesive fracture mechanics and assess adhesive bond effectiveness through the calculation of the Mode I strain release rate (interlaminar fracture toughness $G_{I C}$ ) and the failure mode of a unidirectional laminated composite specimen. Mode I failure is attributed to opposite normal forces as loading propagates a crack longitudinally between two bonded specimen in the fiber's direction [102].

\subsubsection{Calculation of Mode I Interlaminar Fracture Toughness}

There are two methods to calculate Mode I interlaminar fracture toughness, namely the area and compliance methods [103]. However, the area method does not yield an initiation value of $G_{I C}$ so it is not recommended for use during calculation [104]. 
ASTM D5528 [39] describes three ways of calculating the $G_{I C}:$ (1) The compliance calibration (CC) method, (2) The modified compliance calibration (MCC) method, and (3) Modified beam theory (MBT) method.

The compliance calibration method uses the slope of a fitted least squares plot of the $\log$ of compliance versus (c) to produce a factor (n) by which a variation the beam theory is multiplied. The expression of Mode I interlaminar fracture toughness as follows:

$$
G_{I C}=\frac{n P \delta}{2 b a}
$$

The modified compliance method includes a least squares plot of the delamination length, normalized by the specimen's width, versus the cubed root of compliance to produce the factor $A_{1}$ by which a variation of the beam theory is multiplied. This expression is as follows:

$$
G_{I C}=\frac{3 P^{2} C^{2 / 3}}{2 A_{1} b h}
$$

The modified beam theory uses a least squares fit of the cubed root of compliance versus the delamination length in order to find the length $|\Delta|$ by which the initial delamination length should be modified. The expression is as follows for Mode I interlaminar fracture toughness according to MBT:

$$
G_{I C}=\frac{3 P \delta}{2 b(a+|\Delta|)}
$$

where $P$ is the load, $\delta$ is the load point displacement, $b$ is the specimen width, $a$ is the crack (delamination) length, and $\Delta$ is the crack length correction factor [39]. We calculate $\Delta$ experimentally by generating a least squares plot of the cube root of compliance, $C^{1 / 3}$, 
as a function of delamination length. The compliance is calculated:

$$
C=\delta / P
$$

MBT is the preferred method for the calculation by ASTM D5528 since it yields the most conservative results [39].

\subsubsection{Delamination Resistance Curve (R Curve)}

A delamination resistance curve (R-curve) uses the $G_{I C}$ values calculated at each 5 $\mathrm{mm}$ increment of delamination for the first $45 \mathrm{~mm}$ after initial delamination, and for each $1 \mathrm{~mm}$ increment of delamination for the remainder of the $50 \mathrm{~mm}$ test.

\subsubsection{DCB Test Failure Analysis}

To decide the quality of the bond at each interface, both specimen geometry, and experimental load are needed to investigate failure modes. Interlaminar failure within the substrate, cohesive failure within the adhesive, and adhesion failure are all possible types of CFRP adhesive bond failures [105]. ASTM D5573 [106] describes seven characterized modes of failure in adhesive joints: adhesive failure, cohesive failure, thin-layer cohesive failure, fiber-tear failure, light-fiber-tear failure, stock-break failure, and mixed failure.

When adhesion failure occurs, it is undesirable as it can unsuspectingly occur at loads below the expected cohesive fracture energy of the testing materials [64]. In contrast, cohesive failure modes are satisfactory because they demonstrate which loads a composite and adhesive can handle. The fracture energies of cohesive failures tend to be the highest while it is the lowest for adhesive failures [105].

\subsection{SUMMARY}

Composite materials have low surface energy [21] causing poor wettability and adhesion, which mean molecules cannot have a strong interaction with each other during 
the bonding process. Plasma treatment, which is one of the surface preparation methods of composite materials, modifies the surfaces without any physical damage. The effects of treatment may be investigated with a contact angle measurement, chemical composition analysis with XPS, or morphological and topographical changing analysis with SEM, and AFM. The effectiveness of bond performance is quantified by DCB test with calculation of Mode I interlaminar fracture toughness and determination of failure mode.

This literature review indicates that plasma treatment increases wettability and surface energy with oxidation and activation of the surfaces. This increased wettability is directly correlated with an increase in adhesive bond strength, demonstrating that treating a surface with plasma is beneficial to its overall bonding capabilities [107]. 


\section{CHAPTER 3}

\section{EXPERIMENTAL TEST PLAN}

\subsection{EXPERIMENTAL OVERVIEW}

The purpose of this study is to determine the optimum APPJ treatment parameters of CFRP surface preparation using the Open-air APPJ system by Plasmatreat ${ }^{\circledR}$ (Steinhagen, Germany). The treatment conditions were used to determine how the bond quality between an adhesive and composite material might be improved. For that purpose, two main DCB test groups were selected: (1) pristine (non-treated) $\mathbf{P}$ detailed in Figure 3.1, and (2) treated $\mathbf{T}$ detailed in Figure 3.2. The DCB test was applied to each test coupon to calculate the opening Mode I interlaminar fracture toughness while simultaneously observing the occurring failure mode. Characterization samples were prepared to determine the surface characteristics prior to (pristine $\mathbf{P}$ ) and after treatment (treated $\mathbf{T})$.

This chapter details all experimental procedures that were conducted in a standardized fashion. The details include (1) materials, (2) the DCB test coupons manufacturing, (3) the characterization samples, (4) each surface characterization method for contact angle measurement, surface chemical modifications, and surface morphological and topographical changes, and finally (5) the performed DCB test, and the calculations of the $G_{I C}$ and $G_{I P}$, to determine the failure mode after DCB tests. 


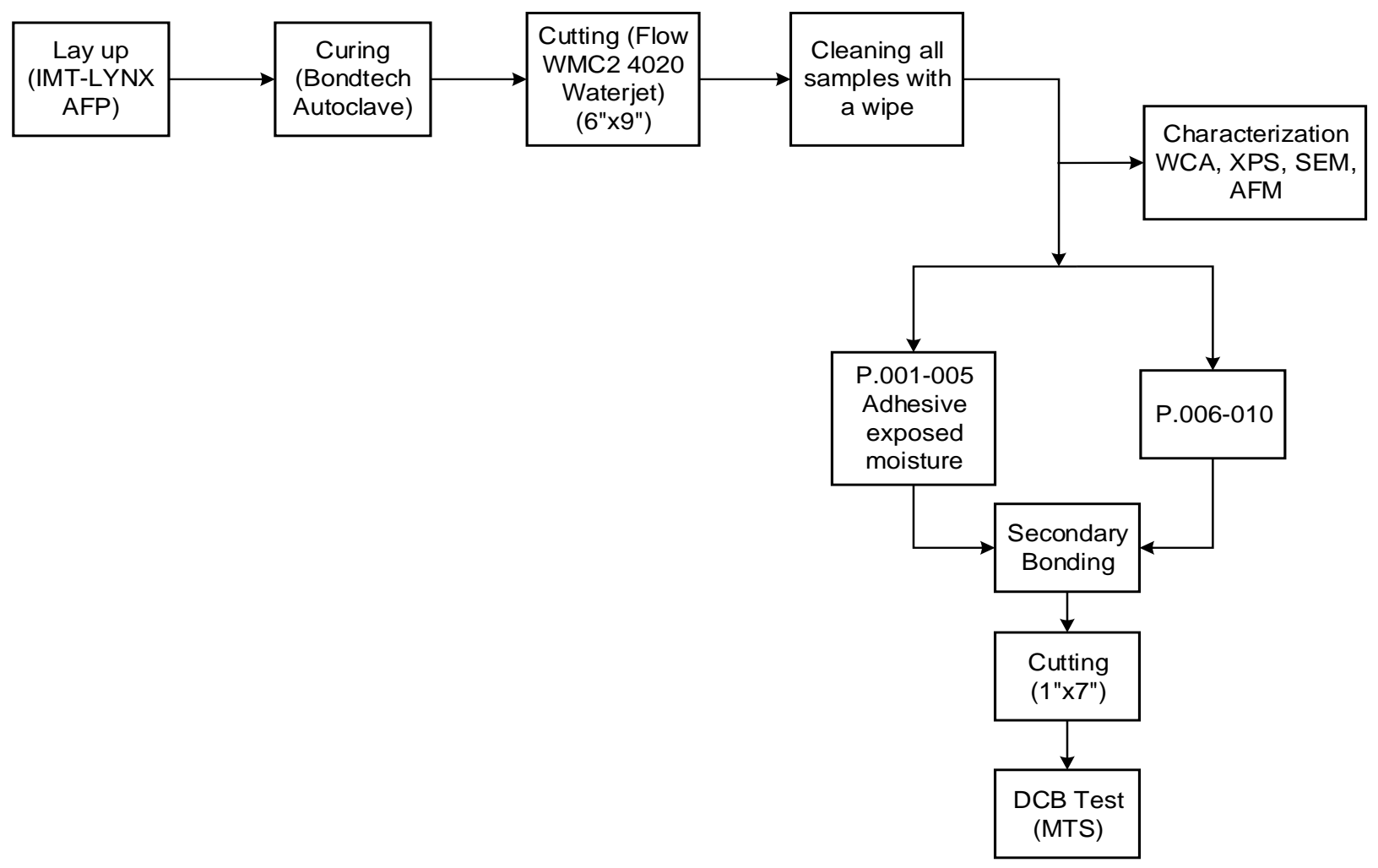

Figure 3.1 Pristine P DCB test and characterization diagram 


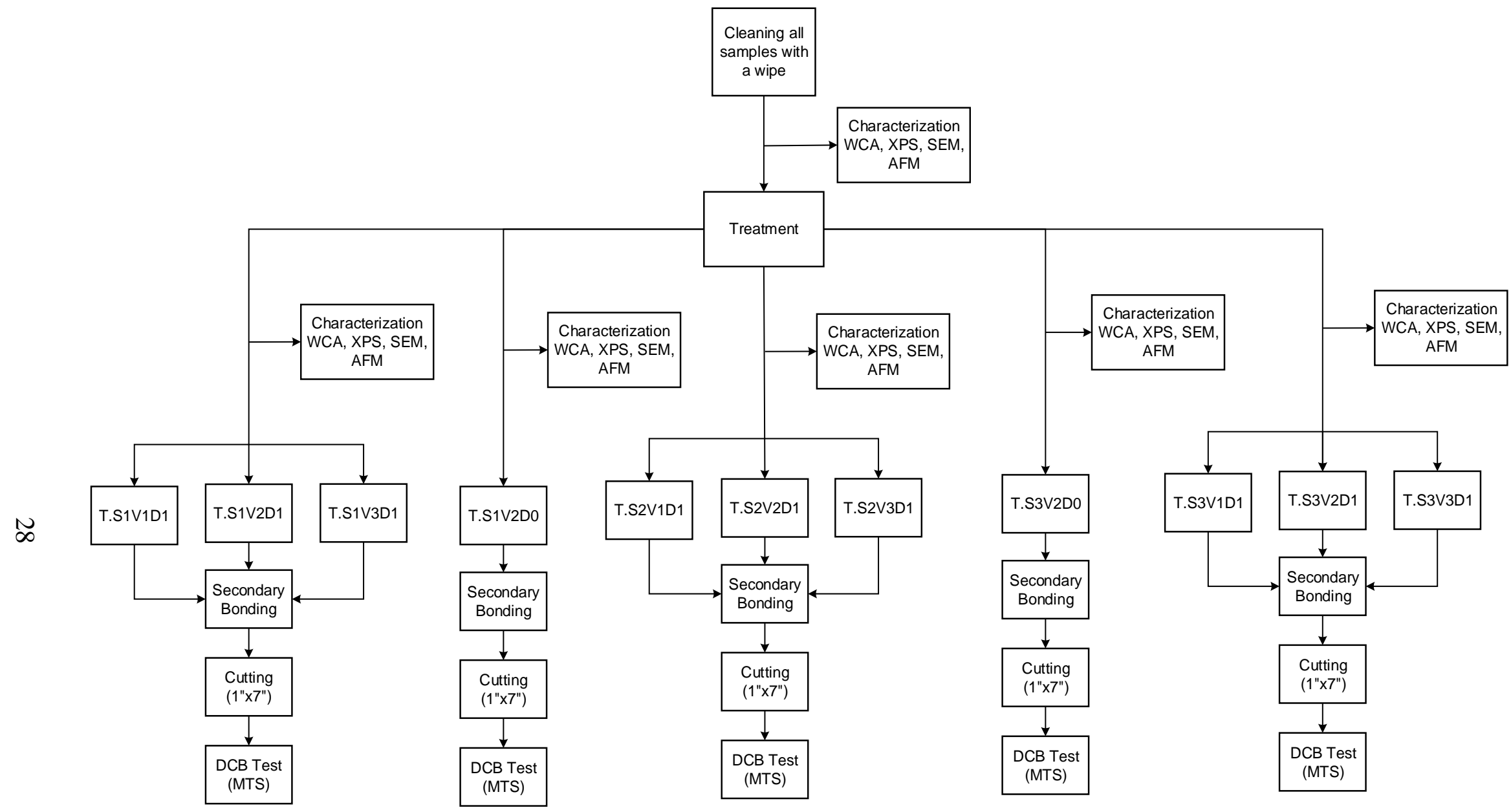

Figure 3.2 Treated T DCB test and characterization diagram 


\subsection{MATERIAL AND TEST COUPON PREPARATION}

\subsubsection{Materials}

In this research, Hexcel® IM7/8552 prepreg, which consists of an 8552 epoxy resin and unidirectional intermediate modulus IM7 carbon fiber reinforcement, was used to fabricate a $35 " \times 25 "[0]_{9}$ composite panel in unidirectional configurations with a post cure thickness of approximately $1.3 \mathrm{~mm}$. Metlbond 1515-3M epoxy film adhesive, which is commonly used in the aircraft industry due to its mechanical properties, is used to bond the two laminates [108] creating an overall thickness of approximately $2.75 \mathrm{~mm}$. J-B Weld adhesive was used to bond aluminum hinges, needed for the DCB test, to the adhesive bonded laminates.

A large roll of adhesive film was delivered in a moisture-proof bag with desiccants. However, due to the current experimental process, only small adhesive strips were used, leaving the rest of the adhesive to be exposed to moisture and atmosphere. To avoid continuous exposure to the open air, the exposed Metlbond on the outer-most layer of the roll was cut and discarded while the rest of the adhesive roll was heat sealed in a bag with desiccants after removing as much air as possible. The adhesive roll was then left under a fan for 5 hours at room temperature before determining that it had been completely thawed. Once this process had been completed, the roll was removed from the bag and individual 7" x 7" pieces were cut. Then, they were heat sealed in MIL-spec bags, by use of a tabletop impulse heat sealer after removing air content from the bag, and refrozen to protect the film from moisture and the surrounding atmosphere. This process improved test preparation efficiency as only one small, sealed bag was used for each bonded laminate that was tested. 


\subsubsection{Composite Production}

Hexcel® IM7/8552 prepreg was laid up with 9-plies $[0]_{9}$ by an IMT® LYNX AFP machine shown in Figure 3.3. The AFP composite manufacturing flowchart is shown in Figure A.1. Staggering of the $0^{\circ}$ orientations were programmed in the toolpath generation software. After the AFP laid up the composite on uncoated, nylon Wrightlon® 8400 Bagging Film, the panel was placed between two stainless steel compression plates which had previously been sealed with Frekote B-15, to ensure there were no leaks during a full vacuum due to scratches, and cured with a release agent Frekote 770-NC. A vacuum bagging technique was applied with a full vacuum in 15-psig pressure. The autoclave temperature was increased to $225^{\circ} \mathrm{F}$ at a rate of $5{ }^{\circ} \mathrm{F}$ per/min. and held at this temperature for 60 minutes. The vacuum was vented when the pressure reached 30 psig as the pressure was increased to $100 \mathrm{psig}$, while the temperature was increased to $350{ }^{\circ} \mathrm{F}$ at a rate of $5{ }^{\circ} \mathrm{F} / \mathrm{min}$. The temperature was held at $350{ }^{\circ} \mathrm{F}$ for 120 minutes and was then cooled to $150{ }^{\circ} \mathrm{F}$ at a rate of $5{ }^{\circ} \mathrm{F}$ per/min. at the vented pressure according to the cure cycle as shown in Figure 3.4 [109]. The autoclave cure cycle flowchart is shown in Figure A.2.

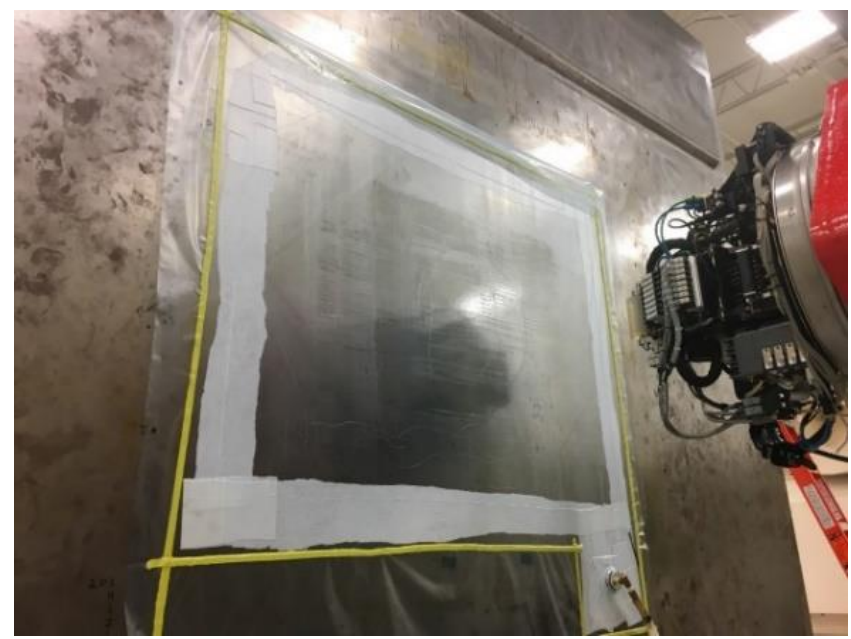

Figure 3.3 AFP lay-up process 


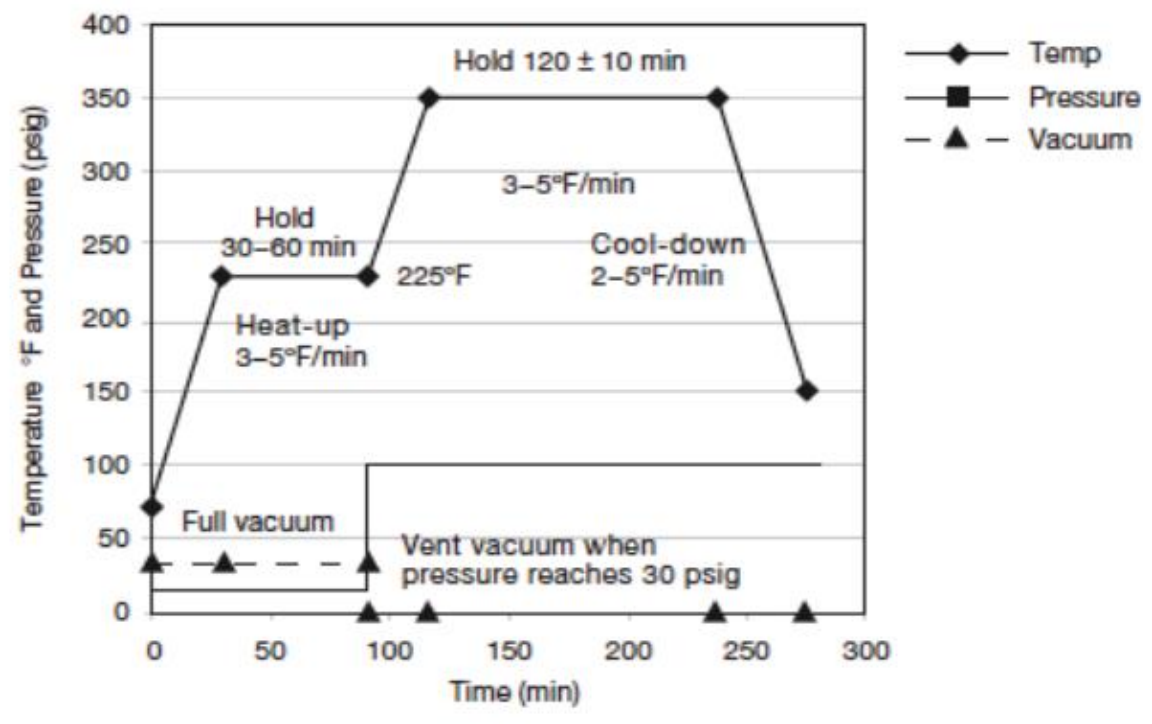

Figure 3.4 Cure cycle of Hexcel IM7/8552 [109]

Each manufactured composite panel was designed to accommodate 9 individual 6" x 9" laminates; these, along with the rest of the dimensions associated with the composite panel, are shown in Figure 3.5.

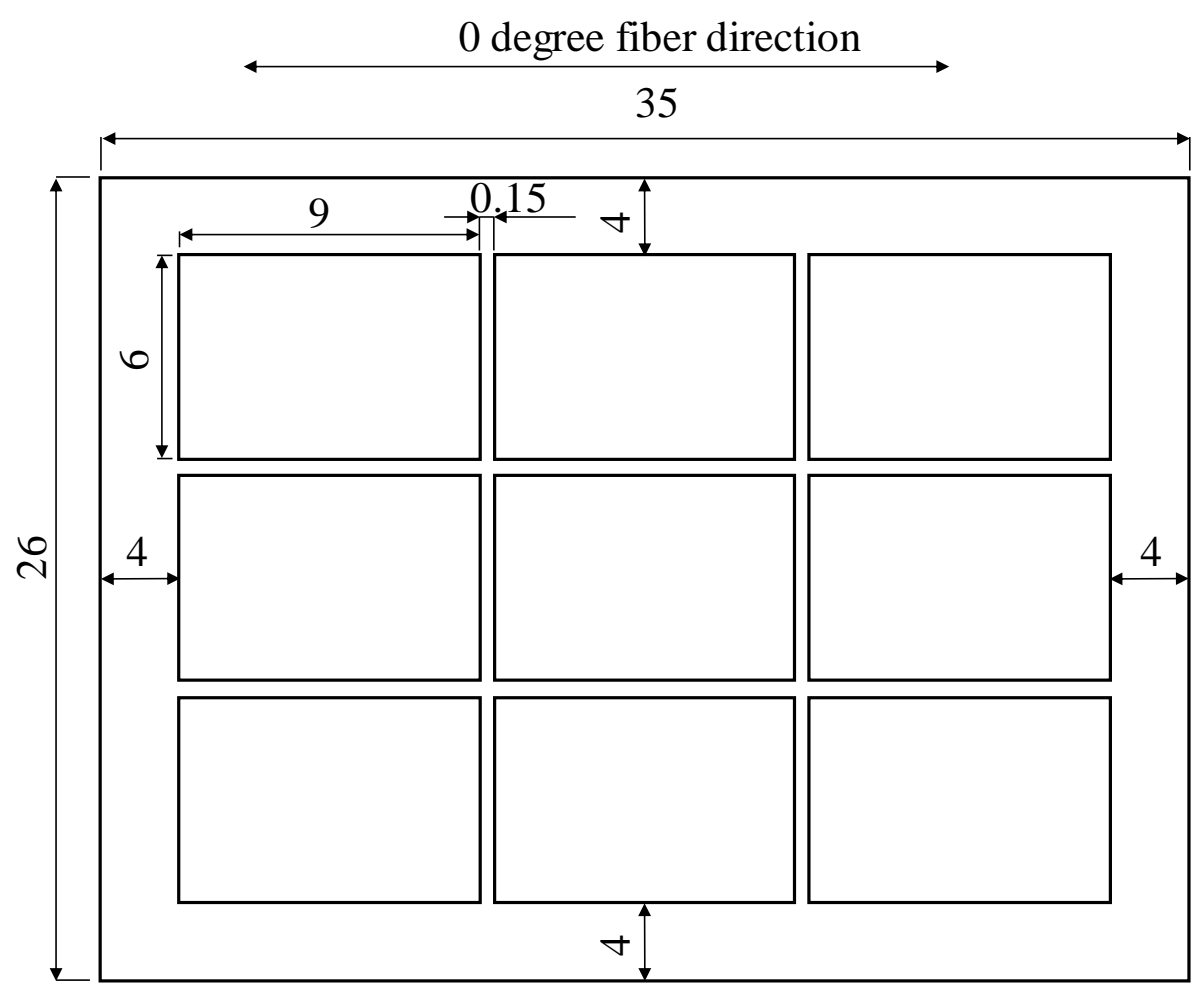

Figure 3.5 Composite panel dimension 


\subsubsection{Groups of Composite Samples}

The composite panel was cut into 9 laminates with a Flow® WMC2 Waterjet. In addition, $10 \mathrm{~mm}$ x $10 \mathrm{~mm}$ samples were also cut for SEM, AFM, and XPS while $25 \mathrm{~mm}$ x $50 \mathrm{~mm}$ samples were cut for WCA surface characteristic analysis. Then, we cut $10 \mathrm{~mm}$ $\mathrm{x} 10 \mathrm{~mm}$ samples to allow them to fit into the sample chambers as it would not have been possible to cut these pieces after plasma treatment without contamination. Two sets of test groups, pristine (non-treated) $\mathbf{P}$ and treated $\mathbf{T}$ were investigated to determine the effects of plasma treatment on a CFRP. These groups and their subgroups are labeled in Table 3.1 while showing their test number description in Table 3.2, and the characterization samples are shown in Table 3.3. These characterization samples differ from the DCB test laminate groups in the sense that overlap was not used; instead, only one pass of the plasma jet nozzle was applied to these samples.

Table 3.1 DCB test groups

\begin{tabular}{l|lcccc}
\hline Groups & Test Number & $\begin{array}{c}\text { Laminate } \\
\text { Number 6"x } 9 "\end{array}$ & $\begin{array}{c}\text { Number } \\
\text { of Tests }\end{array}$ & $\begin{array}{c}\text { Treatment } \\
\text { Speed (in/s) }\end{array}$ & $\begin{array}{c}\text { Treatment } \\
\text { Overlap (\%) }\end{array}$ \\
\hline Pristine P & P.001-005 & 2 & 5 & - & - \\
& P.006-010 & 2 & 5 & - & - \\
\hline \multirow{5}{*}{ Treated T } & T.S1V1D1 & 2 & 5 & 0.1 & 25 \\
& T.S1V2D1 & 2 & 5 & 0.1 & 50 \\
\cline { 2 - 6 } & T.S2V1D1 & 2 & 5 & 0.1 & 75 \\
\cline { 2 - 6 } & T.S1V3D1 & 2 & 5 & 0.1 & 50 \\
\hline & T.S2V2D1 & 2 & 5 & 0.5 & 25 \\
\cline { 2 - 6 } & T.S2V3D1 & 2 & 5 & 0.5 & 50 \\
& T.S3V1D1 & 2 & 5 & 0.5 & 75 \\
\hline & T.S3V2D1 & 2 & 5 & 1.0 & 25 \\
& T.S3V3D1 & 2 & 5 & 1.0 & 50 \\
\cline { 2 - 6 } & T.S3V2D0 & 2 & 5 & 1.0 & 75 \\
\hline
\end{tabular}


Table 3.2 DCB test number description and plasma process parameters

\begin{tabular}{lll}
\hline P. & Pristine & - \\
\hline T. & Treated & - \\
\hline S1 & Treatment speed 1 & $0.1 \mathrm{in} / \mathrm{s}$ \\
S2 & Treatment speed 2 & $0.5 \mathrm{in} / \mathrm{s}$ \\
S3 & Treatment speed 3 & $1.0 \mathrm{in} / \mathrm{s}$ \\
\hline V1 & Treatment overlap 1 & $25 \%$ \\
V2 & Treatment overlap 2 & $50 \%$ \\
V3 & Treatment overlap 3 & $75 \%$ \\
\hline D0 & Distance from the nozzle to the surface 0 & $0.25 \mathrm{in}$ \\
D1 & Distance from the nozzle to the surface 1 & $0.5 \mathrm{in}$ \\
\hline .001 & Test number & - \\
\hline
\end{tabular}

Table 3.3 Characterization samples

\begin{tabular}{l|lcccl}
\hline Method & Groups & $\begin{array}{c}\text { Treatment } \\
\text { Speed (in/s) }\end{array}$ & $\begin{array}{l}\text { Distance } \\
\text { (in) }\end{array}$ & $\begin{array}{l}\text { Number of } \\
\text { Samples }\end{array}$ & $\begin{array}{l}\text { Treatment } \\
\text { Overlap (\%) }\end{array}$ \\
\hline \multirow{3}{*}{ WCA } & Pristine - Treated & 0.10 & 0.5 & 1 & 1 pass with nozzle \\
SEM & Pristine - Treated & 0.10 & 0.25 & 1 & 1 pass with nozzle \\
AFM & Pristine - Treated & 0.50 & 0.5 & 1 & 1 pass with nozzle \\
XPS & Pristine - Treated & 1.0 & 0.5 & 1 & 1 pass with nozzle \\
& Pristine - Treated & 1.0 & 0.25 & 1 & 1 pass with nozzle \\
\hline
\end{tabular}

Along with the different plasma parameters, the effect of moisture on adhesive was also explored, providing two different pristine $\mathbf{P}$ tests numbered in Table 3.1. The first DCB tests (P.001-005) had been bonded together with adhesive which had not been sealed in a moisture-proof bag. That had been left wrapped in a plastic bag with its open top folded over. It was closed off to moisture, but not sealed, whereas the second (P.006010) was bonded with an adhesive which had been sealed in moisture-proof bags. 


\subsubsection{DCB Test Coupon Assembly and Specifics}

A non-adhesive FEP film by CS Hyde ${ }^{\circledR}$, a Metlbond 1515-3M film adhesive, and two of the composite laminates 6" x 9" were used to assemble each test coupon. The FEP film was cut into a strip approximately $4.15 "$ x 6 " to be used as a site for the initial delamination [39] meant to initiate the crack tip of the propagation along the DCB test coupon [110]. This film had a thickness of $13 \mu \mathrm{m}$, which adheres to the ASTM D5528 suggestion of using an insert film with a thickness of no more than $13 \mu \mathrm{m}$ [39].

The initial assembly of a test coupon consisted of the following details:

1. After taking out the adhesive from the freezer and letting it thaw until it reached the room temperature, it was cut into $4.85 "$ x 6 " strip.

2. Before the assembly of the coupon, each laminate in the pristine $\mathbf{P}$ test group was wiped with a Kimberly-Clark Kimtech W4 alcohol wipe, while those in the treated $\mathbf{T}$ group were wiped before treatment.

3. During this secondary bonding process, FEP film was inserted at the end of the laminate while the remaining part of the composite was covered by the adhesive as shown in Figure 3.6.

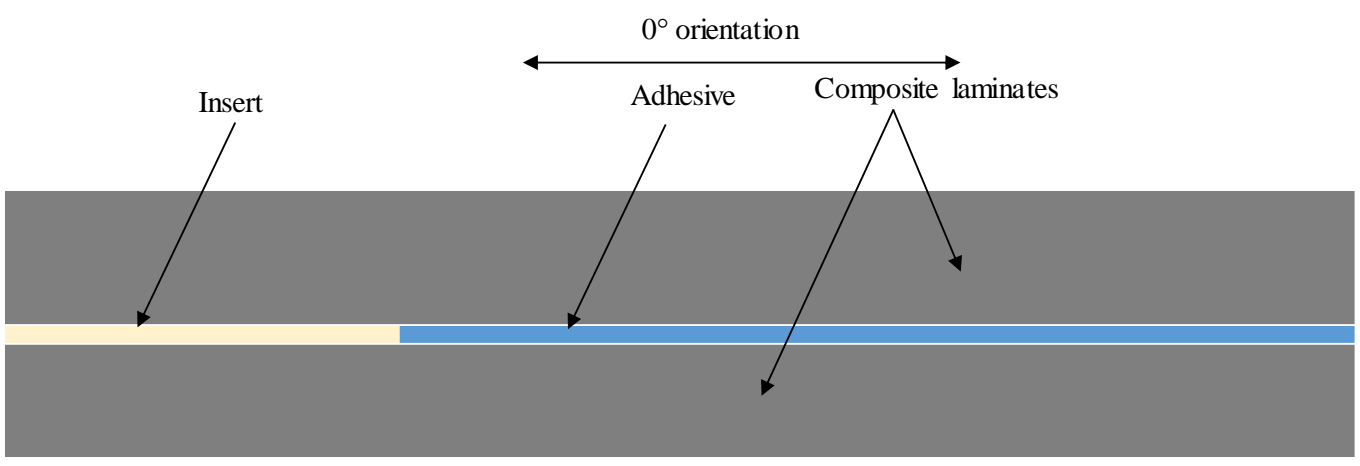

Figure 3.6 Laminates bonding assembly 
The application of the adhesive strip consisted of removing the outside layer of protection and rolling the paper-backed side of the strip onto one end of the laminate as seen in Figure $3.7 \mathrm{a} \& \mathrm{~b}$. The FEP film was then placed in the remaining uncovered area of the laminate. Both films were then completely covered with the second laminate and rolled again on both outer sides of the composite shown in Figure 3.7c \& d. The bonding laminates flowchart is shown in Figure A.3.

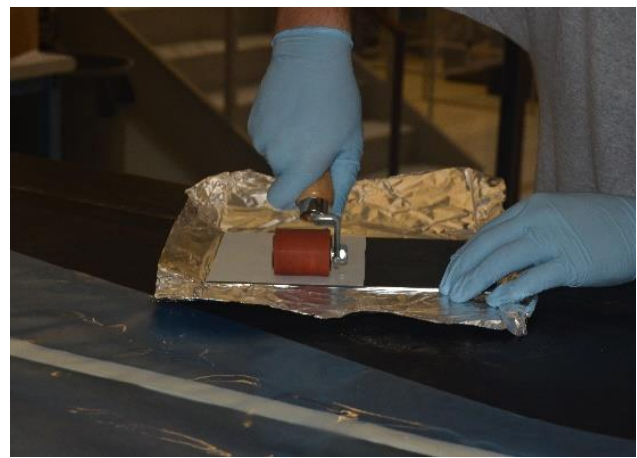

(a)

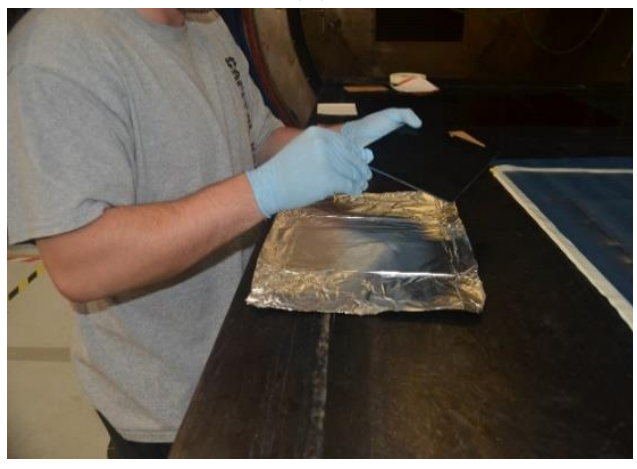

(c)

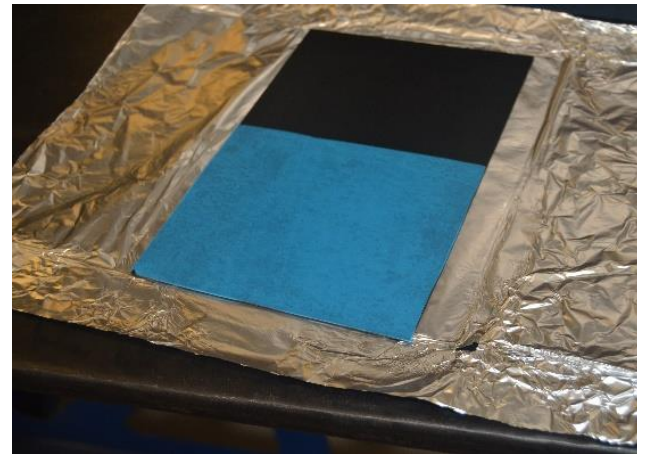

(b)

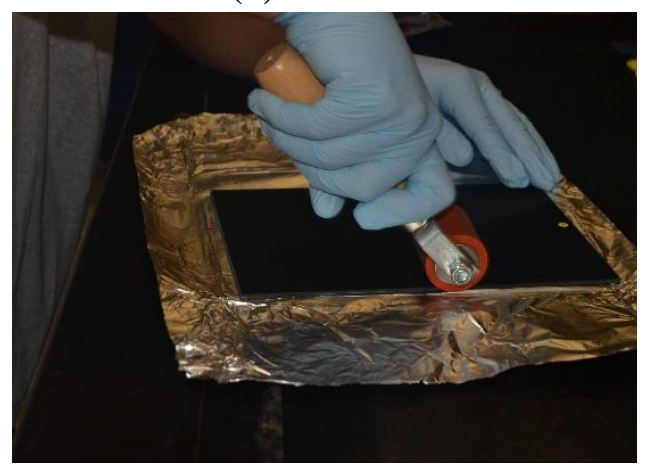

(d)

Figure 3.7 Adhesive bonding application

Vacuum bagging technique was used where the sandwiched laminates were placed upon a nylon film between two steel plates, and vacuum sealed as seen in Figure 3.8a. An autoclave by Bondtech ${ }^{\circledR}$, which is shown in Figure 3.8b, was used for the recommended Metlbond 1515-3M curing cycle. We applied a 45 psi pressure, and the temperature was increased to $350{ }^{\circ} \mathrm{F}$ from room temperature at a $5{ }^{\circ} \mathrm{F} / \mathrm{min}$ (recommended at a $\left.1-5^{\circ} \mathrm{F} / \mathrm{min}\right)$. The temperature was held constant $\left(350 \pm 10{ }^{\circ} \mathrm{F}\right)$ for 120 
minutes before being cooled to $125^{\circ} \mathrm{F}$ at $5^{\circ} \mathrm{F} / \mathrm{min}\left(<140^{\circ} \mathrm{F}\right)$ under the same pressure.

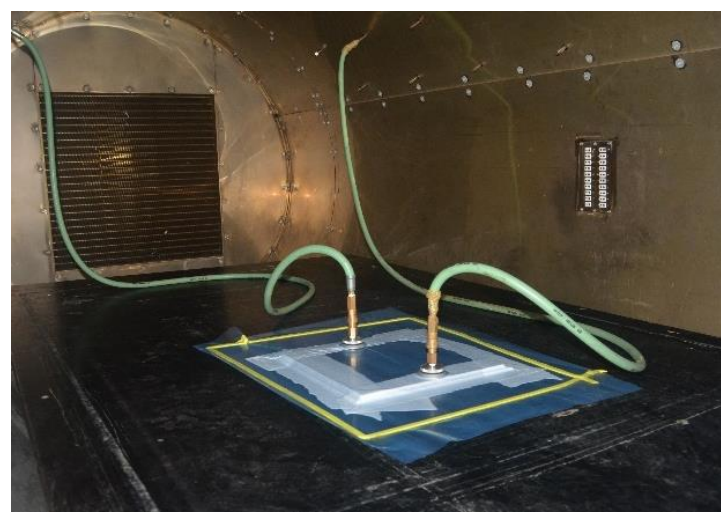

a

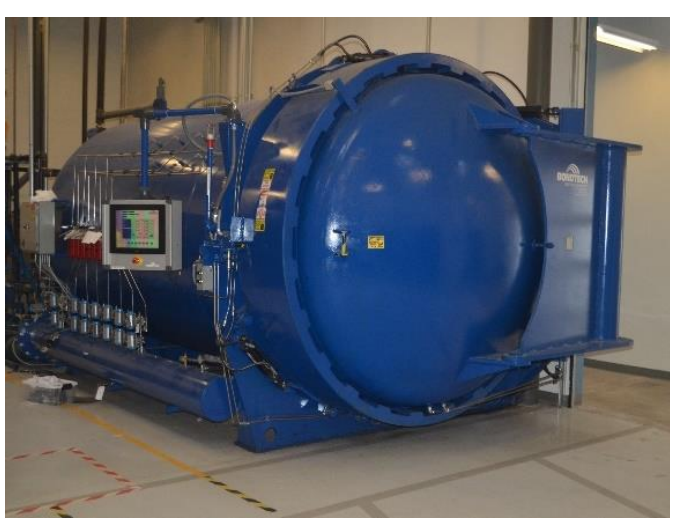

b

Figure 3.8 Autoclave bonding process for secondary bonding

After curing, the bonded laminates (6" x 9") were trimmed 0.5 " on the 9" side and 1.0 " on the 6 " side which resulted in a 5" $\mathrm{x} 7$ " laminate. It was then cut into individual 1" x 7" pieces using a Kobalt ${ }^{\circ}$ KWS S10-06 diamond saw shown in Figure 3.9a \& b.

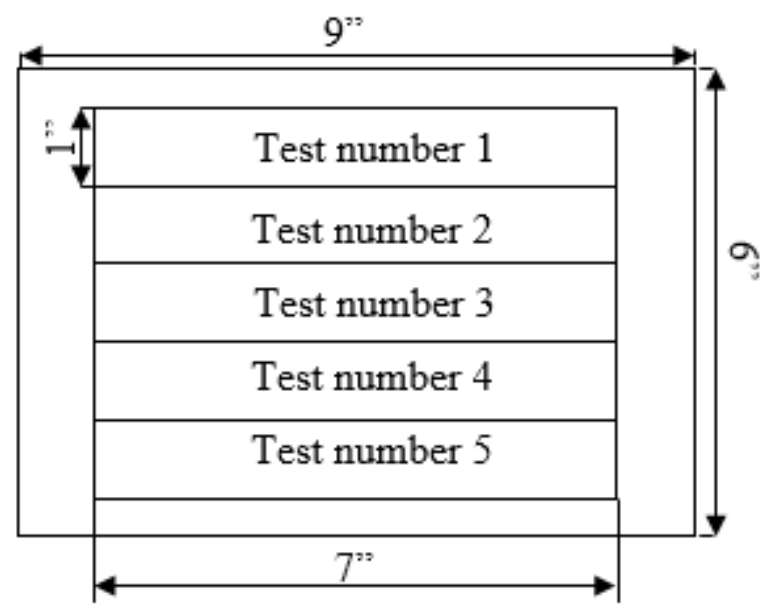

a

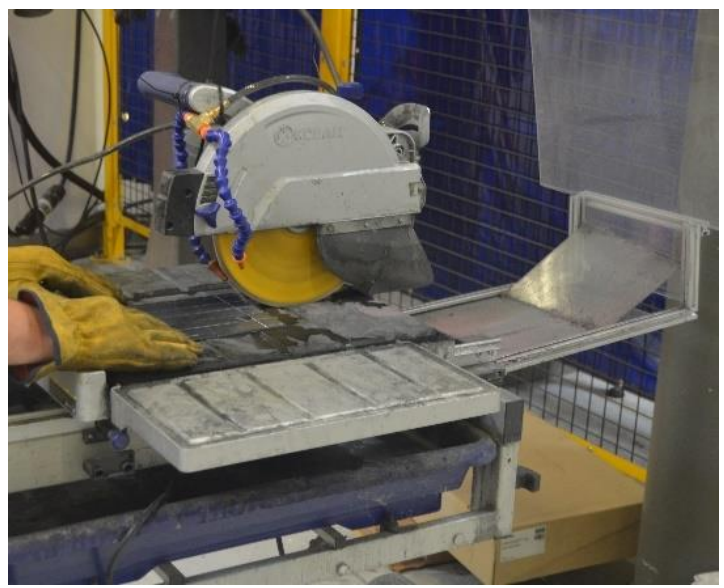

$\mathrm{b}$

Figure 3.9 Drawing outline and cutting coupons

Opening forces can be applied to the test coupon through metal loading-blocks or aluminum piano hinges [39]. For this project, two aluminum piano hinges with base dimensions of 1 " $\times 1.5$ " were attached to the bonded laminate with J-B Weld adhesive to provide holding points for the test machine. The hinges were bonded on their 1" side 
along the 1" end of the specimen containing the FEP film shown in Figure 3.10. Before bonding each hinge to the specimen, the hinge surface was abraded with 120 grit sandpaper prior to being cleaned with acetone and alcohol respectively. Meanwhile, the surface of the composite was also cleaned in that order as well. After applying the adhesive to the 1" side of both piano hinges, one clamp was used to hold the hinges to the specimen's surface while the cure took place. The adhesives' curing time, according to the J-B weld technical document, is $15-24$ hours at room temperature and the coupons were cured for approximately 24 hours. The hinge bonding flowchart is shown in Figure A.4.

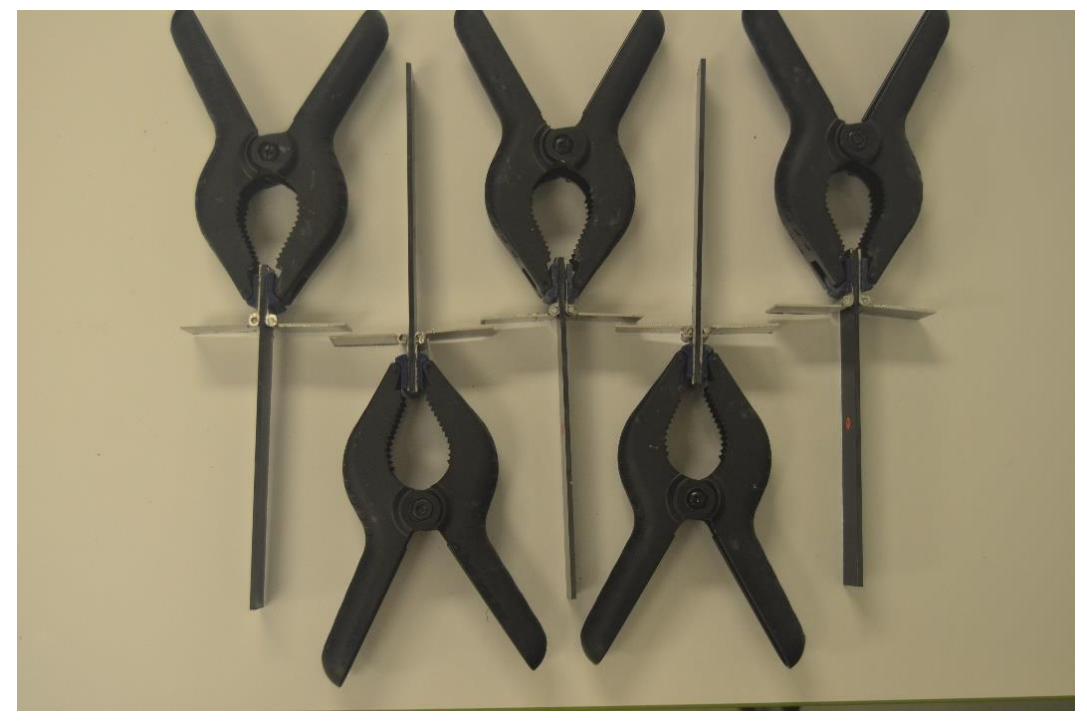

Figure 3.10 Clamping piano hinge while J-B Weld cures

The resulting DCB test coupon, which is shown in Figure 3.11, had a uniform thickness and width with the final dimensions of the DCB test coupon given in Table 3.4. Table 3.4 DCB test coupon dimensions

\begin{tabular}{cccc}
\hline $\begin{array}{c}\text { Length } L \\
\text { (in) }\end{array}$ & $\begin{array}{c}\text { Width } b \\
\text { (in) }\end{array}$ & $\begin{array}{c}\text { Thickness } h \\
\text { (in) }\end{array}$ & $\begin{array}{c}\text { Initial Crack Length } a_{0} \\
\text { (in) }\end{array}$ \\
\hline 7 & 1 & $\sim 0.108(\sim 2.75 \mathrm{~mm})$ & $\sim 2(50 \mathrm{~mm})$ \\
\hline
\end{tabular}




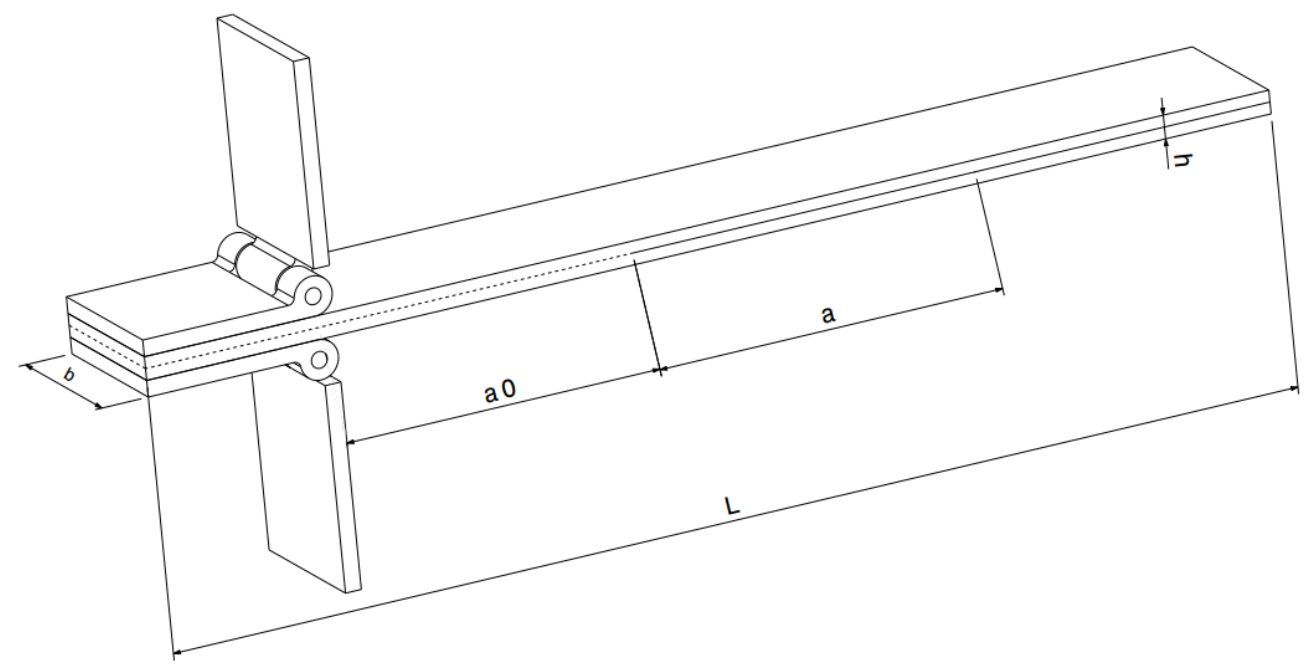

Figure 3.11 DCB test coupon assembly

\subsection{OPEN-AIR PLASMA TREATMENT}

Open-air plasma technology by Plasmatreat ${ }^{\circledR}$ was used for the treatment of the laminate surfaces in the treated $\mathbf{T}$ test group. It is described as an atmospheric pressure plasma jet (APPJ) [19], and plasma is generated in an arc and extended with the gas flow [35]. It creates an electrical discharge inside the jet and blows it out as a stream of air, which is known as open air plasma. This plasma treatment can be considered indirect contact since the plasma is created within the jet; however, the plasma discharge range could be extended 1-2 cm past the end of the jet nozzle [35]. The plasma is generated and dispensed from the nozzle as a result of the high voltage between the stator and the rotor. It supplies a chemical-free micro-fine cleaning and activates surfaces before bonding. The FG5002S plasma generator in Figure 3.12 and RD1004 plasma rotary nozzle in Figure 3.13 were used for the process and dry compressed air was used as the gas. A PTF 2647-2 stainless steel nozzle with an angle of $14^{\circ}$ was used to create a treatment width of approximately $1 ”$. 


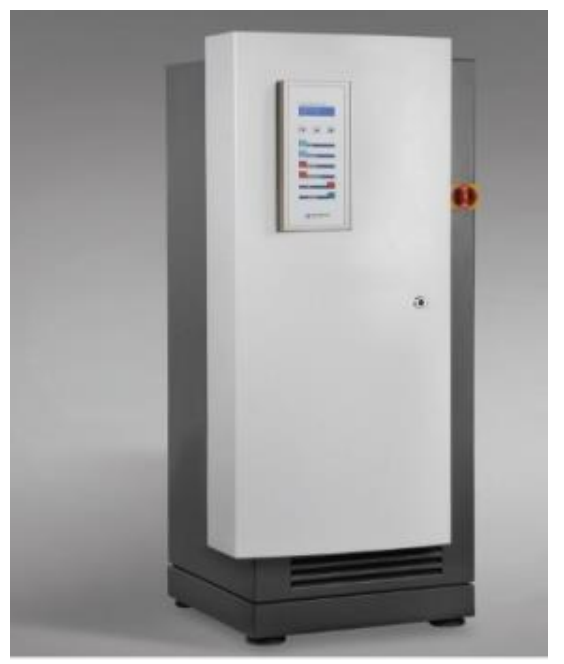

Figure 3.12 Plasma generator Figure 3.13 Plasma jet

Process parameters are shown in Table 3.2 and operating parameters are shown in Table 3.5. The treated $\mathbf{T}$ test groups which were performed ranged from $0.1 \mathrm{in} / \mathrm{s}, 25 \%$ overlap, and $0.25 "$ distance, to $1.0 \mathrm{in} / \mathrm{s}, 75 \%$ overlap, and $0.5 "$ distance.

Table 3.5 Operating parameters

\section{Working frequency}

Power

Feed Gas

Feed Gas Flow Rate

Jet Rotation

Output Voltage

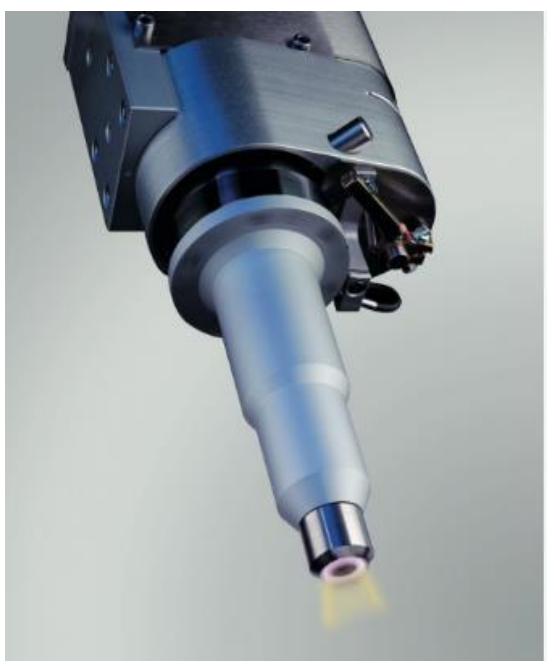


Sender allowed for the visualization of the path of the code and control of the hardware itself, while also allowing the upload of G-Code files and alteration of stepper motor settings. The plasma treatment flowchart is shown in Figure A.5.

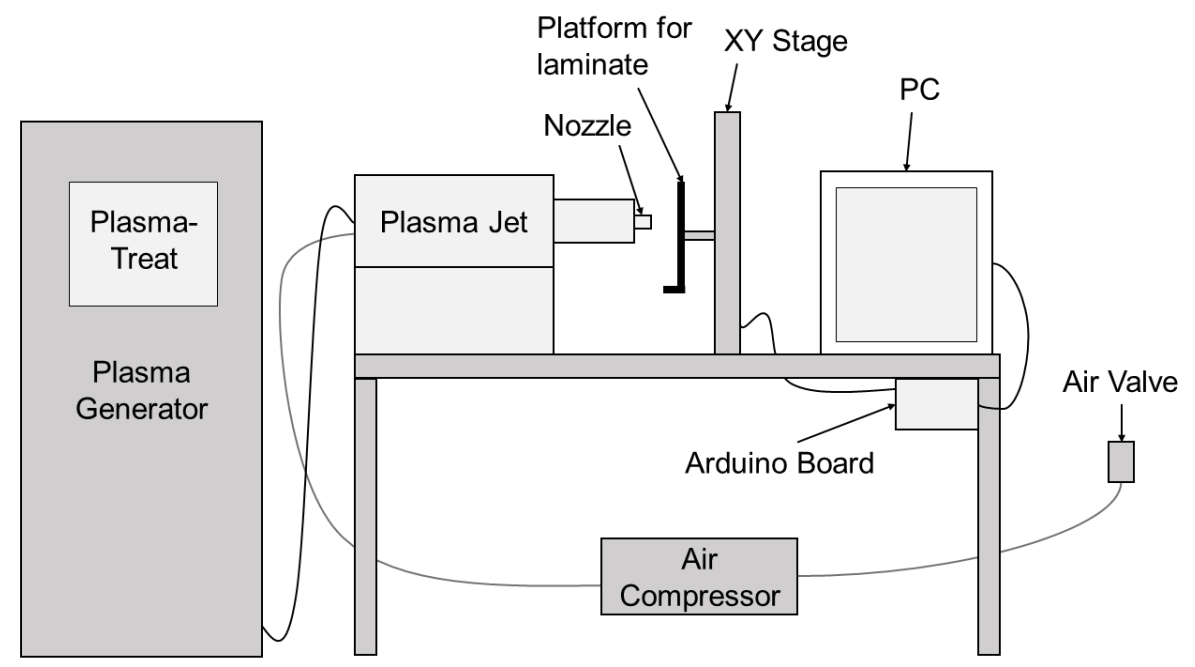

Figure 3.14 Plasma treatment system

Prior to the plasma treatment application, each laminate in the treated $\mathbf{T}$ group was wiped with a Kimberly-Clark® Kimtech P2 Aviation Wipe. Each plasma jet nozzle was placed at a distance of 0.5 " or 0.25 " from the surface of the composite part, based on the experimental selection.

Treatment overlap was not used for characterization samples because the samples' dimensions were too small to use the overlap. A single pass of the plasma jet nozzle was sufficient. One sample was used for every set of test parameters (treatment speed; distance from the plasma nozzle to the composite surface); this also included pristine samples (wiped).

After plasma treatment, all samples were wrapped in aluminum foil to prevent the contamination of their surfaces by air pollutants until subsequent bonding or characterization. All laminates were bonded with Metlbond for the test coupon or 
analyzed with WCA, XPS, SEM, and AFM methods within 1 hour of the treatment, and they were kept in aluminum foil until they were ready to be measured.

\subsection{SURFACE CHARACTERIZATION}

\subsubsection{Water Contact Angle (WCA)}

The WCA was measured using a SA3001 Surface Analyst device by BTG Labs® (Cincinnati, $\mathrm{OH}$ ), shown in Figure 3.15, and the contact angle flowchart is shown in Figure A.6. The device measures the receding contact angle with a pulsed stream of nanoliter-sized microdroplets [49], a method which is commonly known as the ballistic deposition method. Both the volume and the diameter of the drop are used to calculate the approximate contact angle by averaging established geometric standards for similarly sized droplets [88]. The contact angle, which is calculated this way, is more inclusive and provides a more accurate representation of the surface energy in the area surrounding the drop [52].

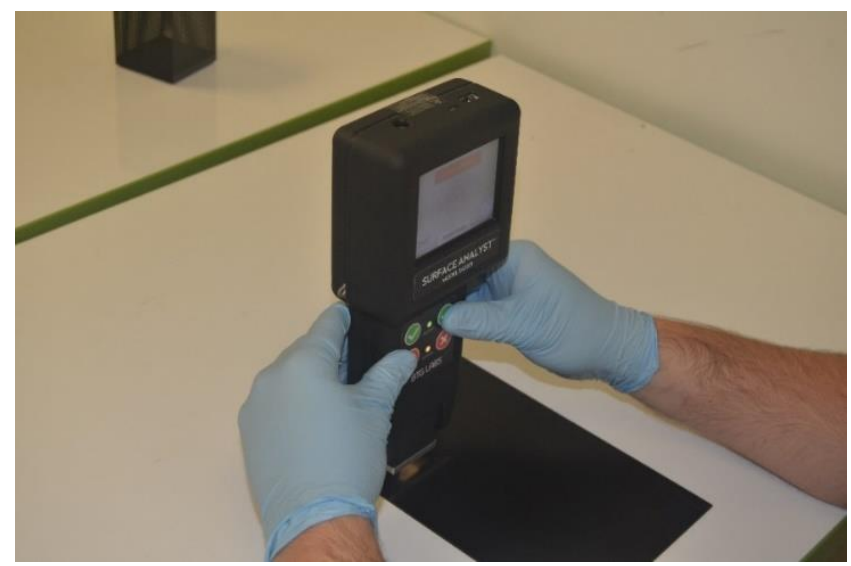

Figure 3.15 Surface analyst device

When a drop detection was not defined well as shown in Figure 3.16, it was rejected; however, when the drop detection was well defined shown in Figure 3.17, it was an acceptable measurement of the contact angle. 


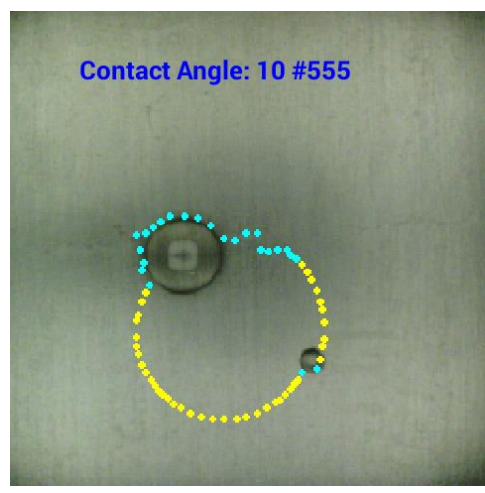

Figure 3.16 Not a good drop detection

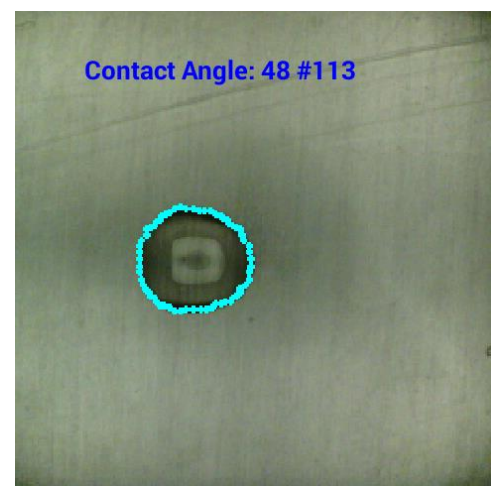

Figure 3.17 Well defined drop detection

To measure the WCA, 5 different samples, as detailed in Table 3.3, were used before (pristine $\mathbf{P}$ ) and after treatment (treated $\mathbf{T}$ ). Treatment overlap was not used for these samples. The WCA was also measured for DCB test laminates before wiping, after wiping (pristine $\mathbf{P}$ ) and after treatment (treated $\mathbf{T}$ ). In each case, it was measured within 10 minutes post wiping and post treatment. A total of 10 measurements were taken and the average of these angles was used.

\subsubsection{Scanning Electron Microscopy (SEM)}

To analyze the morphological changes prior to and after treatment, which reveals the effect that plasma treatment has on the microstructural surface features of the samples, a Tescan® Vega 3 SEM, shown in Figure 3.18, was used to take images with an electron beam of energy $10 \mathrm{kV}$ at approximately 5-7 mm working distance. Sputter coating was applied using a Denton ${ }^{\circledR}$ Desk II sputter coater for all samples before introduction into the SEM chamber. The same five points marked using a micro indenter were analyzed for each magnification of image as pristine $\mathbf{P}$ and treated $\mathbf{T}$. The flowchart of SEM is shown in Figure A.7. All images were captured at both 1000x and 5000x magnifications for all the points. 


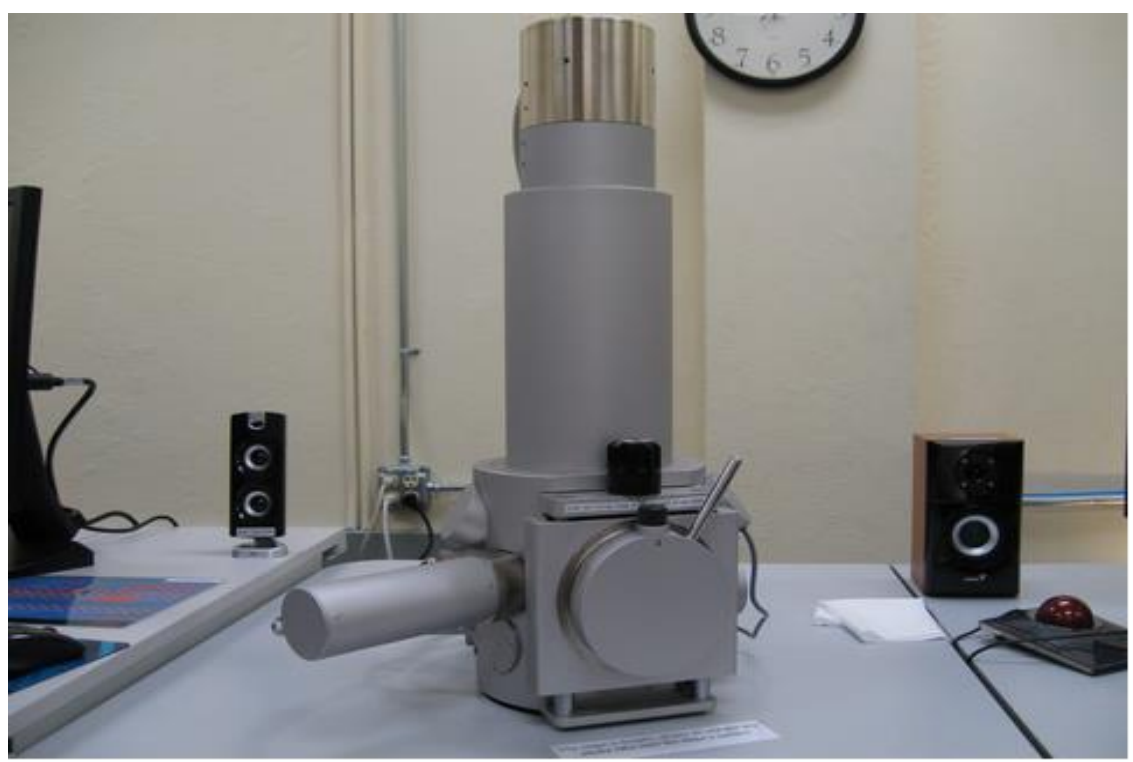

Figure 3.18 Tescan Vega SBU variable pressure SEM

5 samples were used for SEM analysis in Table 3.3. Treatment overlap was not used, and in each case, SEM was performed within 1 hour of either wiping (pristine $\mathbf{P}$ ) or after treatment (treated $\mathbf{T})$.

\subsubsection{Atomic Force Microscopy}

The surface topography was also studied with AFM at room temperature and under ambient conditions using a Nanoscope ${ }^{\circledR}$ Dimension 3100 Controller. Scanning was achieved in a $5 \mu \mathrm{m} \times 5 \mu \mathrm{m}$ area in the non-contact mode with a standard silicon tip. The root mean square (rms) roughness and three-dimensional (3D) images were obtained by using the Nanoscope software.

\subsubsection{X-ray Photoelectron Spectroscopy (XPS)}

Kratos® Axis Ultra XPS, shown in Figure 3.19, was used to link surface free energy evolution to the surface elemental composition and chemical bonds before and after treatment. A beam of X-rays simultaneously measures the kinetic energy and number of the electrons that escape from the surface of the test material. It analyzed the atomic composition of the top $10 \mathrm{~nm}$ of the composite surface, specifically used for the 
determination of the effect that plasma treatment, by determining the level of oxidation on the elements at the surface.

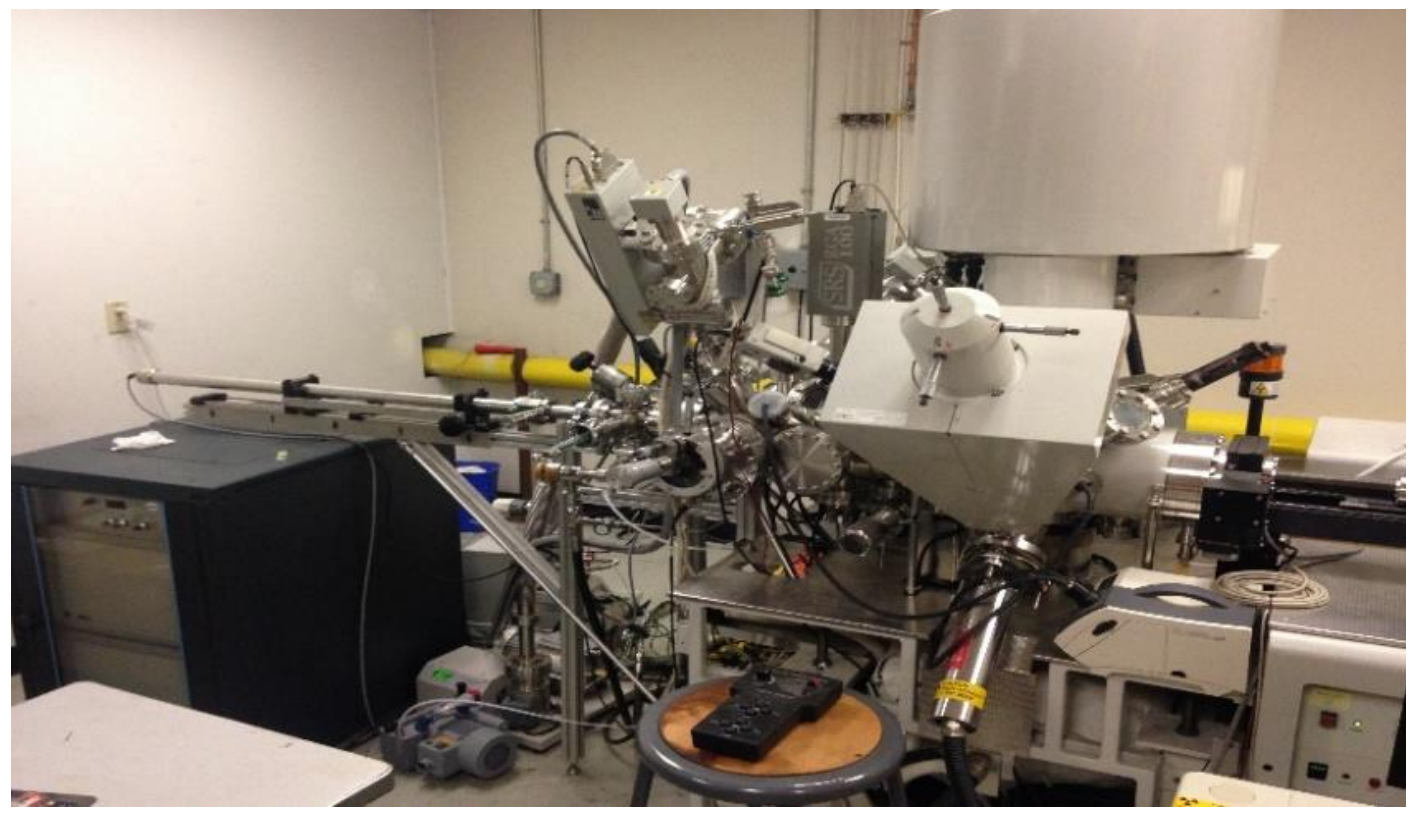

Figure 3.19 Kratos Axis Ultra XPS

Kratos AXIS Ultra spectrometer was used for the XPS analysis with a monochromatic Al Ka X-ray radiation source and hemispherical electrostatic energy analyzer. The system was operated at $15 \mathrm{keV}$ and $150 \mathrm{~W}$. X-rays were produced at a $45^{\circ}$ angle in regard to the surface. The composite samples in the chamber were analyzed at a pressure under $1 \times 10^{-9}$ mbar. High-resolution, core-level spectra were recorded with a pass energy of $40 \mathrm{eV}$ while survey scans with a pass energy of $160 \mathrm{eV}$. An electron beam was directed on the sample for charge neutralization to perform this analysis. The latter was performed using XPSPEAK 4.1 software, and plots of intensity as a function of electron binding energy for each element were also found.

The XPS characterization samples were detailed in Table 3.3. Treatment overlap was not used because of their small dimensions. In each case, XPS was performed within 
1 hour after wiping or after treatment. The same area was analyzed each time to measure the surface chemical composition.

\subsection{DOUBLE CANTILEVER BEAM (DCB) TEST}

The DCB test, which its schematic is shown in Figure 3.20, was performed on the adhesively bonded composite coupons with a MTS ${ }^{\circledR}$ testing machine (MTS, Minneapolis, MN) which is shown in Figure 3.21. It is an experimental test method designed to determine the opening Mode I interlaminar fracture toughness of unidirectional CFRP using the DCB test coupon in Figure 3.11, and the calculation is based on its width, crack-propagation length, the applied load and displacement of the DCB test coupon. This test aims to study the optimal plasma process parameters. The DCB test flowchart is shown in Figure A.8.

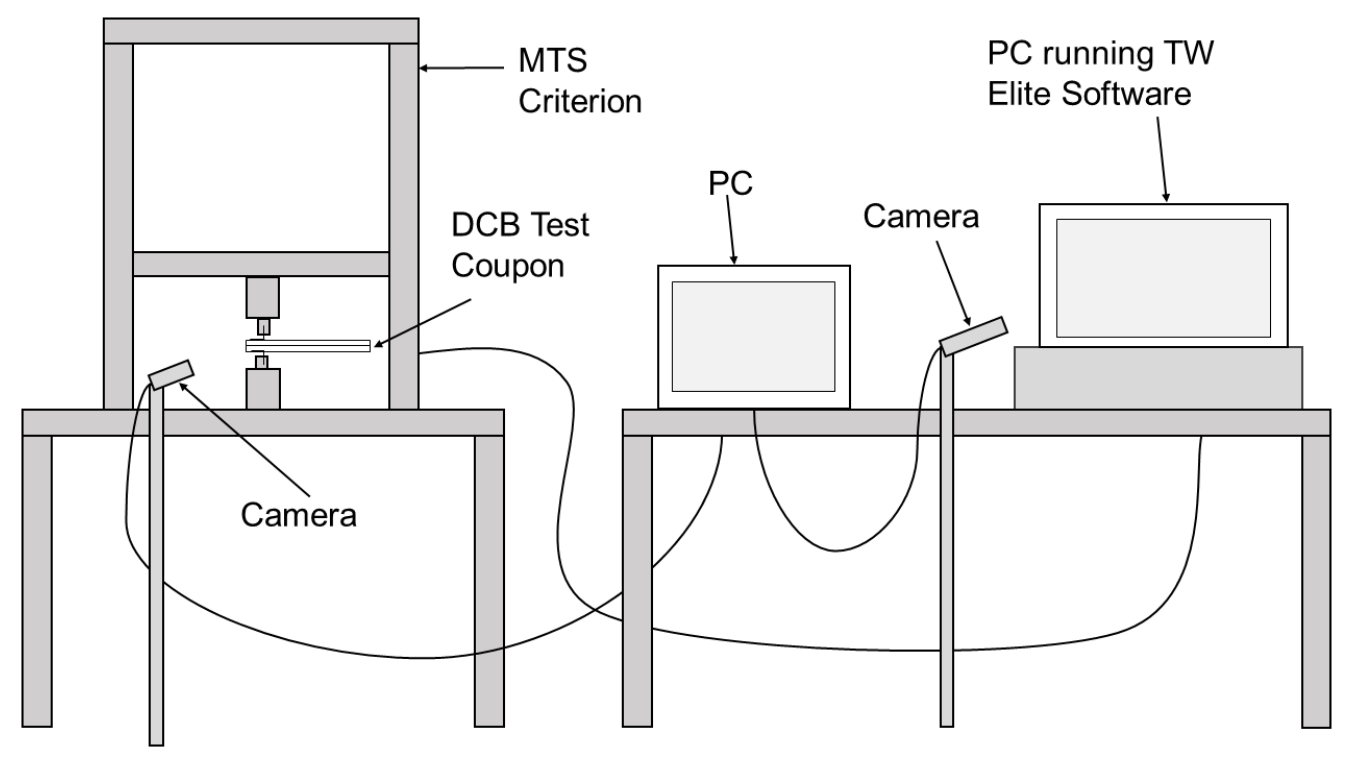

Figure 3.20 DCB test schematic

The load was applied to the end of the test coupon while the other end was free, as seen in Figure 3.21. The resistance to crack initiation and propagation was to be 
determined under the crack-opening mode, Mode 1 . The Mode 1 pre-crack was used to create an initial site of delamination on the coupon.

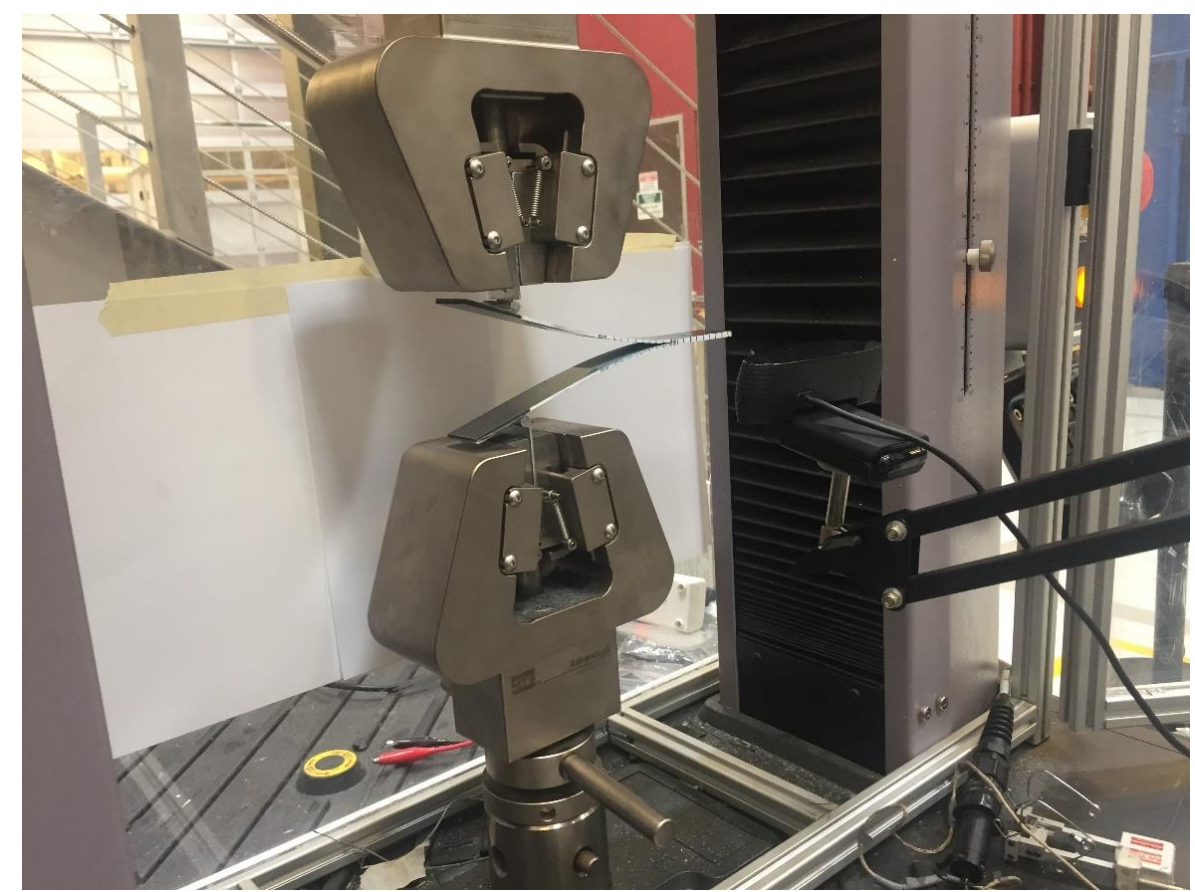

Figure 3.21 DCB test setup

A load and displacement curve was recorded with MTS $®$ TestSuite ${ }^{\mathrm{TM}}$ TW Elite software during the test. Two cameras were set up with the Open Broadcast Software to concurrently record the actions of the DCB test coupon, as seen in Figure 3.21, and the load and crosshead displacement values displayed on the software running on the computer screen. This allowed for the tracking of the propagation of the crack at different load and displacement values by viewing the marks on the side of the test coupon. The initiation and propagation values of $\mathrm{G}_{\mathrm{IC}}$ and $\mathrm{G}_{\mathrm{IP}}$ were calculated using this recorded data with the Modified Beam Theory (MBT) method.

The first $5 \mathrm{~mm}$ past initial crack (delamination) was marked every $1 \mathrm{~mm}$, the following $45 \mathrm{~mm}$ was marked every $5 \mathrm{~mm}$, prior to marking the $46^{\text {th }}$ through $50^{\text {th }} \mathrm{mm}$ 
every $1 \mathrm{~mm}$, as shown in Figure 3.22. The remaining length of the coupon was marked every $5 \mathrm{~mm}$ to provide a reference of delamination crack during the test.

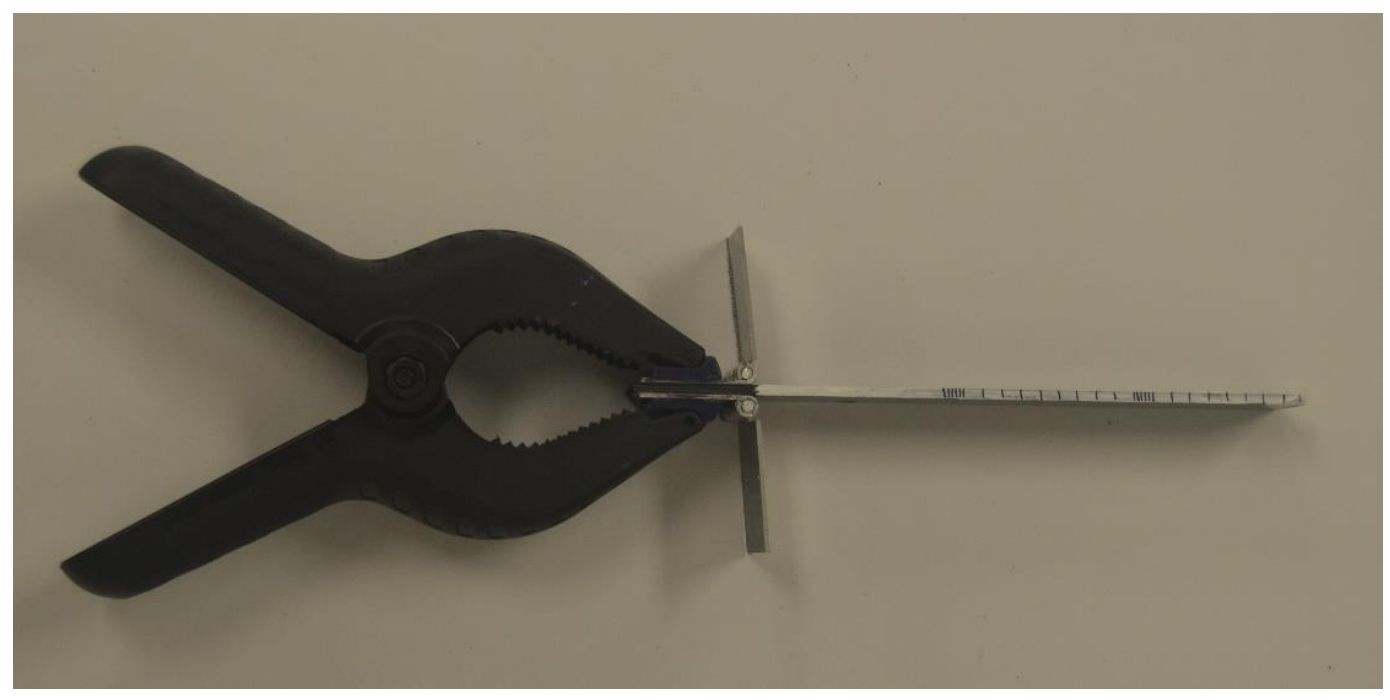

Figure 3.22 DCB test coupon marked

The total crack propagation from the initial crack tip was approximately $50 \mathrm{~mm}$ for DCB tests. Three different loading and unloading methods were used in accordance with ASTM D5528-01 [39]. The first loading sequence was used to pre-crack the test coupon about 3-5 mm following the length of the insert. That was done to eliminate the initial spike in the results which could result in outliers in the data. The second loading sequence propagated the crack an additional $50 \mathrm{~mm}$ [110]; this second sequence was used as the main group of data points. The third loading sequence was initiated to conclude which failure mode existed.

\subsubsection{Initial Loading}

The piano hinges were attached to the MTS test machine in Figure 3.21 where the DCB test was performed. The ASTM D5528-01 [39] gives the loading rate for the DCB test coupon with $1-5 \mathrm{~mm} / \mathrm{min}$; however, the coupon was loaded at a constant crosshead rate of $1.0 \mathrm{in} / \mathrm{min}$. A point on the load-displacement curve was made, marking the 
beginning of the crack movement from the insert, which was observed from the recording of the edge of the coupon.

Loading was stopped as soon as the delamination crack growth was seen to reach an increment of 3 to $5 \mathrm{~mm}$. At this point, the coupon was unloaded at a constant crosshead rate of up to $1.0 \mathrm{in} / \mathrm{min}$. The position of the tip of the pre-crack was marked on both sides of the coupon; if these marks differed by more than $2 \mathrm{~mm}$ it was noted in the report, as this variation could indicate asymmetrical loading [39].

\subsubsection{Reloading}

The load was reapplied on the coupon, at the same crosshead rate of $1.0 \mathrm{in} / \mathrm{min}$ and a point on the load-displacement curve was made, marking the crack movement from the tip of the pre-crack on the edge of the coupon. The load and displacement data were recorded at every $5 \mathrm{~mm}$ increment until the delamination crack had propagated at least 45 $\mathrm{mm}$ from the tip of the pre-crack, and at every $1 \mathrm{~mm}$ increment of crack growth for the following and final $5 \mathrm{~mm}$ of delamination propagation. When delamination crack reached $50 \mathrm{~mm}$, loading was stopped and it was unloaded at a constant crosshead rate of up to 1.0 in/min.

To determine which failure mode occurred on the bonded area, the test coupon was reloaded again at the same crosshead rate of $1.0 \mathrm{in} / \mathrm{min}$ until the end of the coupon without stopping.

\subsubsection{Modified Beam Theory (MBT) Method}

The modified beam theory equation was used to calculate the interlaminar fracture toughness $\left(G_{I C}\right)$ in equation (2.8) using the load and crosshead distance data recorded during the test. 
The $\left(G_{I P}\right)$ value given in equation (3.1) was calculated by taking the area under the load and displacement curve (E) and dividing it by the propagation length (a) multiplied by the width of the coupon (b). This number represents a more general value to classify fracture toughness.

$$
G_{I P}=\frac{E}{a x b}
$$

\subsubsection{Delamination Resistance Curve (R Curve)}

Resulting from a DCB test, delamination grows from the tip of the insert and a resistance-type fracture behavior develops in the adhesive where the calculated $G_{I C}$ first increases monotonically [39]. A resistance $\mathrm{R}$ curve shown in Figure 3.23 shows the relationship between the strain energy release rate $\left(G_{I C}\right)$ and the delamination length (crack length, $a$ ).

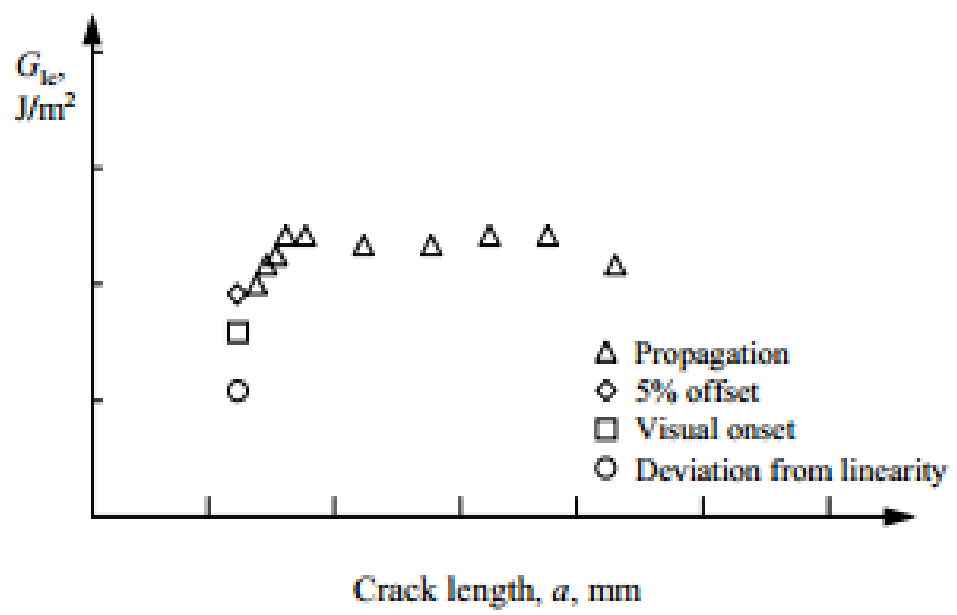

Figure 3.23 Delamination resistance curve (R curve) [39]

\subsubsection{Failure Modes}

Fracture surfaces were analyzed visually to decide what mode of failure the test resulted in. According to ASTM D5573 [106], seven failure modes were adapted as shown in Figure 3.24. They each have the ability to occur on the test coupon [106]. 


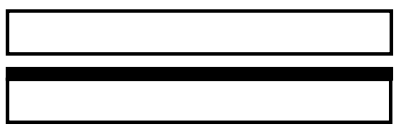

(a)

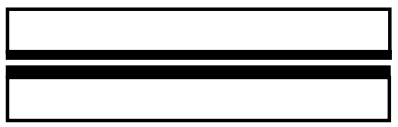

(c)

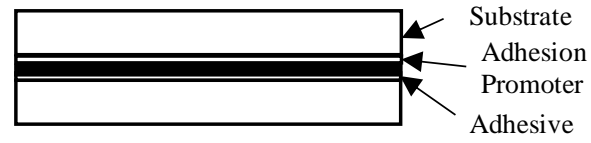

(e)

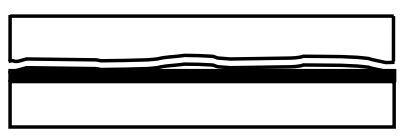

(g)

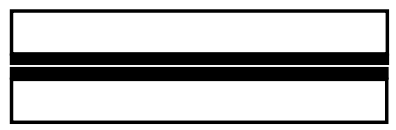

(b)

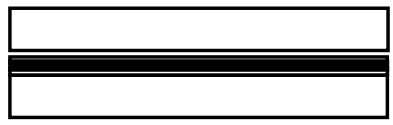

(d)

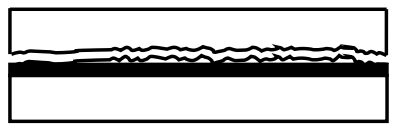

(f)

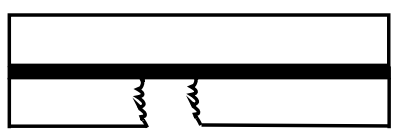

(h)

Figure 3.24 DCB failure modes a) Adhesive failure b) Cohesive failure c) Thin layer cohesive failure d) Adhesion promoter to substrate e) Adhesive to adhesion promoter f) Fiber tear failure g) Light fiber tear failure h) Stock break failure 


\section{CHAPTER 4}

\section{RESULTS AND DISCUSSION}

This chapter presents the experimental results of the conducted test plan to identify the effect of APPJ treatment. It discusses both (1) the characterization methods: WCA, SEM, AFM, and XPS; and (2) the DCB tests: Mode I interlaminar fracture toughness and failure mode. Characterization samples were plasma treated following the same sequence for all the test specimens. The first three samples were treated with speeds of $0.1 \mathrm{in} / \mathrm{s}(\mathrm{S} 1), 0.5 \mathrm{in} / \mathrm{s}(\mathrm{S} 2)$ and $1.0 \mathrm{in} / \mathrm{s}(\mathrm{S} 3)$ at $0.5 \mathrm{in}(\mathrm{D} 1)$ distance from the plasma jet nozzle to the surface respectively, while samples 4 and 5 were treated with a treatment speed of $0.1 \mathrm{in} / \mathrm{s}(\mathrm{S} 1)$ and $1.0 \mathrm{in} / \mathrm{s}$ (S3) at distance of $0.25 \mathrm{in}$ (D0) respectively. Treatment overlap was not relevant for the characterization samples: they were treated with a single pass of the plasma jet.

\subsection{WATER CONTACT ANGLE (WCA)}

The WCA results of the pristine $\mathbf{P}$ (in red) and treated $\mathbf{T}$ samples (in grey) are shown in Figure 4.1. Results show that the amount of wiping did have an effect on the contact angle; however, it varied due to the fact that it was done manually and thus it is prone to human err. A sharp decrease in the contact angle was observed after treatment for all the samples. The lowest angle $\left(13.5^{\circ}\right)$ was taken at conditions: D1 for distance, S1 for treatment speed. These conditions had the longest treatment duration which promoted the low WCA. When the treatment speed increased at distance D1, we observed that the 
contact angle also increased. The decrease in the contact angle demonstrates an enhancing surface roughness [11], the formation of polar groups $[11,20]$ on the surface through the increase of hydrophilicity when the treatment time was raised with a constant distance [22]. Li et al [22], states that maximizing polar surface with a longer treatment time causes the increase of surface wettability [11].

When distance decreased to 0.25 in (D0), an increase of the contact angle occurred within the same treatment speeds. As such, we observed that the angle of sample 4 was lower with treatment speed S1 than the contact angle of sample 5 with speed S3. Results clearly indicate that surface hydrophilicity raised with lower contact angle and the higher polar surface which has enhanced polar groups and oxidation after treatment [26].

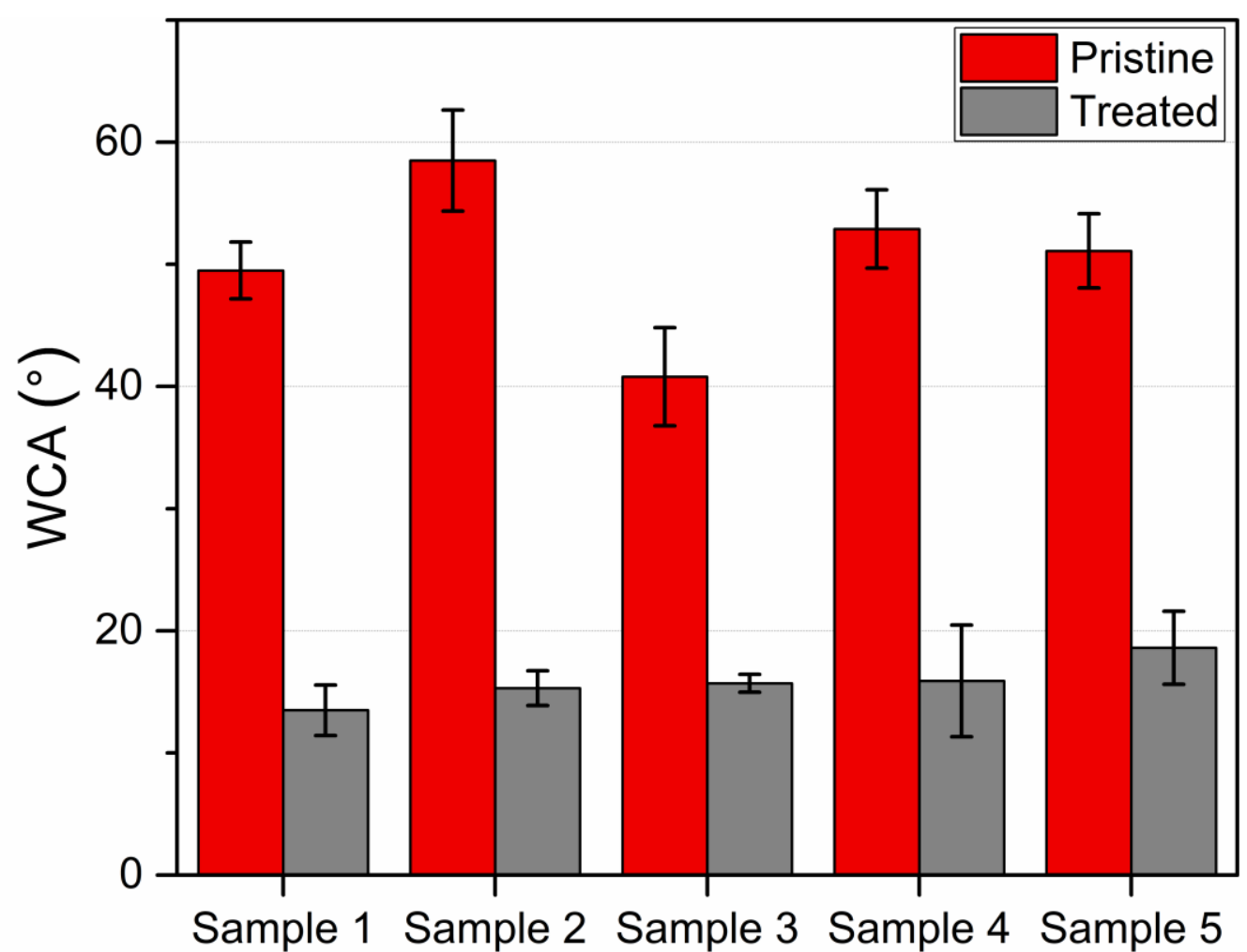

Figure 4.1 WCA for pristine and treated samples 
In addition to the above five samples, WCA was also measured for each DCB test laminate (6" x 9"), and the results are presented in: Figure 4.2 for Speed 1, Figure 4.3 for Speed 2, Figure 4.4 for Speed 3, and Figure 4.5 for a refined selection. The contact angles were within the range of $82^{\circ}-89^{\circ}$ for each laminate before wiping and showed a decrease to a range of $55^{\circ}-75^{\circ}$ following the wiping process. However, it sharply dropped to the $10.9^{\circ}-23.9^{\circ}$ range following the surface plasma treatment. The lowest angle was measured on the laminate treated with speed S2, overlap V1, and distance D1 in Figure 4.3 while the highest was recorded for the slowest treatment speed S1 with the highest overlap V3, at the same distance D1, in Figure 4.2.

When the distance dropped to 0.25 in (D0) from plasma jet to composite surface, the contact angle increased with the same treatment speed and overlap value.

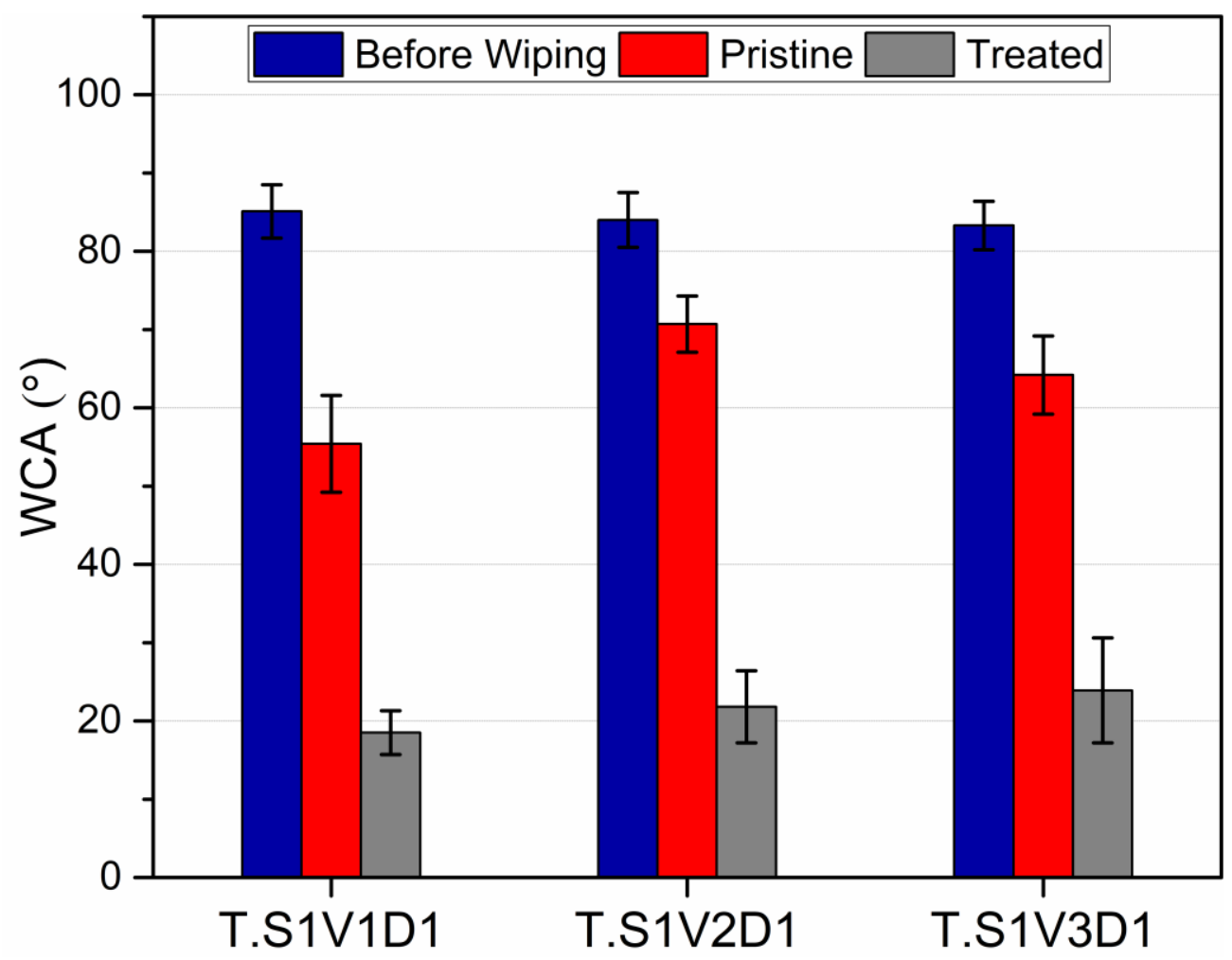

Figure 4.2 WCA for pristine and treated samples (S1,V1-2-3, and D1) 


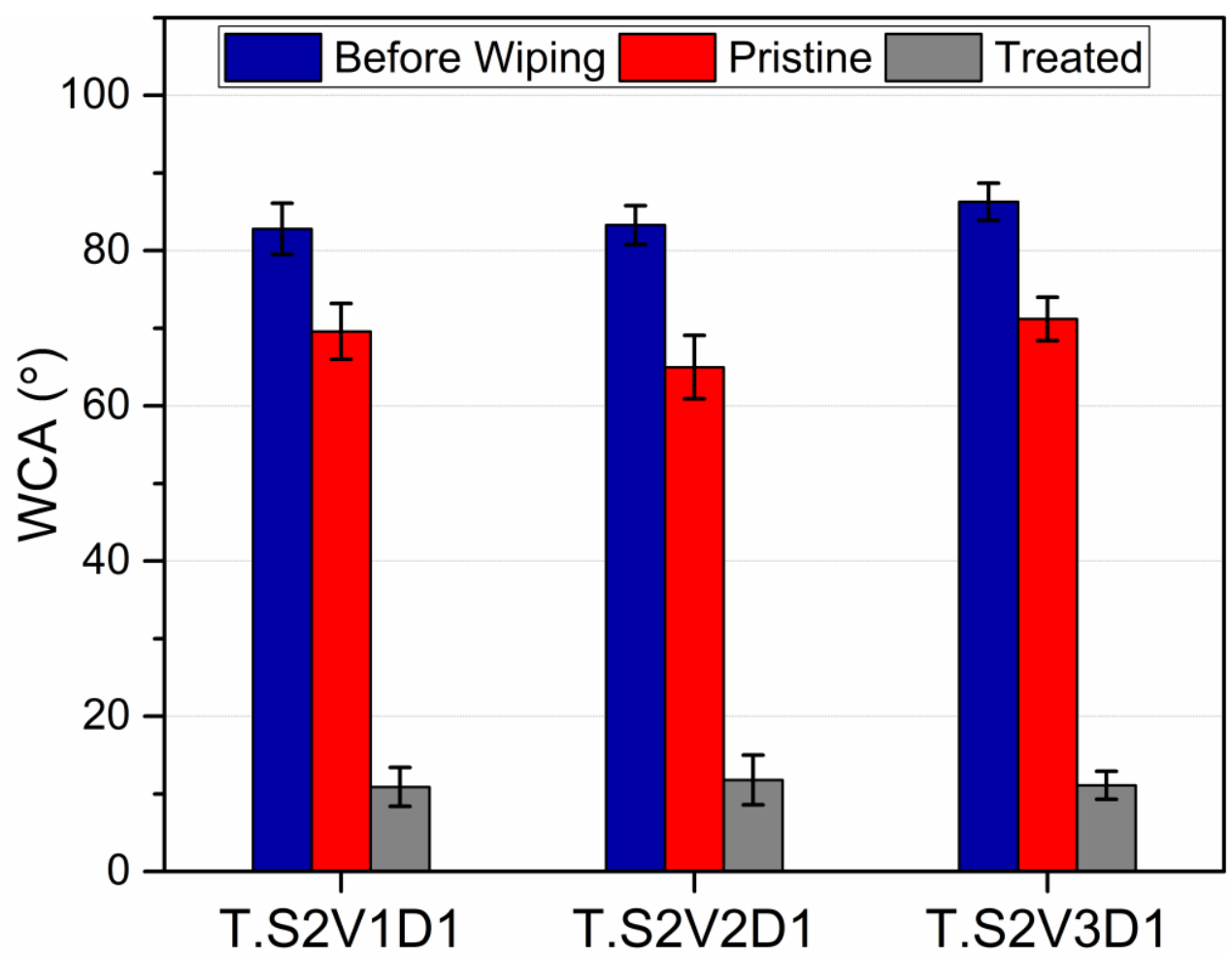

Figure 4.3 WCA for pristine and treated samples (S2,V1-2-3, and D1)

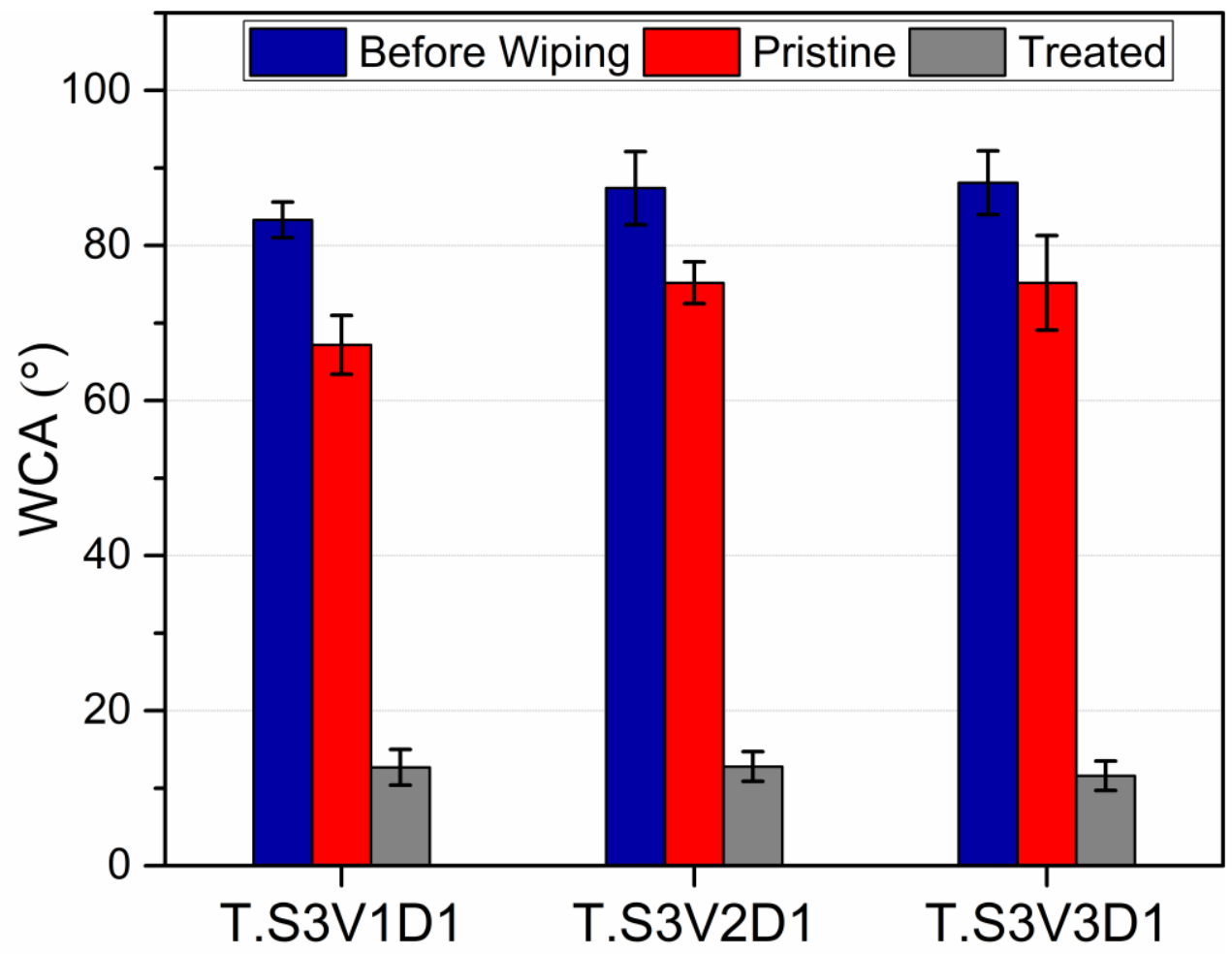

Figure 4.4 WCA for pristine and treated samples (S3,V1-2-3, and D1) 


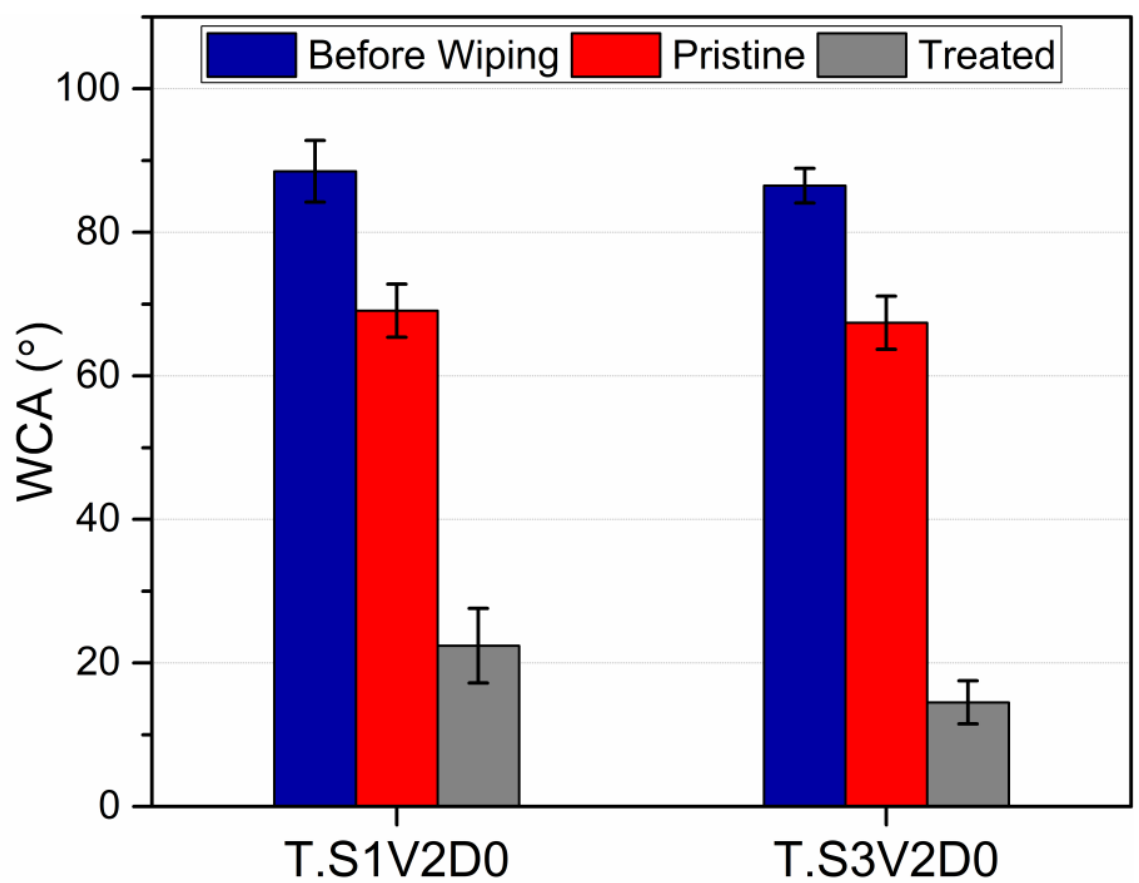

Figure 4.5 WCA for pristine and treated samples (S1-3,V2, and D0)

This section has clearly demonstrated that the surface treatment has an effect on the WCA as we see the sharp and steep decrease. However, it is to note that while the contact angle indicated a surface change, it does not correlate to the level of functionalization. It provides a first, and very important data point to be analyzed in context with the subsequent characterization and testing plan.

\subsection{SCANNING ELECTRON MICROSCOPY (SEM)}

SEM images of pristine $\mathbf{P}$ and treated $\mathbf{T}$ samples are presented with magnifications 1000x and 5000x in Figure 4.6, Figure 4.7, Figure 4.8, Figure 4.9, and Figure 4.10 respectively. In each figure the magnification on the left is the 1000x and the one on the right is the 5000x of the same sample. These figures show the pristine $\mathbf{P}$ samples having a relatively smooth morphology; on the other hand, treated $\mathbf{T}$ samples have a relatively rougher surface in microstructural features caused by the applied process parameters. No or little etching is observed for all of the treated $\mathbf{T}$ parts. Additionally, all treatment 
speeds of APPJ with both distances D0 and D1 were able to remove all the impurities on the surface, which helps to improve the bond itself [111].

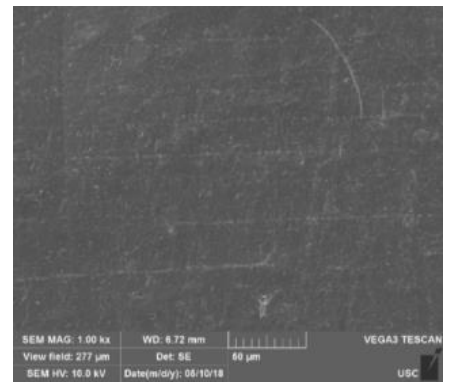

(a)

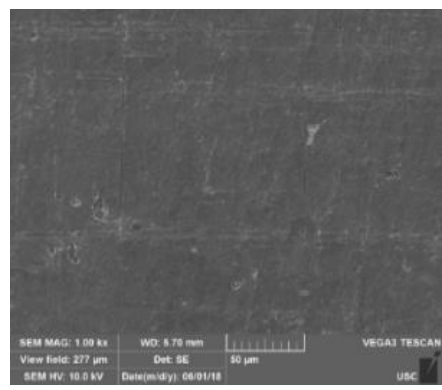

(c)

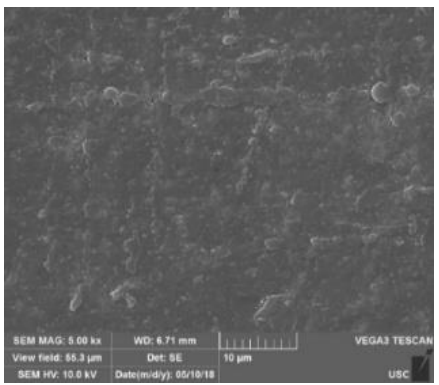

(b)

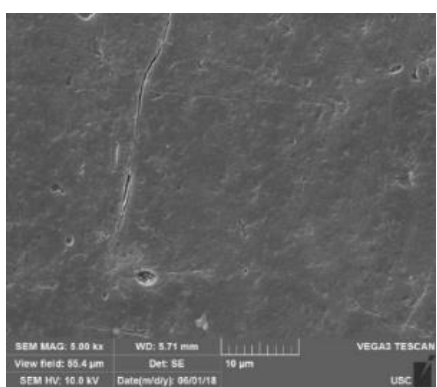

(d)

Figure 4.6 Sample 1 SEM images a) Pristine M:1000x b) Pristine M:5000x c) Treated M:1000x (S1, D1) d) Treated M:5000x (S1, D1)

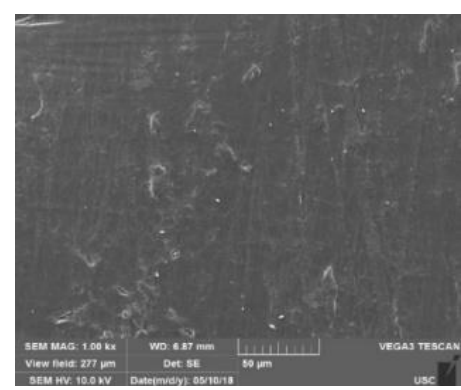

(a)

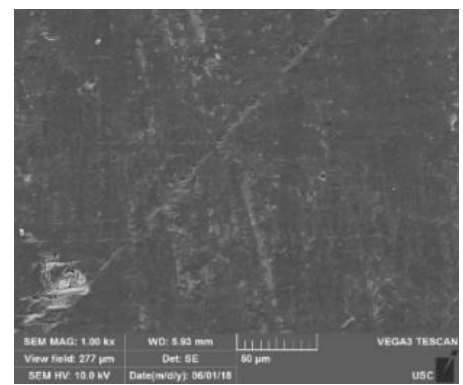

(c)

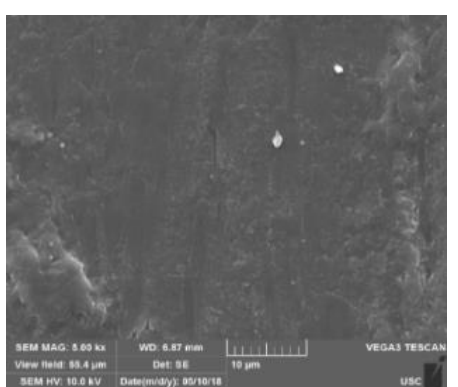

(b)

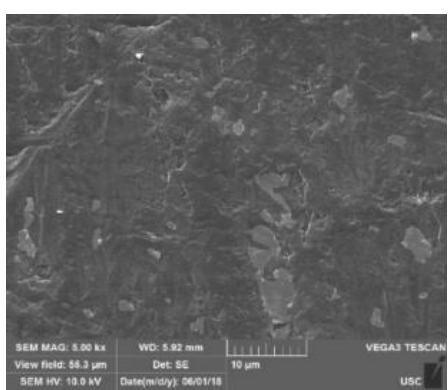

(d)

Figure 4.7 Sample 2 SEM images a) Pristine M:1000x b) Pristine M:5000x c) Treated M:1000x (S2, D1) d) Treated M:5000x (S2, D1) 


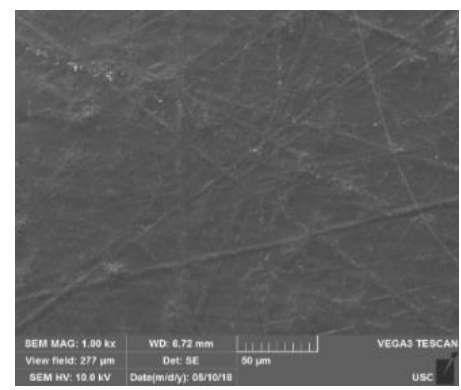

(a)

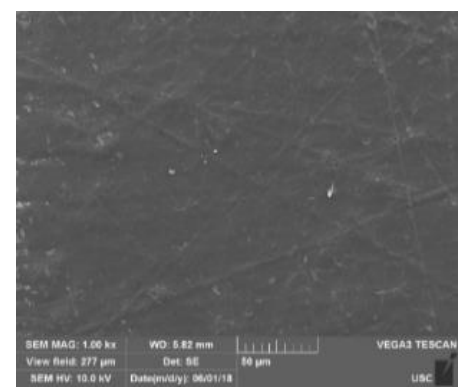

(c)

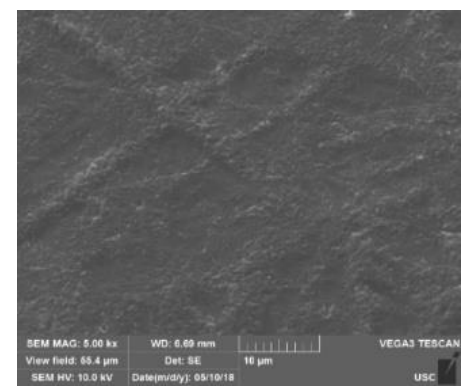

(b)

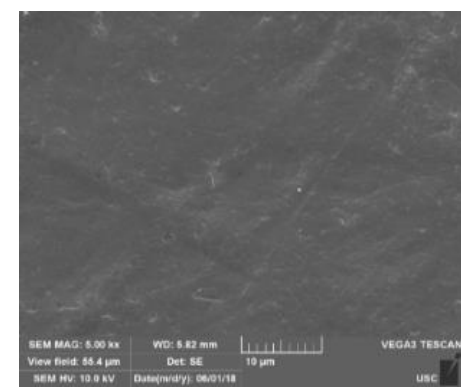

(d)

Figure 4.8 Sample 3 SEM images a) Pristine M:1000x b) Pristine M:5000x c) Treated M:1000x (S3, D1) d) Treated M:5000x (S3, D1)

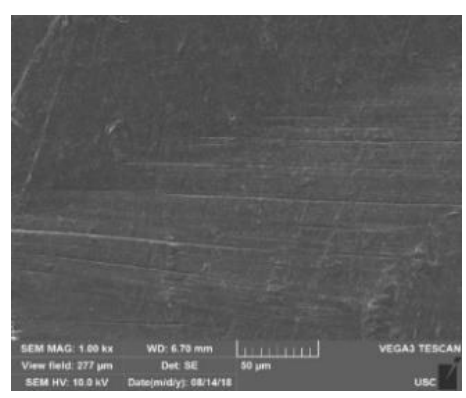

(a)

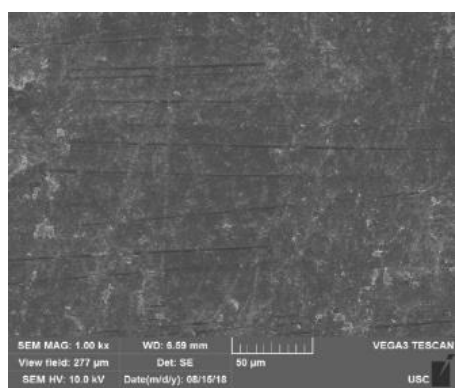

(c)

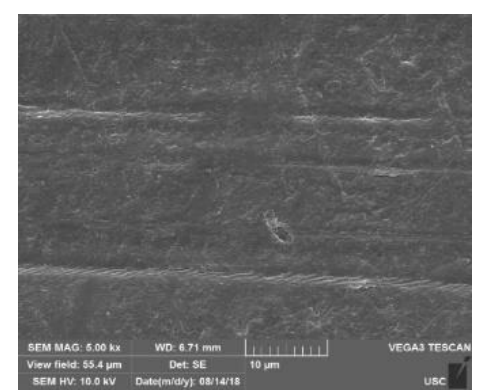

(b)

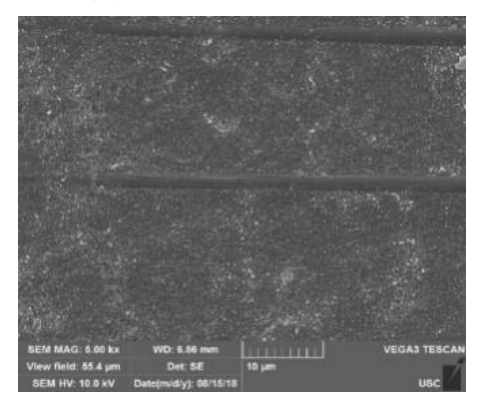

(d)

Figure 4.9 Sample 4 SEM images a) Pristine M:1000x b) Pristine M:5000x c) Treated M:1000x (S1, D0) d) Treated M:5000x (S1, D0) 


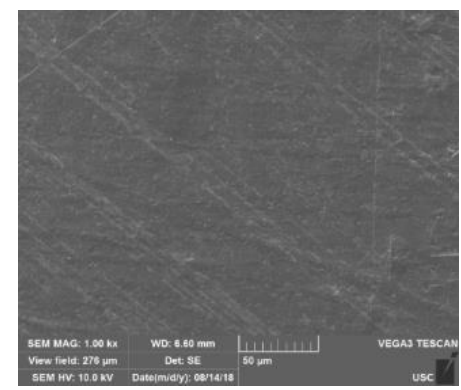

(a)

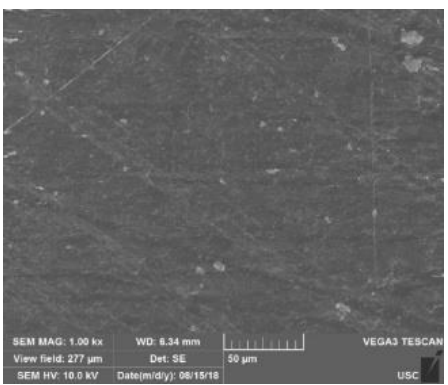

(c)

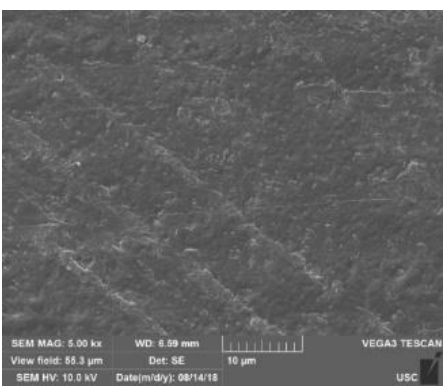

(b)

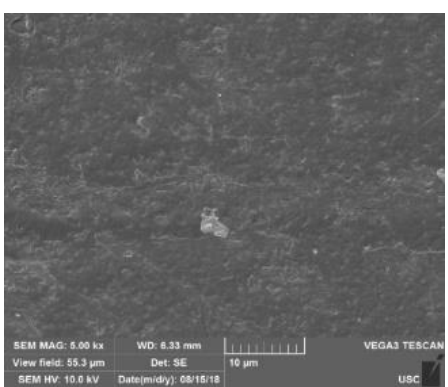

(d)

Figure 4.10 Sample 5 SEM images a) Pristine M:1000x b) Pristine M:5000x

c) Treated M:1000x (S3, D0) d) Treated M:5000x (S3, D0)

When distance dropped to D0, it can be seen that some exposed fiber outlines with longer treatment duration in Figure 4.9. White areas in Figure 4.9d may indicate higher oxidation with this speed and shorter distance.

SEM results demonstrate that there is not any noticeable damage to the fibers after treatment with any treatment speeds or distances. On the other hand, SEM images are not conclusive to explain the effectiveness of plasma conditions and how they correlate to surface functionalization.

\subsection{ATOMIC FORCE MICROSCOPY (AFM)}

The root mean square (rms) was measured to investigate surface topographical modifications on the nanoscale by $\mathrm{AFM}$ as pristine $\mathbf{P}$ and treated $\mathbf{T}$. Rms results are shown in Table 4.1 while three-dimensional (3D) images are presented in Figure 4.11, Figure 4.12, Figure 4.13, Figure 4.14, and Figure 4.15 respectively. It can be clearly 
observed and deduced that the surface roughness is increased for all the samples following treatment. Figure 4.14b with treatment conditions: speed S1 and distance D0, drastically differs with the steadier rougher surface from other images. Higher surface roughness may increase adhesion [62]; however, one cannot correlate between treatment speed and surface roughness according to the results.

Table 4.1 Rms surface roughness for pristine and treated samples

\begin{tabular}{llccc}
\hline & & $\begin{array}{c}\text { Treatment speed } \\
(\text { in/s })\end{array}$ & $\begin{array}{c}\text { Distance } \\
(\text { in })\end{array}$ & $\begin{array}{c}\text { Rms surface roughness } \\
(\mathrm{nm})\end{array}$ \\
\hline Sample1 & Pristine & - & - & 12.576 \\
& Treated & 0.1 & 0.5 & 29.937 \\
\hline Sample2 & Pristine & - & - & 10.965 \\
& Treated & 0.5 & 0.5 & 37.370 \\
\hline Sample3 & Pristine & - & - & 22.300 \\
& Treated & 1.0 & 0.5 & 42.360 \\
\hline Sample4 & Pristine & - & - & 25.307 \\
& Treated & 0.1 & 0.25 & 35.170 \\
\hline Sample5 & Pristine & - & - & 16.954 \\
& Treated & 1.0 & 0.25 & 23.647 \\
\hline
\end{tabular}

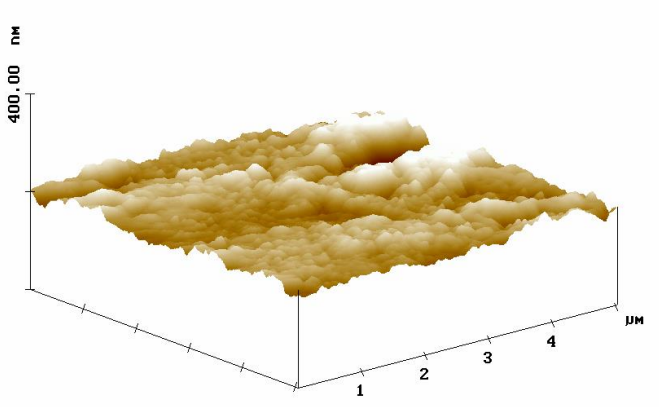

a

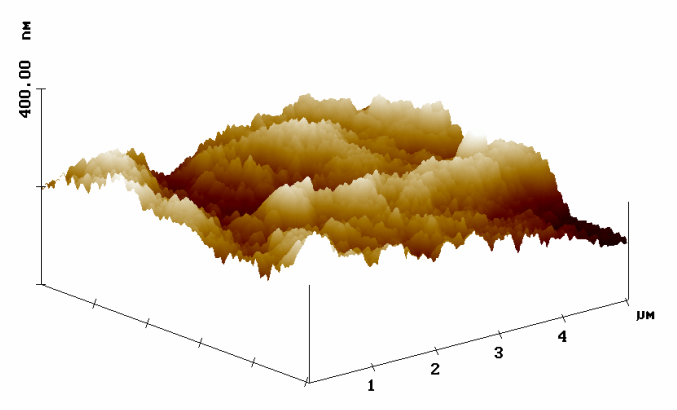

b

Figure 4.11 Sample 1 3D images a) Pristine b) Treated (S1, D1) 


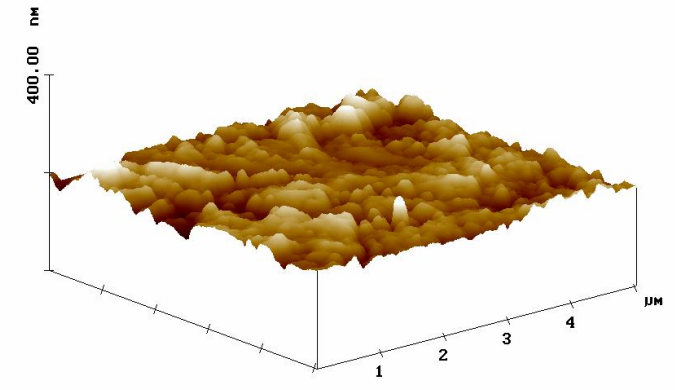

a

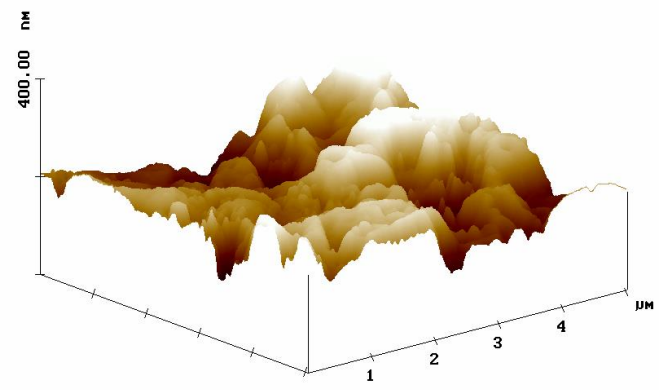

b

Figure 4.12 Sample 2 3D images a) Pristine b) Treated (S2, D1)

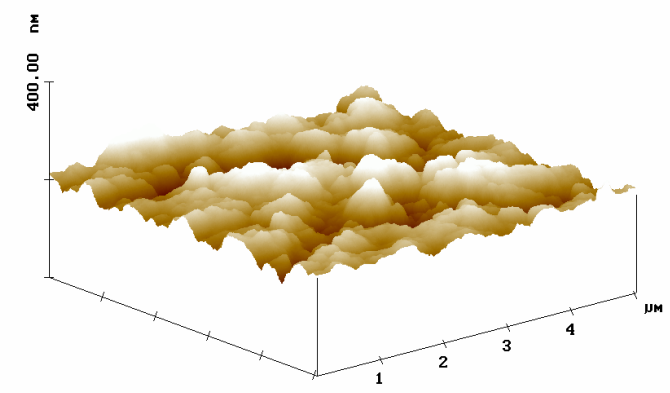

a

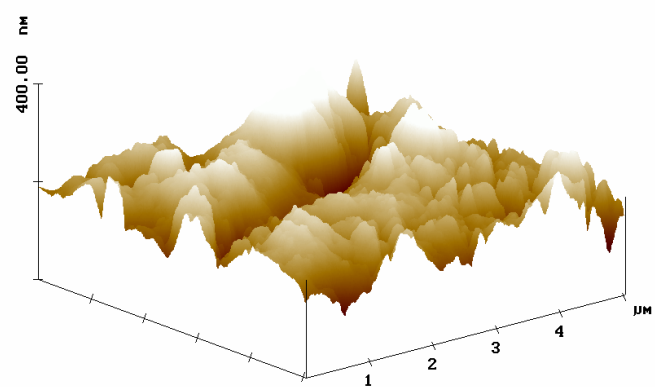

$\mathrm{b}$

Figure 4.13 Sample 3 3D images a) Pristine b) Treated (S3, D1)

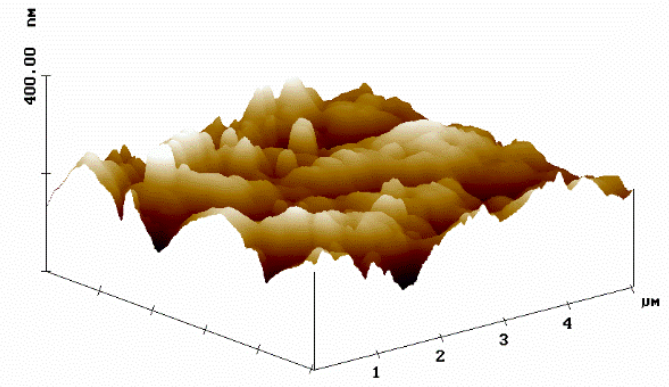

a

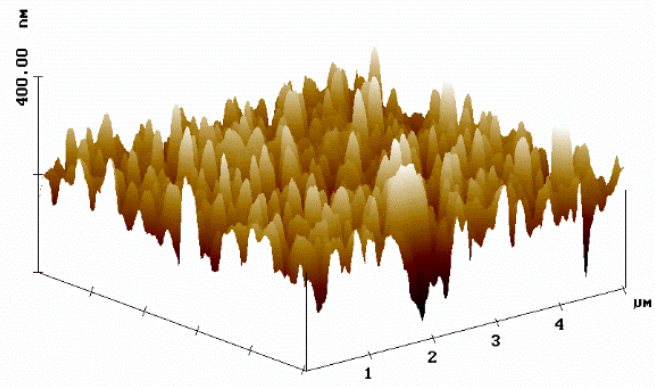

b

Figure 4.14 Sample 4 3D images a) Pristine b) Treated (S1, D0) 


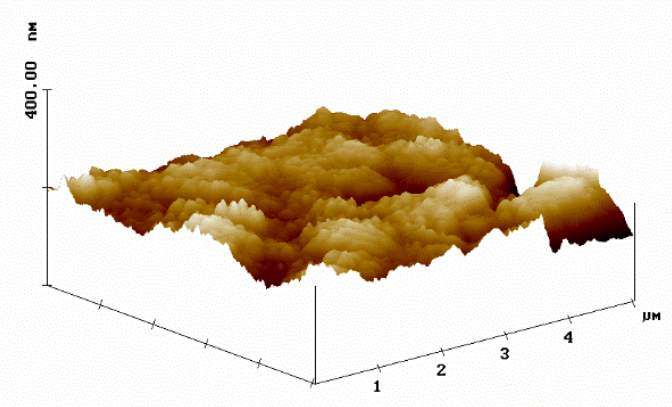

a

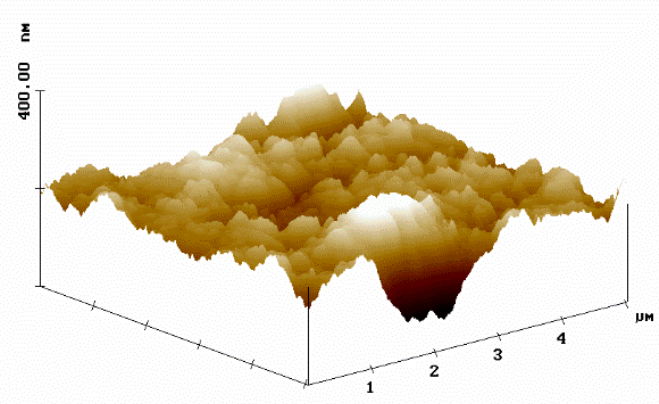

b

Figure 4.15 Sample 5 3D images a) Pristine b) Treated (S3, D0)

\subsection{X-RAY PHOTOELECTRON SPECTROSCOPY (XPS)}

XPS regional analysis was carried out on the pristine $\mathbf{P}$ and treated $\mathbf{T}$ samples to investigate the observed quantitative atomic composition and functional group differences through interactions between the composite surface and the APPJ treatment.

XPS atomic concentration with the ratios of $\mathrm{O} / \mathrm{C}$ (in \%) for the pristine $\mathbf{P}$ and treated $\mathbf{T}$ samples are compared in Table 4.2. All the five surfaces were composed of carbon $(\mathrm{C} 1 \mathrm{~s})$, oxygen $(\mathrm{O} 1 \mathrm{~s})$, nitrogen $(\mathrm{N} 1 \mathrm{~s})$, sulfur $(\mathrm{S} 2 \mathrm{p})$ and silicon $(\mathrm{Si} 2 \mathrm{p})$. Silicon was probably related to the contamination of stainless steel, by a mold release agent (Frekote 710-NC). The mold release agent consists of silicon compounds, and it was used during the autoclave-curing process of the panel manufacturing.

XPS survey spectra analysis demonstrates C1s had the highest intensity prior to and after treatment. The air APPJ treatment caused a significant reduction of carbon concentration $[20,30,112]$ and a slight increase of nitrogen for the last two samples, but also a slight decrease of nitrogen for the first three samples. However, O1s intensity had a remarkable increase $[20,30,112,113]$ after treatment due to the air in the plasma [22], the reaction of free radicals and the unstable species interaction with oxygen from the 
active species resides in the plasma. XPS results show sample 4 had a highest oxygen content (hydrophilic behavior [7]) after treatment. It comes directly from the plasmas interaction with the composite surface by enhancing oxygen-containing functional (polar) groups $[9,20,30]$, and decreasing carbon-containing groups. In other words, hydrophilic chemical compositions increased while hydrophobic composition decreased [22]. The surface oxygen-content enhancement correlates with better adhesive strength with epoxy matrix [114], surface oxidation [21, 32] and improved wettability properties with surface activation $[11,20]$. Sulfur content showed a slight increase for sample 1, 4 and 5; however, it decreased in small amounts for samples 2 and 3. The atomic silicon amount showed a relatable behavior with a small increase for the samples 2,3 and 5 while it decreased for samples 1 and 4.

Table 4.2 XPS elemental composition of pristine and treated samples

\begin{tabular}{|c|c|c|c|c|c|c|}
\hline & & & $\begin{array}{r}\text { nical co } \\
(\%\end{array}$ & ition & & $\begin{array}{l}\text { Atomic } \\
\text { ratio }(\%)\end{array}$ \\
\hline & $\mathrm{C}$ & $\mathrm{O}$ & $\mathrm{N}$ & $S$ & $\mathrm{Si}$ & $\mathrm{O} / \mathrm{C}$ \\
\hline Pristine 1 & 62.8 & 24.1 & 7.02 & 1.9 & 3.9 & 38 \\
\hline T.S1.D1 & 52.7 & 32.7 & 6.03 & 3.7 & 3.7 & 62 \\
\hline Pristine2 & 67.6 & 20.6 & 7.1 & 1.7 & 2.9 & 30 \\
\hline T.S2.D1 & 57.7 & 31.1 & 5.2 & 1.2 & 3 & 54 \\
\hline Pristine 3 & 67.4 & 21 & 6.74 & 1.5 & 2.9 & 31 \\
\hline T.S3.D1 & 58.2 & 31.7 & 4.8 & 1 & 3.5 & 54 \\
\hline Pristine4 & 72.17 & 18.25 & 4.58 & 1.60 & 3.39 & 25 \\
\hline T.S1.D0 & 42.11 & 36.68 & 10.20 & 6.60 & 2.56 & 87 \\
\hline Pristine5 & 76.50 & 15.24 & 4.89 & 1.19 & 2.15 & 20 \\
\hline T.S3.D0 & 57.91 & 30.33 & 6.99 & 2.47 & 2.39 & 52 \\
\hline
\end{tabular}


It is found that the $\mathrm{O} / \mathrm{C}$ ratio, which represents functionalization levels [20], increased significantly by showing the oxygen-containing groups which were introduced to the surfaces of all the treated $\mathbf{T}$ samples [32]. O/C ratio of sample 4, which was treated with the speed of S1 and distance D0, was highest due to more oxygenated surface with longer treatment duration and closer distance.

The differences in bond structures, indicated from the XPS peak analysis, are detailed in Table 4.3 for carbon and in Table 4.4 for oxygen and silicon. The deconvolution analysis of carbon (C1s), oxygen (O1s), and silicon (Si2p) performed with XPS peak 4.1 software is given as pristine $\mathbf{P}$ and treated $\mathbf{T}$ for sample 1 in Figure 4.16, Figure 4.17, and Figure 4.18 respectively. The three peaks of $\mathrm{C} 1 \mathrm{~s}$ binding energies at $284.6 \mathrm{eV}, 285.9 \pm 0.2 \mathrm{eV}$, and $288.5 \pm 0.2 \mathrm{eV}$ correspond to $\mathrm{C}=\mathrm{C}, \mathrm{C}-\mathrm{N} / \mathrm{C}-\mathrm{C} / \mathrm{C}-\mathrm{O}$ and $\mathrm{O}-$ $\mathrm{C}=\mathrm{O}$ components, respectively. (1) $\mathrm{C}=\mathrm{C}$ double bond remained almost unchanged with a $0.2 \%$ increase for sample 1 while it decreased for other samples. (2) The C-N/C-C/C-O group had decreased for sample 1; however, it was almost same for samples 2 and 3, and it increased for samples 4 and 5 that with distance D0. (3) The O-C=O (ester or carboxylic acid) functional group increased significantly for sample 1 compared to other samples. Sample 4 showed a different behavior with speed S1 and distance D0 than other

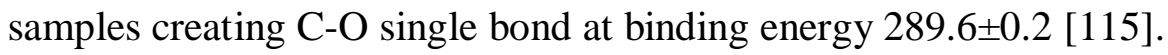

The two peaks of $\mathrm{O} 1 \mathrm{~s}$ binding energies at $532 \pm 0.2 \mathrm{eV}$ and $533.3 \pm 0.2 \mathrm{eV}$ correspond to $\mathrm{C}-\mathrm{O}$ and $\mathrm{C}=\mathrm{O}$ components, respectively. The $\mathrm{C}-\mathrm{O}$ single bond was detected with a small increase for sample 1, while decreased for other samples. Therefore, the $\mathrm{C}=\mathrm{O}$ group showed a similar behavior with the plasma treatment. 


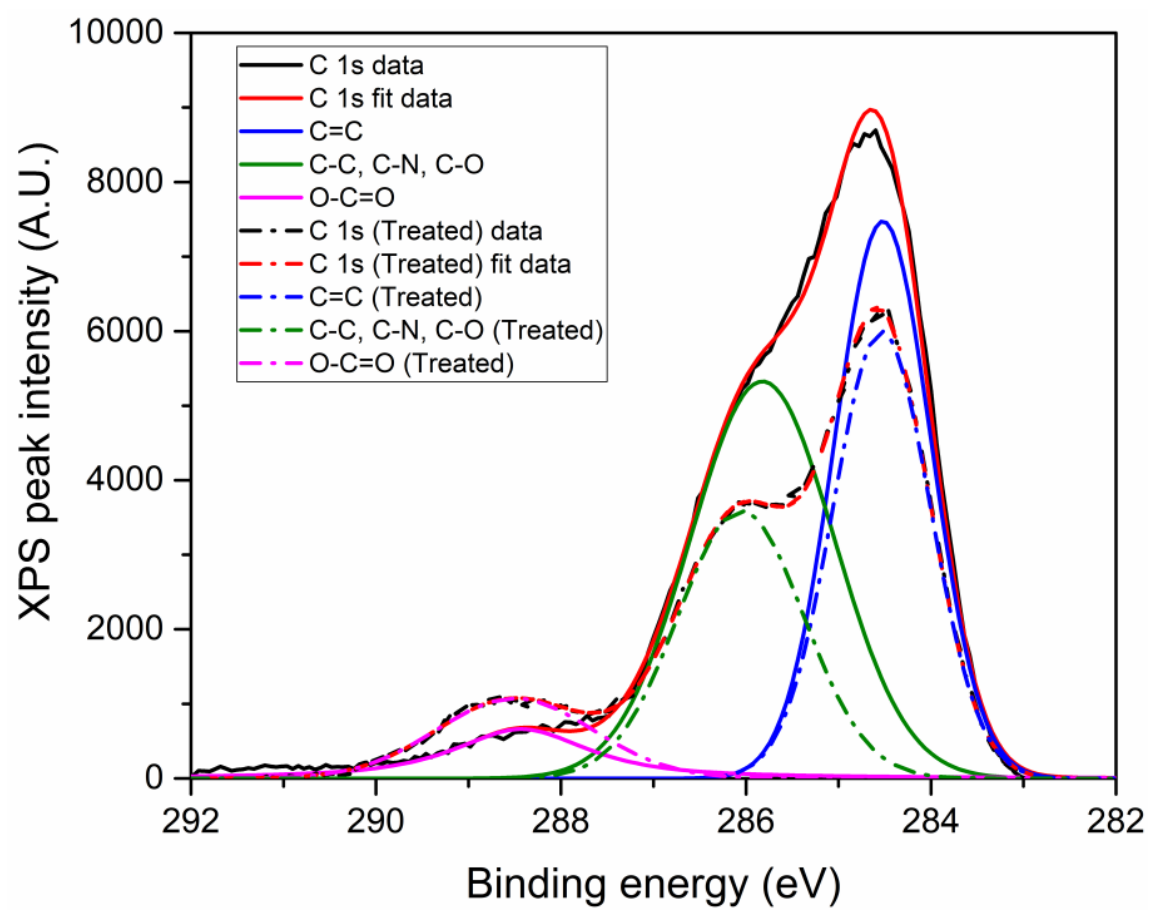

Figure 4.16 Sample 1 Carbon (C1s) deconvolution of pristine and treated

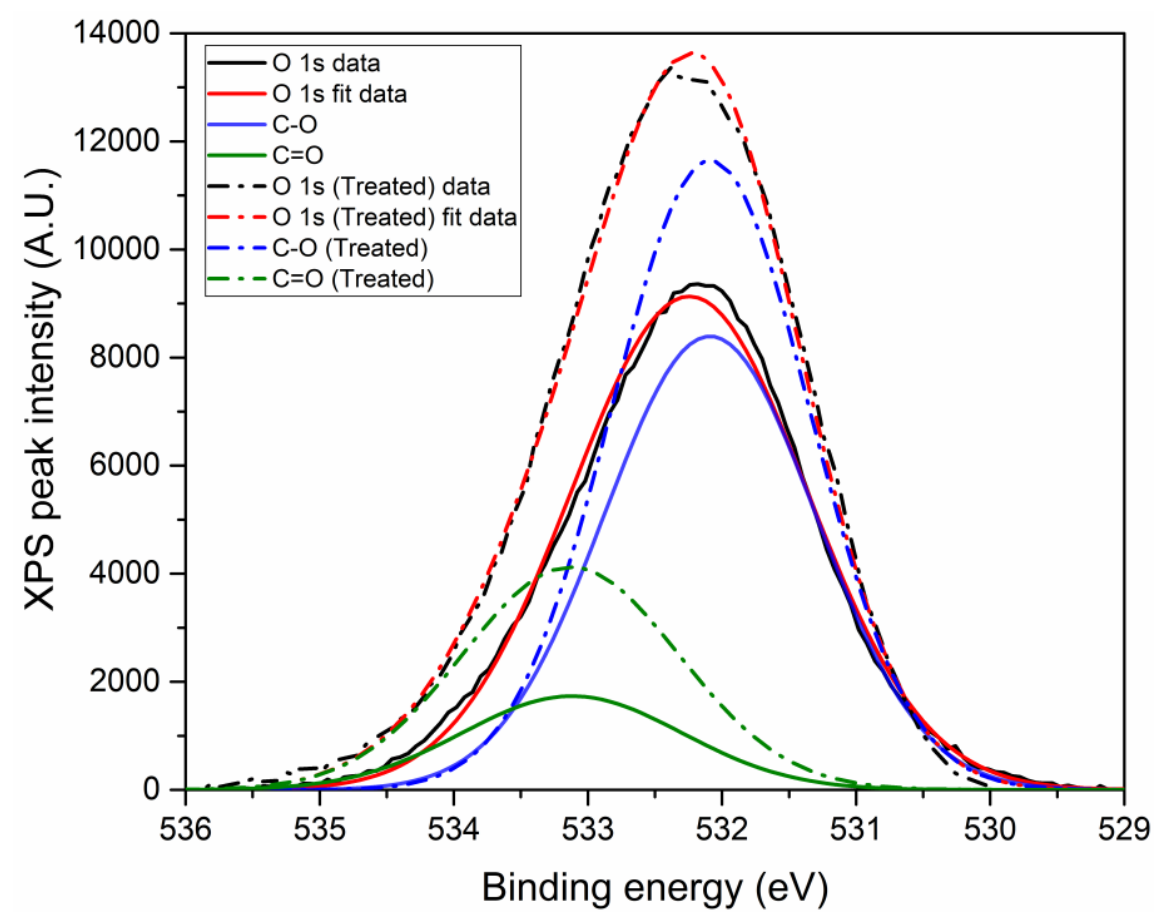

Figure 4.17 Sample 1 Oxygen (O1s) deconvolution of pristine and treated 


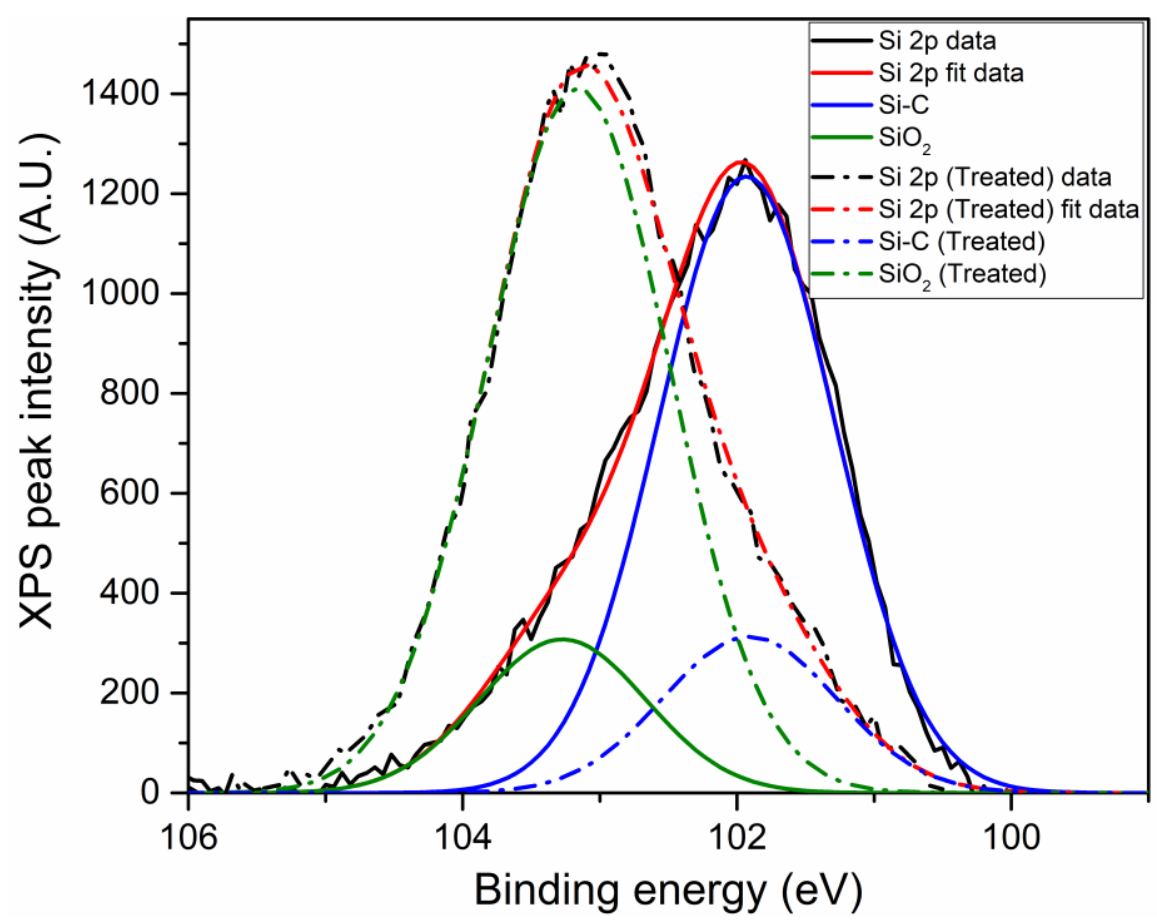

Figure 4.18 Sample 1 Silicon (Si2p) deconvolution of pristine and treated

Table 4.3 XPS contributions of Carbon chemical bonds/groups

\begin{tabular}{l|cccc}
\hline $\begin{array}{l}\text { Chemical } \\
\text { bond/group }\end{array}$ & $\mathrm{C}=\mathrm{C}$ & $\mathrm{C}-\mathrm{N} / \mathrm{C}-\mathrm{C} / \mathrm{C}-\mathrm{O}$ & $\mathrm{O}-\mathrm{C}=\mathrm{O}$ & $\mathrm{C}-\mathrm{O}$ \\
\hline Binding energy (eV) & 284.6 & $285.9 \pm 0.2$ & $288.5 \pm 0.2$ & $289.6 \pm 0.2$ \\
\hline Pristine1 & 47.8 & 51 & 1.2 & - \\
T.S1.D1 & 48 & 38 & 14 & - \\
\hline Pristine2 & 61.3 & 35.3 & 3.4 & - \\
T.S2.D1 & 48 & 34 & 18 & - \\
\hline Pristine3 & 58.7 & 30.6 & 10.7 & - \\
T.S3.D1 & 51.8 & 31.9 & 16.3 & - \\
\hline Pristine4 & 65.4 & 30.2 & 4.4 & - \\
T.S1.D0 & 33.7 & 37.2 & 17 & 12.1 \\
\hline Pristine5 & 70 & 24.1 & 5.9 & - \\
T.S3.D0 & 45.6 & 39.1 & 15.3 & - \\
\hline
\end{tabular}


Prior to treatment, the silicon present on the samples was predominantly $\mathrm{SiC}$; however, the $\mathrm{SiO}_{2}$ amount increased significantly for all the treated $\mathbf{T}$ samples, showing the oxidation of silicon, while $\mathrm{SiC}$ observed a sharp decrease $[116,117]$. SiC XPS peak was not found for sample 4 after treatment. Instead, $\mathrm{SiO}_{2}$ was detected at binding energies 103.3 $\pm 0.2 \mathrm{eV}$ and $105 \mathrm{eV}$ showed all silicon oxidized [118, 119].

Table 4.4 XPS contributions of Oxygen and Silicon chemical bonds/groups

\begin{tabular}{|c|c|c|c|c|c|}
\hline & \multicolumn{2}{|c|}{$\mathrm{O} 1 \mathrm{~s}$} & \multicolumn{2}{|c|}{ Si 2p } & \\
\hline Chemical bond/group & $\mathrm{C}-\mathrm{O}$ & $\mathrm{C}=\mathrm{O}$ & $\mathrm{SiO}$ & & $\mathrm{SiC}$ \\
\hline Binding energy $(\mathrm{eV})$ & $532 \pm 0.2$ & $533.3 \pm 0.2$ & $103.3 \pm 0.2$ & 105 & $101.8 \pm 0.1$ \\
\hline Pristine1 & 70 & 30 & 20 & & 80 \\
\hline T.S1.D1 & 72 & 28 & 82 & & 18 \\
\hline Pristine 2 & 78.6 & 21.4 & 15.7 & & 84.3 \\
\hline T.S2.D1 & 74 & 26 & 81 & & 19 \\
\hline Pristine 3 & 79.6 & 20.4 & 15 & & 85 \\
\hline T.S3.D1 & 73 & 27 & 68 & & 32 \\
\hline Pristine 4 & 80.9 & 19.1 & 27 & & 73 \\
\hline T.S1.D0 & 76.5 & 23.5 & 66.2 & 33.8 & - \\
\hline Pristine5 & 79.6 & 20.4 & 30.7 & & 69.3 \\
\hline T.S3.D0 & 60 & 40 & 75.4 & & 24.6 \\
\hline
\end{tabular}

This section clearly validated that plasma treatment decreased carbon content, increased oxygen content, oxygen functional group, and $\mathrm{O} / \mathrm{C}$ ratio. Functionalization level $(\mathrm{O} / \mathrm{C})$ of sample 4 was the highest with a ratio of $87 \%$. That can be probably attributed to the prolonged treatment time which caused activated sites at the initiation of the treatment cycle to become reactive with atmospheric radicals. Therefore, silicon experienced oxidation and sample 4 with S1 and D0 showed a 100\% oxidize appearing 
$\mathrm{SiO}_{2}$ at two binding energies. It can be concluded that better bonding characteristics and increased hydrophilicity may occur on the composite surfaces after plasma treatment [32].

\subsection{DOUBLE CANTILEVER BEAM (DCB) TEST}

The Mode I interlaminar fracture toughness of adhesive joints, for both pristine $\mathbf{P}$ and treated $\mathbf{T}$ laminates, was experimentally derived by conducting a DCB test containing five tests each. The average load-displacement curves of P.001-005, T.S1V2D1, and T.S3V2D1 are shown in Figure 4.19, and it is shown in Figure 4.20 for P.006-010, T.S1V2D0 and T.S3V2D0 with standard deviations. Load-displacement values for P.001-005 bonded with the adhesive exposed to moisture were lower than those of the standard group of pristine $\mathbf{P}$ coupons (P.006-010).

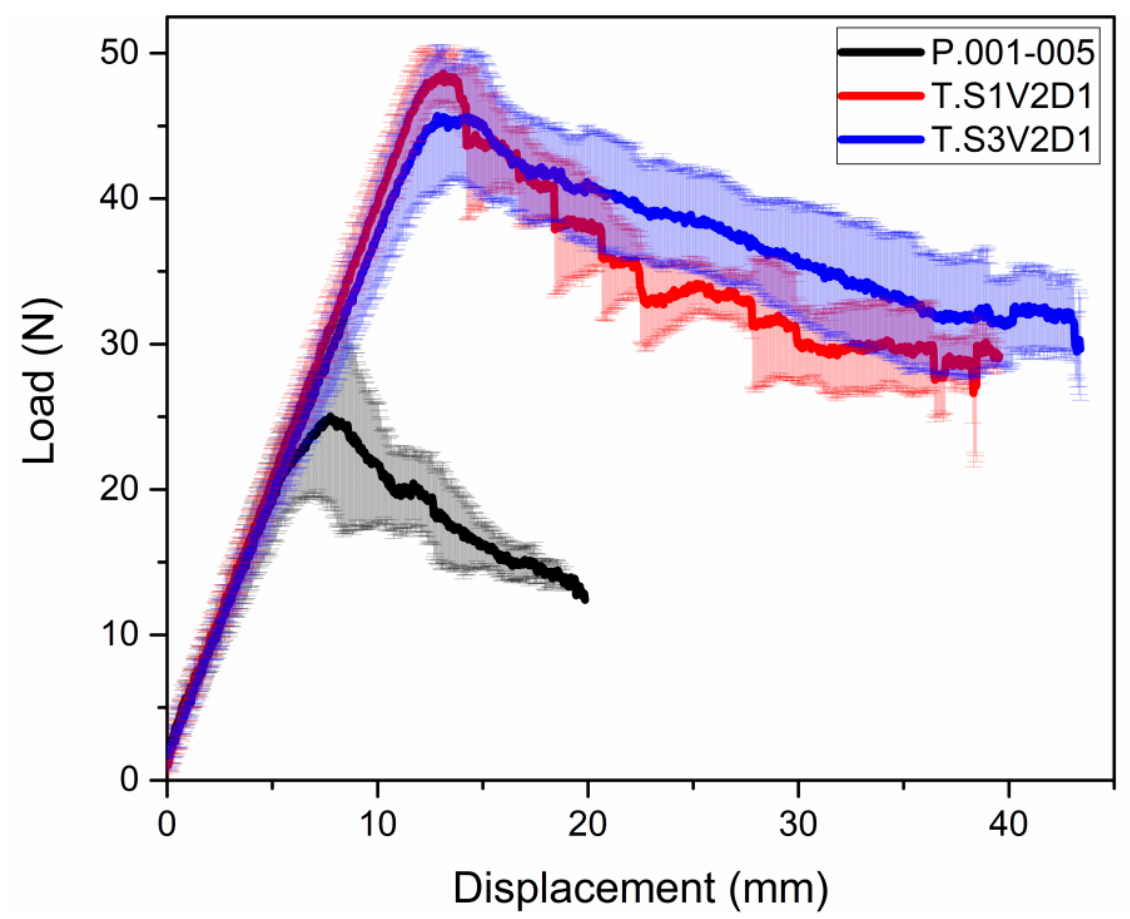

Figure 4.19 Load-displacement curves of P.001-005, T.S1V2D1, and T.S3V2D1 
In comparison, the DCB test results showed that coupons made from laminates with APPJ treatment can sustain much higher loads those made from laminates that have only been alcohol wiped. Pristine P tests behaved differently under the load pressure and showed a decrease in the load with an increase in delamination length by presenting a few sharp drops in applied load while the majority of treated $\mathrm{T}$ load-displacement curves showed a similar behavior for the crack propagation.

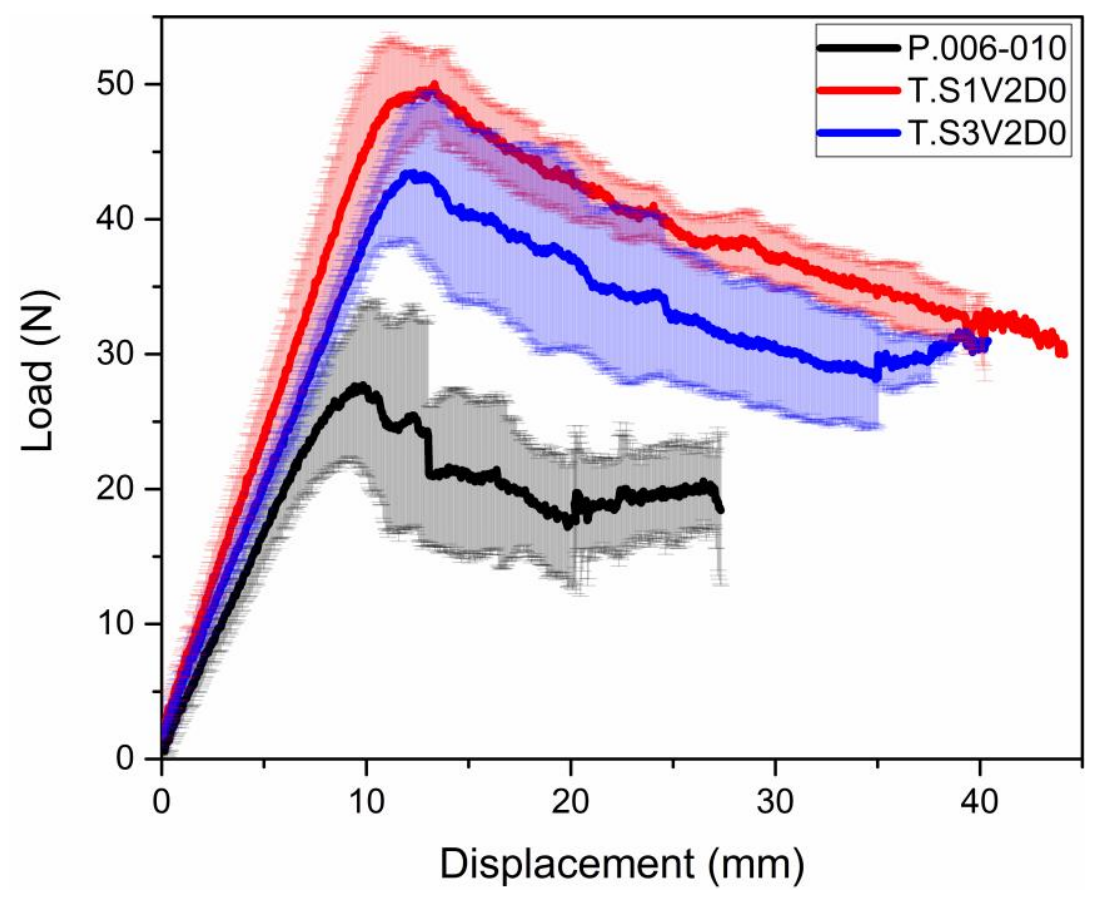

Figure 4.20 Load-displacement curves of P.006-010, T.S1V2D0, and T.S3V2D0 Average fracture toughness $\left(G_{I P}\right)$ was calculated according to the area method in equation (3.1). All the $G_{I P}$ values of DCB tests are shown with their standard deviations in Figure 4.21. Results indicate that the values of fracture toughness for treated $\mathbf{T}$ DCB tests were more than twofold higher than pristine'. The increase in the fracture toughness depends on enhancement in polar groups for the treated $\mathbf{T}$ samples $[7,120,121]$. The lowest $G_{I P}$ was for the pristine $\mathbf{P}$ group which was tested with the adhesive exposed to moisture while the highest was for speed S1, overlap V2 and distance D0. However, the 
$G_{I P}$ value of speed 3 and overlap V2 at distance D1 was close to the maximum result. Results show that despite only minor deviations in $G_{I P}$ among combinations of treatment parameters, four coupons: T.S1V3D1, T.S1V2D0, T.S2V1D1, and T.S3V2D1 appear to have higher fracture toughness than the rest.

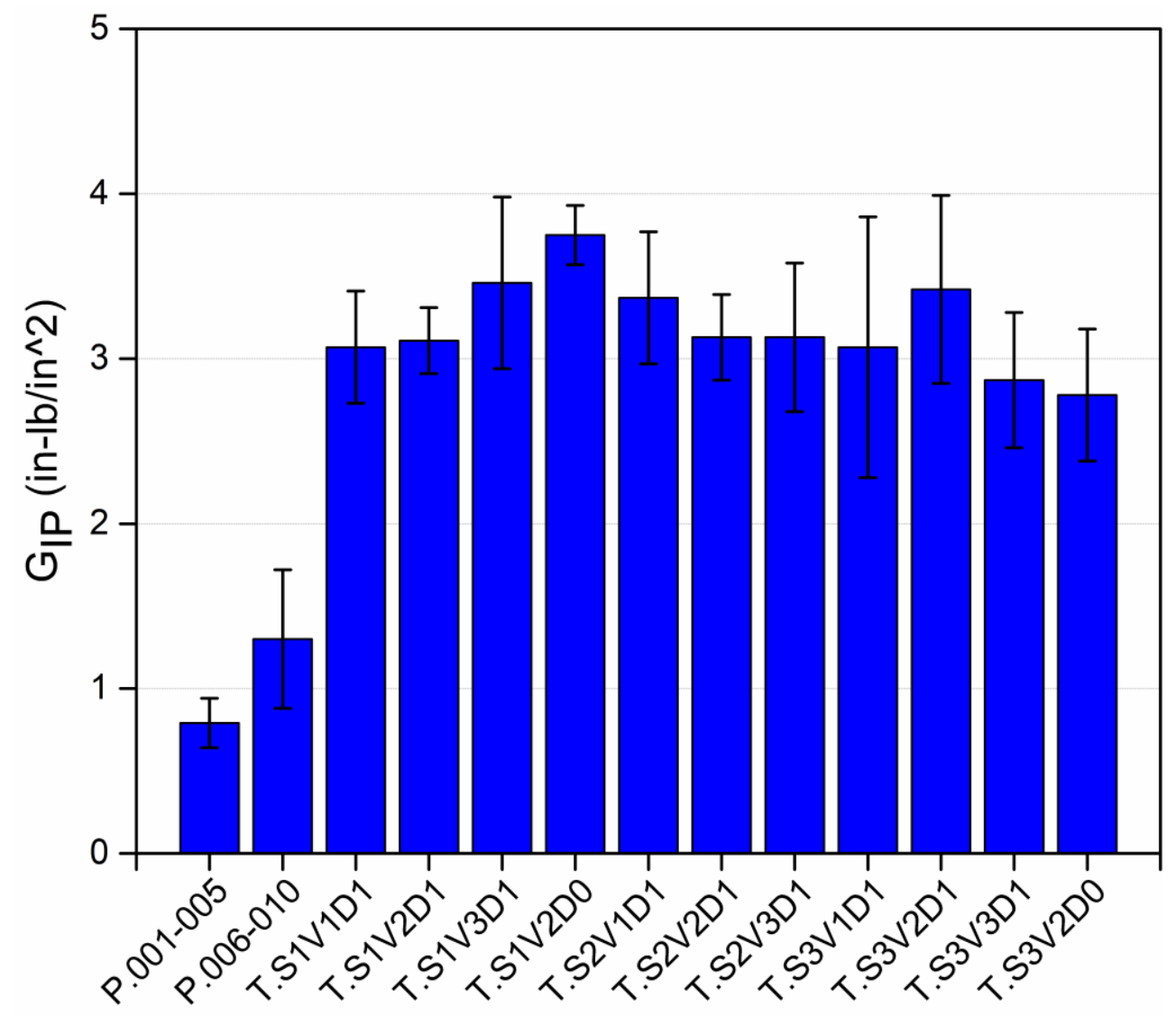

Figure $4.21 G_{I P}$ results for pristine and treated DCB tests

Results demonstrate that the average fracture toughness was the highest when it had a higher oxygen content and $\mathrm{O} / \mathrm{C}$ ratio which were related to more hydrophilic behavior [7]. Some results vary causing decreased or enhanced average values with a high standard deviation [7].

The Mode I delamination resistance curve ( $\mathrm{R}$ curve) is shown as a function of crack growth in Figure 4.22 for pristine $\mathbf{P}$ tests, in Figure 4.23 for speed S1 \& S3, overlap V2 and distance D0, in Figure 4.24 for speed S1, overlap V1 \& V2 \& V3, and distance 
D1, in Figure 4.25 for speed S2, overlap V1 \& V2 \& V3, and distance D1, and in Figure 4.26 for speed S3, overlap V1 \& V2 \& V3, and distance D1. The lowest results represented here were for the P.001-005 numbered pristine $\mathbf{P}$ tests, while the maximum values were for the slowest speed of $0.1 \mathrm{in} / \mathrm{s}$ with a $50 \%$ overlap at distance of $0.25 \mathrm{in}$ (T.S1V2D0). The exception was T.S3V1D1 with the highest standard error bars; where the $G_{I C}$ of treated $\mathbf{T}$ tests were mostly consistent, one of the DCB tests from the T.S3V1D1 group behaved differently with an adhesive failure type.

It was also noted that $G_{I C}$ appears to be independent of the amount of silicon contaminant on the CFRP surface. Referring to Table 4.2 and fracture toughness results, treated $\mathbf{T}$ laminates produced coupons with higher results despite having the same composition of silicon as pristine $\mathbf{P}$ laminates. Thus, it can also be stated that surface functionalization by APPJ treatment is sufficiently robust to mitigate detrimental effects on adhesive bonding due to the silicon contaminant.

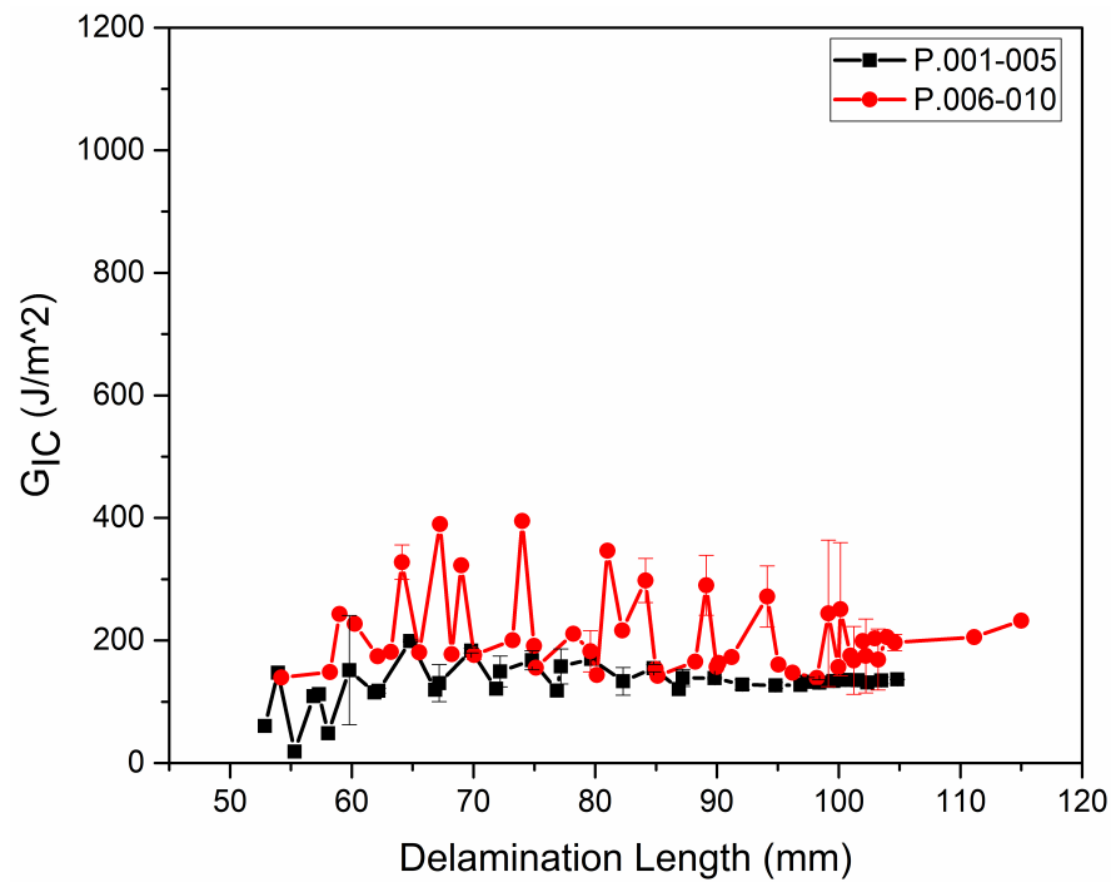

Figure 4.22 Mode I delamination resistance curve (R curve) of pristine tests 


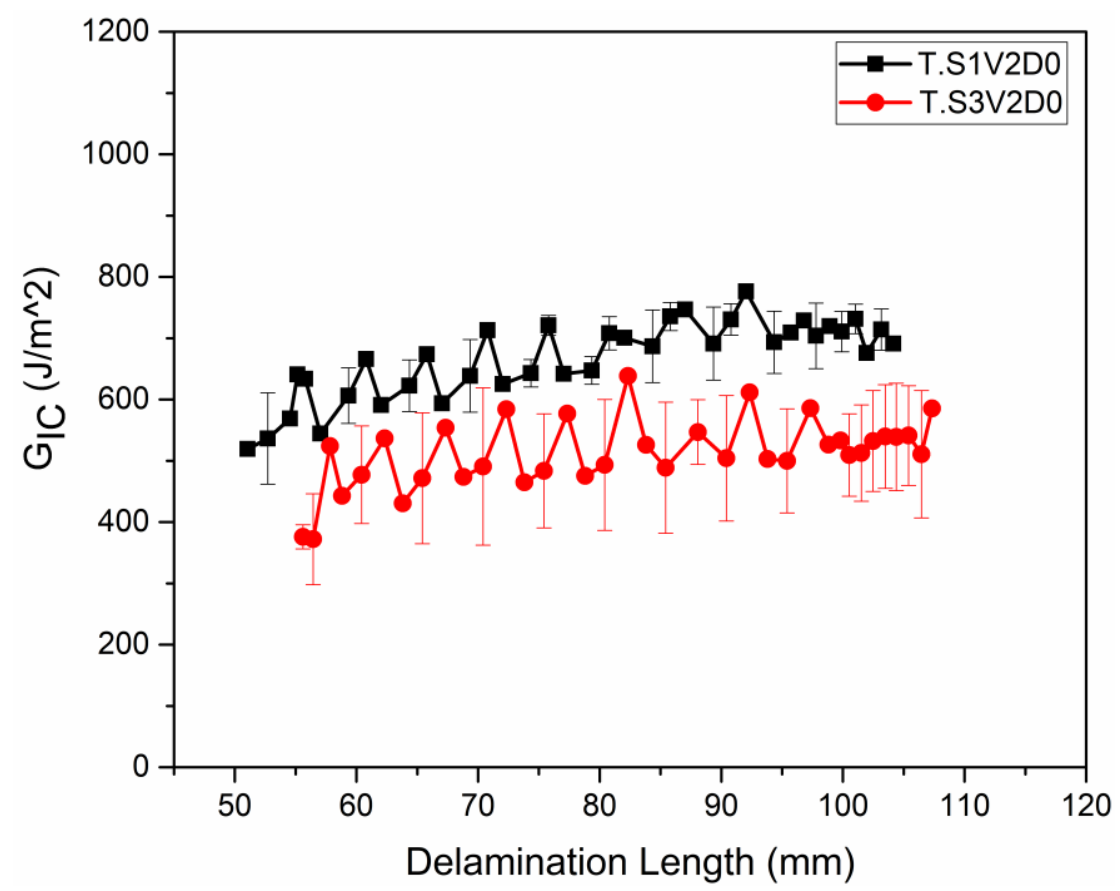

Figure 4.23 Mode I delamination resistance curve (R curve) (T.S1V2D0-T.S3V2D0)

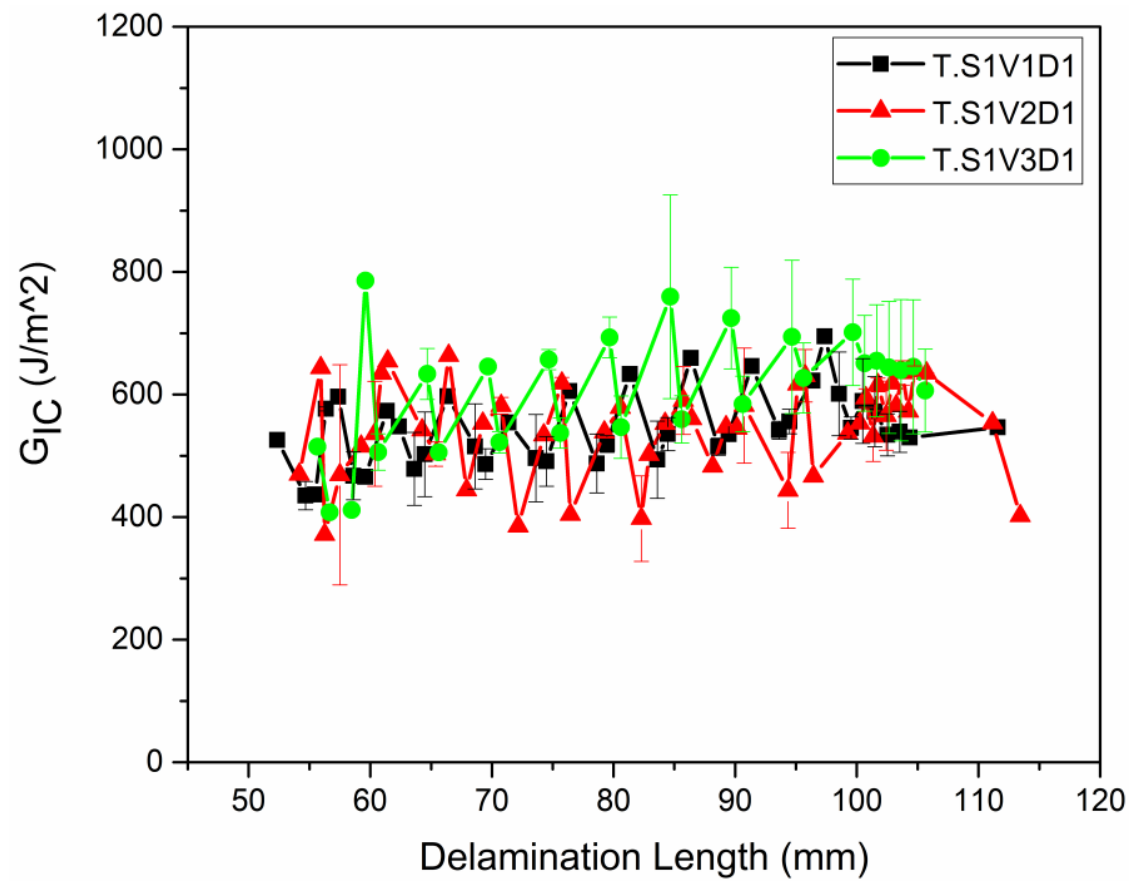

Figure 4.24 Mode I delamination resistance curve (R curve) (T.S1V1D1-T.S1V2D1T.S1V3D1) 


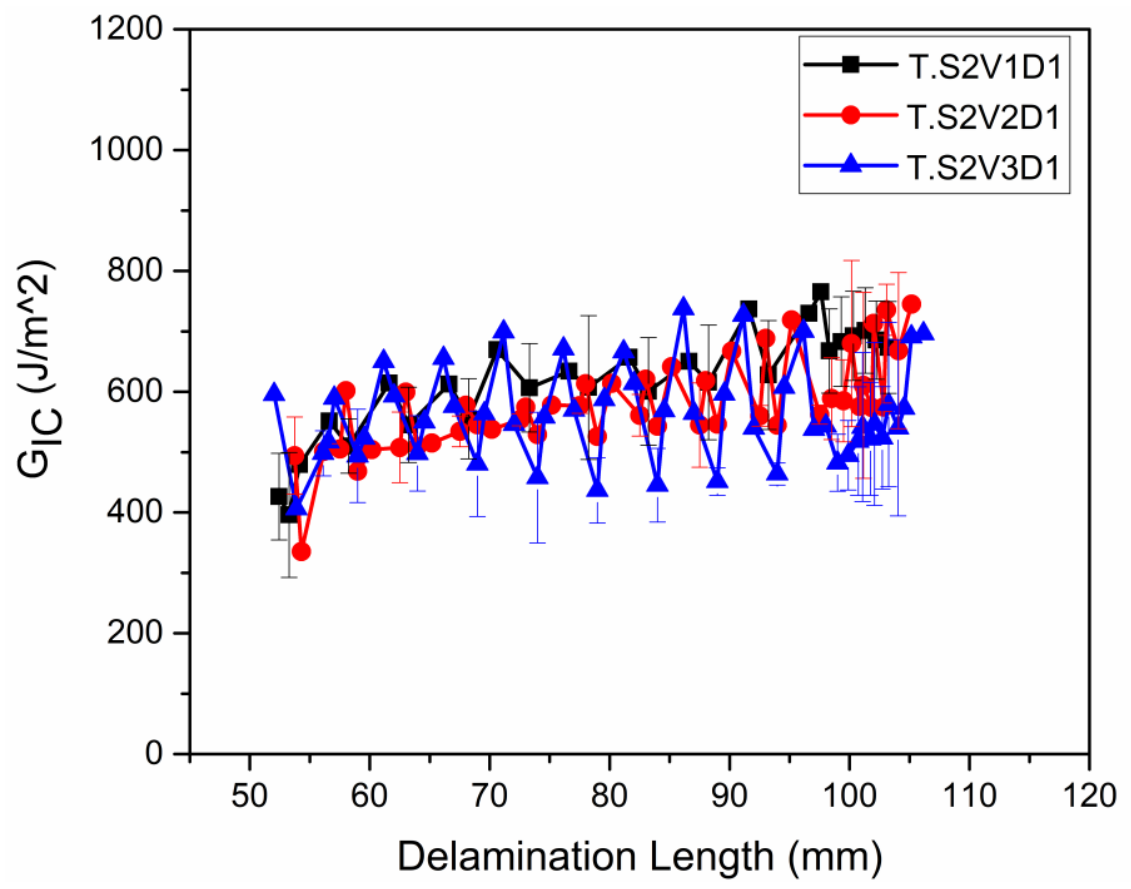

Figure 4.25 Mode I delamination resistance curve (R curve) (T.S2V1D1-T.S2V2D1T.S2V3D1)

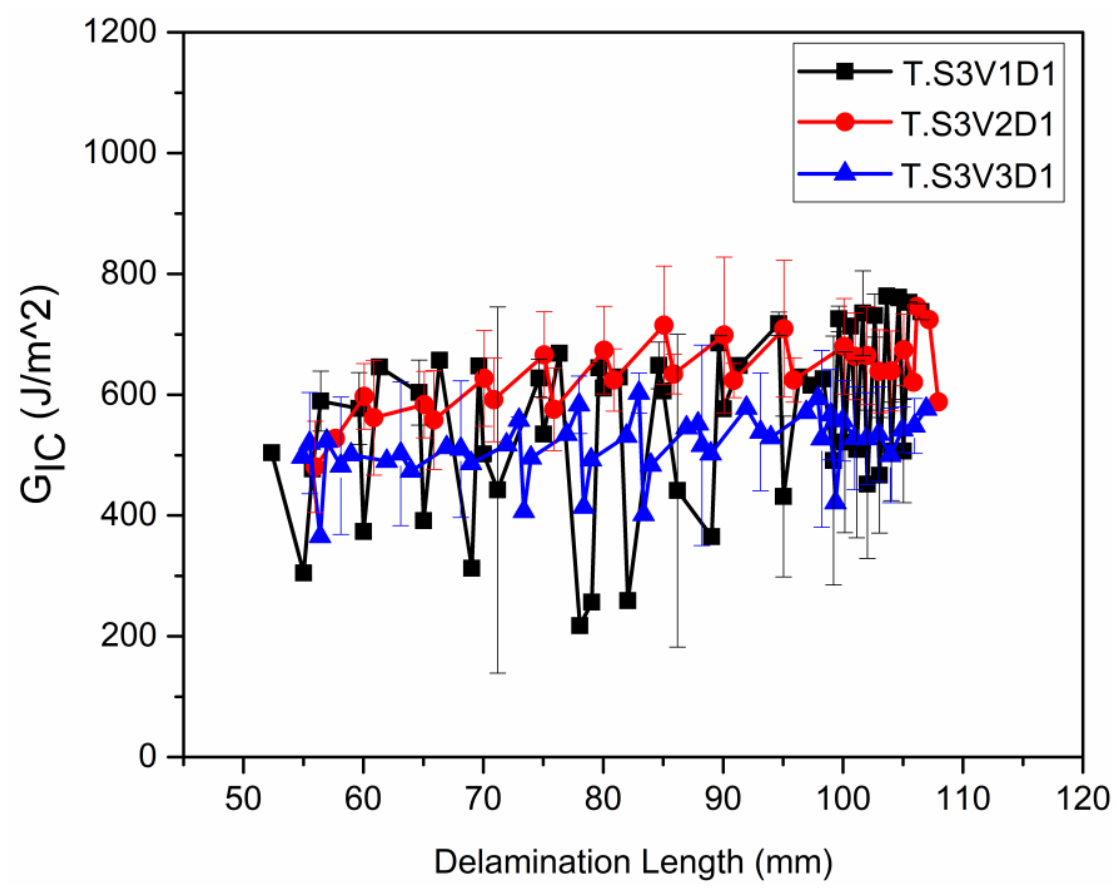

Figure 4.26 Mode I delamination resistance curve (R curve) (T.S3V1D1-T.S3V2D1T.S3V3D1) 
One failure mode interface of each bonding is shown in Figure 4.27. Failure interface of pristine $\mathbf{P}$ coupons showed that each of them underwent adhesive failure whereas every treated $\mathbf{T}$ coupon failed cohesively, thus depicting a stronger adhesive bonding with the higher Mode I interlaminar fracture toughness for DCB tests.

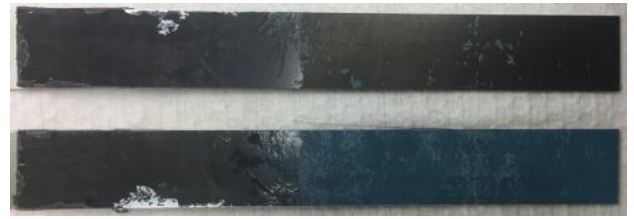

(a)

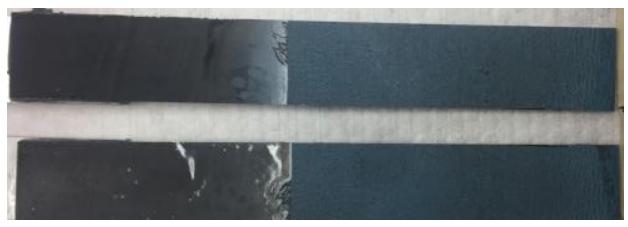

(c)

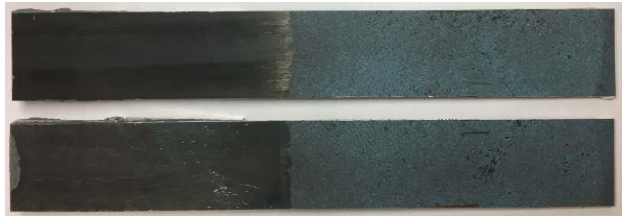

(e)

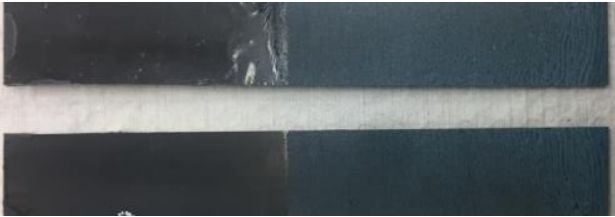

(b)

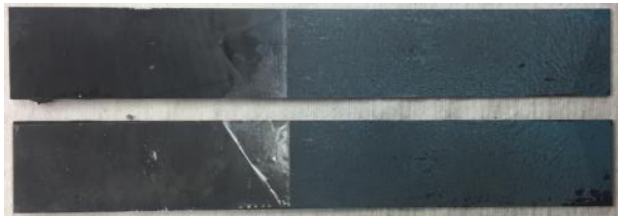

(d)

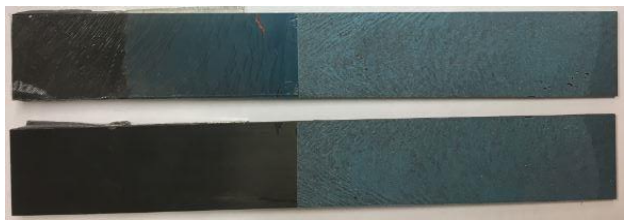

(f)

Figure 4.27 Failure modes (a) Pristine (b) T.S1V1D1 (c) T.S2V1D1 (d) T.S3V2D1 (e) T.S1V2D0 (f) T.S3V2D0

This section demonstrated that treated $\mathbf{T}$ coupons distinctly had much higher loads and greater delamination resistance $\left(G_{I C}\right.$ or $\left.G_{I P}\right)$ than pristine $\mathbf{P}$ ones. All pristine $\mathbf{P}$ tests showed adhesive failure, while treated $\mathbf{T}$ test resulted with cohesive failure modes. This showed improved adhesive strength. Thus, it can be stated that APPJ treatment increases the fracture toughness of coupons compared to only using alcohol wipes. Fractures toughness increased with a higher surface roughness and the most decrement in WCA, leading to the most increment in surface energy. As long as treated $\mathbf{T}$ coupons had cohesive failure, variations in $G_{I C}$ might not be significant as it may have resulted due to 
failure initiations at different depths along the adherend. In such cases, treatment parameters could be chosen on basis of duration and cost-effectiveness. In the present case, combinations of S2 \& V1 \& D1 and S3 \& V2 \& D1 would also be expected to be among the most cost-effective ones. Thus, either of these two combinations of treatment parameters could be relied upon based on manufacturing convenience. 


\section{CHAPTER 5}

\section{CONCLUSIONS AND FUTURE WORK}

In this work, APPJ surface preparation method, which is a low-temperature, reliable, automated, and environmentally benign plasma, has been experimented to improve the adhesive bond strength of CFRPs, which were produced with IM7/8552 prepreg material. The effects of plasma treatment on composite material have been analyzed with a water contact angle measurement called ballistic deposition method, XPS for chemical modifications, and SEM and AFM for surface morphological and topographical changes. The bond strength of pristine $\mathbf{P}$ and treated $\mathbf{T}$ composites has been evaluated with the DCB test by calculating Mode I interlaminar fracture toughness according to modified beam theory $\left(G_{I C}\right)$ and area method $\left(G_{I P}\right)$ and determining failure modes.

\subsection{CONCLUSION}

The receding water contact angle with surface analyst device, which is used as an estimation of surface energy, decreased following plasma treatment which indicated an increase in surface energy and higher hydrophilicity. XPS results prior to and following treatment has shown a noticeable decrease in carbon content and a significant increase in oxygen content with enhanced oxygen-containing functional groups. The $\mathrm{O} / \mathrm{C}$ ratio, which is used for functionalization level, has shown an increase with treatment, and it was the highest due to higher treatment duration for the slowest speed (S1), overlap 50\% 
(V2) at distance D0 (0.25 in). While all the samples have had predominantly SiC for pristine, $\mathrm{SiO}_{2}$ has increased remarkably via plasma treatment which has shown oxidation of silicon. SEM images have shown no visible damage on the carbon fibers themselves, and plasma treatment has cleaned the surface from the impurities which prevent a stronger bond. The higher surface roughness (rms) which indicates a higher adhesion was measured for the treated $\mathbf{T}$ samples with AFM. DCB test results have proved that APPJ treatment does have the potential to increase fracture toughness by the occurring cohesive failure and improved bond consistency. Comparison of the fracture toughness has shown around a three-time increase in $G_{I C}$ and a twofold increase in $G_{I P}$ for treated $\mathbf{T}$ samples. Analysis of interfacial failures of the pristine $\mathbf{P}$ tests has had adhesive failures for all the tests, whereas the treated $\mathbf{T}$ tests have had all cohesive failure modes which reflect greater $G_{I P}$ and $G_{I C}$ values.

This increase on fracture toughness is a result of lower water contact angle, higher $\mathrm{O} / \mathrm{C}$ ratio, increased oxygen-functional groups, higher surface roughness and cleaned surface contaminants.

\subsection{FUTURE WORK}

Future work could involve the use of various characterization techniques to investigate the effect of atmospheric pressure plasma jet treatment on carbon fiber reinforced polymers, in order to improve bond strength. For instance, Fourier Transform Infrared (FTIR) Spectroscopy could be used to quantify the chemical changing on the surface, and the results can be compared with those from XPS analysis.

Also, different variations of plasma process parameters could be used to examine the plasma effects and determine Mode I interlaminar fracture toughness and failure 
modes. For example, the use of higher treatment speeds with closer and further distances from plasma jet to the composite surface could be investigated.

In addition, bondline thickness could be investigated on certain points, and the maximum, minimum, and average value on the test coupon could be taken to figure out its effects for cohesive failure modes and $G_{I C}$ values.

Ultimately, silicon has been detected by XPS for the composite panels which were tested in this study, but contamination process has not been included for this research. Future work might be focused on the investigation of fracture toughness and the plasma treatment effects with the produced composite panels, without an exposure to silicon during the manufacturing process. The contamination process that results from the presence of higher silicon amounts on composite samples has not been included in this study. Composite panels can be contaminated and then treated before testing, or they can be contaminated and tested without the treatment process.

\subsection{SITUATION OF RESEARCH}

Understanding the effects of surface preparation on AFP manufactured coupons subscribe to an overall AFP research undertaken at the University of South Carolina's McNair Center. This research complements path planning studies for AFP [122-125] where finding the optimal tool path for laying fibers is sought. One of the principal conditions is the minimization of AFP defects $[126,127]$ and the effect they can have on the integrity of the structure [128-130]. Efficient design processes [131, 132] and rapid assessment tools [133] can practically support a better integral lay-up quality. This study pushes the boundary to understand the composite behavior, when both efficient design and manufacturing are used to obtain the laminate. This opens the possibility for design 
to overcome the issues with mechanical joining of composites. To better illustrate the goal, we will forward two design scenarios:

1) Adhesive bonding is not efficient and should not be used.

2) Adhesive bonding is efficient and can be used.

In scenario one, if a mechanical joints are needed at location 1 in Figure 5.1, the lay-up strategy needs to account for that and possible solutions are Figure 5.1b\&c.

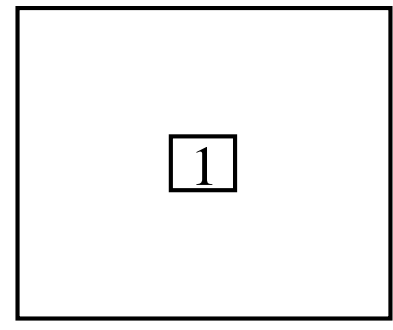

(a)

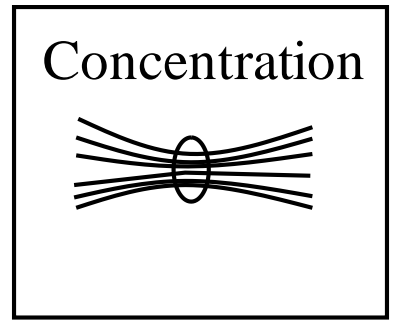

(b)

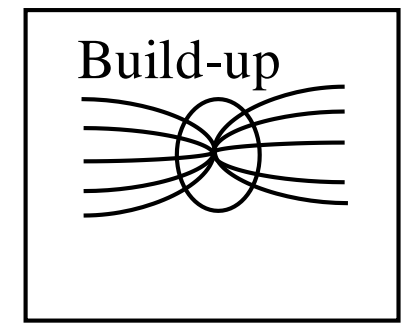

(c)

Figure 5.1 Lay-up strategy considerations

In scenario two, since mechanical joints are not needed, we can relax the concentration of reinforcement requirement of Figure 5.1b\&c.

Finally, the composite lifecycle, currently not integrated, can profit by reducing overall design constraints making solution finding easier similar to [134-135]. 


\section{REFERENCES}

1. He, R., et al., Improved mechanical properties of carbon fiber reinforced PTFE composites by growing graphene oxide on carbon fiber surface. Composite Interfaces, 2018. 25(11): p. 995-1004.

2. Mishnaevsky, L. and G. Dai, Hybrid and hierarchical nanoreinforced polymer composites: Computational modelling of structure-properties relationships. Composite Structures, 2014. 117: p. 156-168.

3. Pendhari, S.S., T. Kant, and Y.M. Desai, Application of polymer composites in civil construction: A general review. Composite Structures, 2008. 84(2): p. 114124.

4. Zhou, H.W., et al., Carbon fiber/carbon nanotube reinforced hierarchical composites: Effect of CNT distribution on shearing strength. Composites Part B: Engineering, 2016. 88: p. 201-211.

5. Boerio, F., et al., Effect of grit-blasting on the surface energy of graphitelepoxy composites. The Journal of Adhesion, 2006. 82(1): p. 19-37.

6. Di Franco, G., L. Fratini, and A. Pasta, Influence of the distance between rivets in self-piercing riveting bonded joints made of carbon fiber panels and AA2024 blanks. Materials \& Design, 2012. 35: p. 342-349.

7. Encinas, N., et al., Surface modification of aircraft used composites for adhesive bonding. International Journal of Adhesion and Adhesives, 2014. 50: p. 157-163.

8. Hegemann, D., H. Brunner, and C. Oehr, Plasma treatment of polymers for surface and adhesion improvement. Nuclear instruments and methods in physics research section B: Beam interactions with materials and atoms, 2003. 208: p. 281-286.

9. Tiwari, S. and J. Bijwe, Surface treatment of carbon fibers-a review. Procedia Technology, 2014. 14: p. 505-512.

10. Banea, M. and L.F. da Silva, Adhesively bonded joints in composite materials: an overview. Proceedings of the Institution of Mechanical Engineers, Part L: Journal of Materials: Design and Applications, 2009. 223(1): p. 1-18.

11. Zaldivar, R., et al., The effect of atmospheric plasma treatment on the chemistry, morphology and resultant bonding behavior of a pan-based carbon fiber- 
reinforced epoxy composite. Journal of composite materials, 2010. 44(2): p. 137156.

12. Dillingham, R.G., B.R. Oakley, and D. Gilpin*, Wetting measurements for identification of specific functional groups responsible for adhesion. The Journal of Adhesion, 2008. 84(12): p. 1007-1022.

13. Anand, M., R.E. Cohen, and R.F. Baddour, Surface modification of low density polyethylene in a fluorine gas plasma. Polymer, 1981. 22(3): p. 361-371.

14. Kim, M., et al., Surface treatment of metals using an atmospheric pressure plasma jet and their surface characteristics. Surface and Coatings Technology, 2003. 174: p. 839-844.

15. Agostino, R., plasma Deposition. Treatment and Etching of Polymers, Academic, Orlando, 1990.

16. Inagaki, N., Plasma surface modification and plasma polymerization. 1996: CRC Press.

17. Greenwood, O.D., et al., Atmospheric silent discharge versus low-pressure plasma treatment of polyethylene, polypropylene, polyisobutylene, and polystyrene. Journal of Adhesion Science and Technology, 1995. 9(3): p. 311326.

18. Taylor, W., Technical synopsis of plasma surface treatments. University of Florida, Gainesville, FL, 2009.

19. Dowling, D.P., et al., Influence of dc pulsed atmospheric pressure plasma jet processing conditions on polymer activation. Plasma Processes and Polymers, 2011. 8(8): p. 718-727.

20. Jordá-Vilaplana, A., et al., Improvement of mechanical properties of polylactic acid adhesion joints with bio-based adhesives by using air atmospheric plasma treatment. Journal of Applied Polymer Science, 2015. 132(32).

21. Shenton, M. and G. Stevens, Surface modification of polymer surfaces: atmospheric plasma versus vacuum plasma treatments. Journal of Physics D: Applied Physics, 2001. 34(18): p. 2761.

22. $\mathrm{Li}, \mathrm{H}$., et al., Air dielectric barrier discharges plasma surface treatment of threedimensional braided carbon fiber reinforced epoxy composites. Surface and Coatings Technology, 2009. 203(10-11): p. 1317-1321.

23. Van de Velde, K. and P. Kiekens, Wettability and surface analysis of glass fibres. 2000. 
24. Tendero, C., et al., Atmospheric pressure plasmas: A review. Spectrochimica Acta Part B: Atomic Spectroscopy, 2006. 61(1): p. 2-30.

25. Borcia, G., C. Anderson, and N. Brown, The surface oxidation of selected polymers using an atmospheric pressure air dielectric barrier discharge. Part II. Applied surface science, 2004. 225(1): p. 186-197.

26. Borcia, G., C.A. Anderson, and N.M.D. Brown, The surface oxidation of selected polymers using an atmospheric pressure air dielectric barrier discharge. Part I. Applied Surface Science, 2004. 221(1): p. 203-214.

27. Noh, B.-I., et al., Effect of plasma treatment on adhesion characteristics at interfaces between underfill and substrate. International journal of adhesion and adhesives, 2007. 27(3): p. 200-206.

28. McDaniel, D., et al. Effect of surface contamination on composite bond integrity and durability. in Advanced Materials in Transport Aircraft Structures Autumn 2011 Meeting. 2011.

29. Lee, H., I. Ohsawa, and J. Takahashi, Effect of plasma surface treatment of recycled carbon fiber on carbon fiber-reinforced plastics (CFRP) interfacial properties. Applied Surface Science, 2015. 328: p. 241-246.

30. Xie, J., et al., Improving carbon fiber adhesion to polyimide with atmospheric pressure plasma treatment. Surface and coatings technology, 2011. 206(2-3): p. 191-201.

31. Noeske, M., et al., Plasma jet treatment of five polymers at atmospheric pressure: surface modifications and the relevance for adhesion. International journal of adhesion and adhesives, 2004. 24(2): p. 171-177.

32. Bozaci, E., et al., Effects of the atmospheric plasma treatments on surface and mechanical properties of flax fiber and adhesion between fiber-matrix for composite materials. Composites Part B: Engineering, 2013. 45(1): p. 565-572.

33. Schutze, A., et al., The atmospheric-pressure plasma jet: a review and comparison to other plasma sources. IEEE transactions on plasma science, 1998. 26(6): p. 1685-1694.

34. Gilpin, A.D., B.R. Oakley, and R.G. Dillingham, Water contact angle as a quantitative measure of total polyethylene surface energy. Journal of Adhesion Science and Technology, 2015. 29(9): p. 890-895.

35. Kusano, Y., Atmospheric pressure plasma processing for polymer adhesion: a review. The Journal of Adhesion, 2014. 90(9): p. 755-777. 
36. Kusano, Y., T.L. Andersen, and P. Michelsen. Atmospheric pressure plasma surface modification of carbon fibres. in Journal of Physics: Conference Series. 2008. IOP Publishing.

37. Ashcroft, I., D. Hughes, and S. Shaw, Mode I fracture of epoxy bonded composite joints: 1. Quasi-static loading. International Journal of Adhesion and Adhesives, 2001. 21(2): p. 87-99.

38. Blackman, B., et al., Measuring the mode I adhesive fracture energy, GIC, of structural adhesive joints: the results of an international round-robin. International journal of adhesion and adhesives, 2003. 23(4): p. 293-305.

39. Standard, A., D5528, 01 (2007) e3," Standard Test Method for Mode I Interlaminar Fracture Toughness of Unidirectional Fiber-Reinforced Polymer Matrix Composites. ASTM International, 2007.

40. De Moura, M., R. Campilho, and J. Gonçalves, Crack equivalent concept applied to the fracture characterization of bonded joints under pure mode I loading. Composites Science and Technology, 2008. 68(10-11): p. 2224-2230.

41. Andersson, T. and U. Stigh, The stress-elongation relation for an adhesive layer loaded in peel using equilibrium of energetic forces. International Journal of Solids and Structures, 2004. 41(2): p. 413-434.

42. Nairn, J.A., Energy release rate analysis for adhesive and laminate double cantilever beam specimens emphasizing the effect of residual stresses. International Journal of Adhesion and Adhesives, 2000. 20(1): p. 59-70.

43. Srinivas, S., Analysis of Bonded Joints. 1975, NATIONAL AERONAUTICS AND SPACE ADMINISTRATION HAMPTON VA LANGLEY RESEARCH CEN TER.

44. Fitton, M.D. and J. Broughton, Variable modulus adhesives: an approach to optimised joint performance. International journal of adhesion and adhesives, 2005. 25(4): p. 329-336.

45. Da Silva, L.F. and R. Adams, Joint strength predictions for adhesive joints to be used over a wide temperature range. International Journal of Adhesion and Adhesives, 2007. 27(5): p. 362-379.

46. Da Silva, L.F. and R. Adams, Adhesive joints at high and low temperatures using similar and dissimilar adherends and dual adhesives. International Journal of Adhesion and Adhesives, 2007. 27(3): p. 216-226.

47. Hart-Smith, L., D. Brown, and S. Wong, Surface preparations for ensuring that the glue will stick in bonded composite structures, in Handbook of Composites. 1998, Springer. p. 667-685. 
48. Kutscha, E.O., et al., Contamination and Surface Preparation Effects on Composite Bonding. 2017.

49. Crane, R., G. Dillingham, and B. Oakley, Progress in the Reliability of Bonded Composite Structures. Applied Composite Materials, 2017. 24(1): p. 221-233.

50. Montes-Morán, M., et al., A study of the effect of plasma treatment on the interfacial properties of carbon fibre-thermoplastic composites. Carbon, 2005. 43(8): p. 1795-1799.

51. Bubert, H., et al., Basic analytical investigation of plasma-chemically modified carbon fibers. Spectrochimica Acta Part B: Atomic Spectroscopy, 2002. 57(10): p. 1601-1610.

52. Dillingham, G., et al., Quantitative detection of peel ply derived contaminants via wettability measurements. Journal of Adhesion Science and Technology, 2012. 26(10-11): p. 1563-1571.

53. Roth, J.R., Industrial Plasma Engineering: Volume 2-Applications to Nonthermal Plasma Processing. Vol. 2. 2001: CRC press.

54. Mittal, K.L., Polymer surface modification: relevance to adhesion. Vol. 3. 2004: CRC Press.

55. Cotter, J. and A. Mahoon, Development of new surface pretreatments, based on alkaline hydrogen peroxide solutions, for adhesive bonding of titanium. International Journal of Adhesion and Adhesives, 1982. 2(1): p. 47-52.

56. Kruse, A., et al., Surface pretreatment of plastics for adhesive bonding. Journal of adhesion science and technology, 1995. 9(12): p. 1611-1621.

57. Molitor, P., V. Barron, and T. Young, Surface treatment of titanium for adhesive bonding to polymer composites: a review. International Journal of Adhesion and Adhesives, 2001. 21(2): p. 129-136.

58. Wu, S., Polymer interface and adhesion. 1982: M. Dekker.

59. Lommatzsch, U., et al., Atmospheric pressure plasma jet treatment of polyethylene surfaces for adhesion improvement. Plasma Processes and Polymers, 2007. 4(S1).

60. Morent, R., et al., Non-thermal plasma treatment of textiles. Surface and coatings technology, 2008. 202(14): p. 3427-3449.

61. Hanusová, J., et al., Atmospheric pressure plasma treatment of polyamide-12 foils. Open Chemistry, 2015. 13(1). 
62. Van Deynse, A., R. Morent, and N. De Geyter, Surface modification of polymers using atmospheric pressure cold plasma technology, in Polymer science: research advances, pratical applications and educational aspects. 2016, Formatex Research Center. p. 506-516.

63. Selwyn, G., et al., Materials processing using an atmospheric pressure, $R F$ generated plasma source. Contributions to Plasma Physics, 2001. 41(6): p. 610619.

64. Tracey, A.C., Effect of Atmospheric Pressure Plasma Treatment on Surface Characteristics and Adhesive Bond Quality of Peel Ply Prepared Composites. 2014.

65. Gerenser, L., Surface chemistry of plasma-treated polymers. 1996, IOP Publishing, Bristol. p. 1.

66. Kumar, S., et al., Effect of atmospheric pressure plasma treatment for repair of polymer matrix composite for aerospace applications. Journal of Composite Materials, 2016. 50(11): p. 1497-1507.

67. Jie, S. and Q. Yiping, The effects of gas composition on the atmospheric pressure plasma jet modification of polyethylene films. Plasma Science and Technology, 2015. 17(5): p. 402.

68. Murokh, I., Atmospheric Plasma Surface Treatment Technique. El Segundo, CA: Tri-Star Technologies, 2005.

69. $\mathrm{Yu}, \mathrm{H} .$, Application of atmospheric pressure plasma in polymer and composite adhesion. 2016, University of California, Los Angeles.

70. Williams, T.S. and R.F. Hicks, Aging mechanism of the native oxide on silicon (100) following atmospheric oxygen plasma cleaning. Journal of Vacuum Science \& Technology A: Vacuum, Surfaces, and Films, 2011. 29(4): p. 041403.

71. Flinn, B.D., et al., Improving Adhesive Bonding of Composites Through Surface Characterization. The Joint Advanced Materials and Structures Center of Excellence, CECAM, and AMTAS, University of Washington in: http://depts. washington. edu/amtas/ev-ents/jams_, 2010. 8: p. 21.

72. Williams, T.S., Surface Modification by Atmospheric Pressure Plasma for Improved Bonding. 2013: University of California, Los Angeles.

73. Fauchais, P. and A. Vardelle, Thermal plasmas. IEEE Transactions on plasma science, 1997. 25(6): p. 1258-1280.

74. Smith, R., D. Wei, and D. Apelian, Thermal plasma materials processingApplications and opportunities. Plasma Chemistry and Plasma Processing, 1989. 9(1): p. 135S-165S. 
75. Ramakrishnan, S. and M. Rogozinski, Properties of electric arc plasma for metal cutting. Journal of Physics D: Applied Physics, 1997. 30(4): p. 636.

76. Yu, R.H., et al., Atmospheric and Vacuum Plasma Treatments of Polymer Surfaces for Enhanced Adhesion in Microelectronics Packaging. Adhesion in Microelectronics, 2014: p. 137-172.

77. Laroussi, M. and T. Akan, Arc-free atmospheric pressure cold plasma jets: a review. Plasma Processes and Polymers, 2007. 4(9): p. 777-788.

78. Elaragi, G. and H. Elaraby, Characterization of an Atmospheric-pressure Cold Plasma Jet.

79. Chen, F.F. and J.P. Chang, Principles of plasma processing. Univ. of California, book, 2002.

80. Babayan, S., et al., Characterization of the active species in the afterglow of a nitrogen and helium atmospheric-pressure plasma. Plasma Chemistry and Plasma Processing, 2002. 22(2): p. 255-269.

81. Kaelble, D., Dispersion-polar surface tension properties of organic solids. The Journal of Adhesion, 1970. 2(2): p. 66-81.

82. Good, R.J., Contact angle, wetting, and adhesion: a critical review. Journal of adhesion science and technology, 1992. 6(12): p. 1269-1302.

83. Jacobasch, H.-J., et al., Application of the surface free energy concept in polymer processing. Journal of adhesion science and technology, 1992. 6(12): p. 13811396.

84. Kwok, D., et al., Measuring and interpreting contact angles: a complex issue. Colloids and Surfaces A: Physicochemical and Engineering Aspects, 1998. 142(23): p. 219-235.

85. Tran, L.Q.N., et al., Wetting analysis and surface characterisation of coir fibres used as reinforcement for composites. Colloids and Surfaces A: Physicochemical and Engineering Aspects, 2011. 377(1): p. 251-260.

86. Yuan, Y. and T.R. Lee, Contact angle and wetting properties, in Surface science techniques. 2013, Springer. p. 3-34.

87. Gao, L. and T. McCarthy, Wetting 101 Langmuir 2009, 25, 14105-14115. DOI.

88. Strobel, M., et al., Contact angle measurements on oxidized polymer surfaces containing water-soluble species. Journal of Adhesion Science and Technology, 2015. 29(14): p. 1483-1507. 
89. Thakker, M., et al., Validation of Low Cost Solid Liquid Contact Angle Instrument Using Drop Shape Image Processing Suitable For Surface Property Measurement. International Journal of Current Engineering and Technology, 2013. 3(3): p. 877-888.

90. Oporto, G.S., et al., Forced air plasma treatment (FAPT) of hybrid wood plastic composite (WPC)-fiber reinforced plastic (FRP) surfaces. Composite Interfaces, 2009. 16(7-9): p. 847-867.

91. Van Deynse, A., et al., Surface modification of polyethylene in an argon atmospheric pressure plasma jet. Surface and Coatings Technology, 2015. 276: p. 384-390.

92. Young, T., III. An essay on the cohesion of fluids. Philosophical transactions of the royal society of London, 1805. 95: p. 65-87.

93. Pappas, D., C. Copeland, and R. Jensen, Wettability Tests of Polymer Films and Fabrics and Determination of Their Surface Energy by Contact-Angle Methods. 2007, ARMY RESEARCH LAB ABERDEEN PROVING GROUND MD.

94. Fowkes, F.M., Additivity of intermolecular forces at interfaces. i. determination of the contribution to surface and interfacial tensions of dispersion forces in various liquids1. The Journal of Physical Chemistry, 1963. 67(12): p. 2538-2541.

95. Owens, D., Some thermodynamic aspects of polymer adhesion. Journal of applied polymer science, 1970. 14(7): p. 1725-1730.

96. Goldstein, J.I., et al., Generation of X-rays in the SEM specimen, in Scanning Electron Microscopy and X-Ray Microanalysis. 2003, Springer. p. 271-296.

97. Skoog, D.A., F.J. Holler, and S.R. Crouch, Principles of instrumental analysis. 2017: Cengage learning.

98. Slayter, E.M. and H.S. Slayter, Light and electron microscopy. 1992: Cambridge University Press.

99. Ren, Y., C. Wang, and Y. Qiu, Aging of surface properties of ultra high modulus polyethylene fibers treated with HelO2 atmospheric pressure plasma jet. Surface and Coatings Technology, 2008. 202(12): p. 2670-2676.

100. Liu, Y., et al., Influence of environmental moisture on atmospheric pressure plasma jet treatment of ultrahigh-modulus polyethylene fibers. Journal of Adhesion Science and Technology, 2007. 21(8): p. 663-676.

101. Gao, Z., et al., Influence of processing parameters on atmospheric pressure plasma etching of polyamide 6 films. Applied Surface Science, 2009. 255(17): p. 7683-7688. 
102. Czabaj, M.W. and J.G. Ratcliffe, Comparison of intralaminar and interlaminar mode I fracture toughnesses of a unidirectional IM7/8552 carbon/epoxy composite. Composites Science and Technology, 2013. 89: p. 15-23.

103. Alfred Franklin, V. and T. Christopher, Fracture energy estimation of DCB specimens made of glass/epoxy: an experimental study. Advances in Materials Science and Engineering, 2013. 2013.

104. Prasad, M.S., C. Venkatesha, and T. Jayaraju, Experimental methods of determining fracture toughness of fiber reinforced polymer composites under various loading conditions. Journal of Minerals and Materials Characterization and Engineering, 2011. 10(13): p. 1263.

105. Tracey, A., Improving Adhesive Bonding Through Surface Characterization: Reverse the Curse of the Nylon Peel Ply. 2013. Boeing Co, 2013.

106. ASTM, D., 5573-99. Standard practice for classifying failure modes in fiberreinforced-plastic (FRP) joints. Annual book of ASTM standards, 2002. 15.

107. Shanahan, M. and C. Bourges-Monnier, Effects of plasma treatment on the adhesion of an epoxy composite. International journal of adhesion and adhesives, 1996. 16(2): p. 129-135.

108. Navarro Rodriguez, B., Plasma pre-treatment for adhesive bonding of aerospace composite components. 2016, Brunel University London.

109. Composites, H., HexPly® 8552 Product Data. 2000, Tech. Rep.(Hexcel, 2013).

110. Mathews, M.J. and S.R. Swanson, Characterization of the interlaminar fracture toughness of a laminated carbon/epoxy composite. Composites Science and Technology, 2007. 67(7-8): p. 1489-1498.

111. Huner, U., H.A. Gulec, and I. Damar Huner, Effect of gas type and application distance on atmospheric pressure plasma jet-treated flax composites. Journal of Reinforced Plastics and Composites, 2017. 36(17): p. 1197-1210.

112. Su, F.-h., et al., Tribological and mechanical properties of the composites made of carbon fabrics modified with various methods. Composites Part A: Applied Science and Manufacturing, 2005. 36(12): p. 1601-1607.

113. Cognard, J., Some recent progress in adhesion technology and science. Comptes Rendus Chimie, 2006. 9(1): p. 13-24.

114. Luo, Y., et al., Surface and wettability property analysis of CCF300 carbon fibers with different sizing or without sizing. Materials \& Design, 2011. 32(2): p. 941946. 
115. Payne, B., M. Biesinger, and N. McIntyre, X-ray photoelectron spectroscopy studies of reactions on chromium metal and chromium oxide surfaces. Journal of Electron Spectroscopy and Related Phenomena, 2011. 184(1-2): p. 29-37.

116. Fang, X., Jalowka, J., Riehl, J., Zhao, W., Goberman, D., Contamination effect on composite-to-metal adhesive bond performance, in SAMPE Conference Proceedings. 2017: Seattle, WA.

117. Fang, X., Sarao, G., Zhao, W., Goberman, D.G., Connell, J.W, Effectiveness of Surface Treatment Techniques for Composite Bonding with Different Contamination Levels, in SAMPE Conference Proceedings. 2018: Long Beach, CA.

118. Webb, L.J., et al., High-resolution X-ray photoelectron spectroscopic studies of alkylated silicon (111) surfaces. The Journal of Physical Chemistry B, 2005. 109(9): p. 3930-3937.

119. Birer, Ö., et al., XPS investigation of thin SiOx and SiOxNy overlayers. Journal of molecular structure, 1999. 480: p. 611-614.

120. Encinas, N., et al., Extreme durability of wettability changes on polyolefin surfaces by atmospheric pressure plasma torch. Surface and Coatings Technology, 2010. 205(2): p. 396-402.

121. Encinas, N., et al., Atmospheric pressure plasma hydrophilic modification of a silicone surface. The Journal of Adhesion, 2012. 88(4-6): p. 321-336.

122. Rousseau G, Wehbe R, Halbritter J, Harik R, Automated Fiber Placement Path Planning: A state-of-the-art, review. Computer-Aided Design \& Applications, 2019. 16(2): p. 172-203.

123. Noevere A, Collier C, Harik R, Halbritter J. Development of a Design for Manufacturing Tool for Automated Fiber Placement Structures. in AIAA Scitech 2019 Forum. 2019.

124. Halbritter J, Harik R, Toren M, Waerdt W van de, Modular Conversion Tool For Generating Fiber Placement Code From Optimized Fiber Steering Path, in The Composites and Advanced Materials Expo CAMX2017. 2017.

125. Halbritter J, Harik R, Zuloaga A, Tooren M. Tool path generation on doublycurved free-form surfaces. Computer-Aided Design and Applications, 2017. 14(6): p. 844-851.

126. Harik R, Saidy C, Williams SJ, Gurdal Z, Grimsley B. Automated fiber placement defect identity cards: cause, anticipation, existence, significance, and progression. in Submission to SAMPE 2018 Conference \& Exhibition, Long Beach, California, US. 2018. 
127. Rajan S, Sutton MA, Wehbe R, Tatting B, Gurdal Z, Kidane A, Harik R. Experimental investigation of prepreg slit tape wrinkling during automated fiber placement process using StereoDIC. Composites Part B: Engineering, 2019. 160: p. 546-557.

128. Anay R, Ziehl P, Tessema A, Wehbe R, Assi L, Kidane A, Harik R, Tatting B, Gurdal Z. An Experimental Investigation Concerning the Effects of AFP Defects on Progressive Failure of Tensile Coupons. in AIAA Scitech 2019 Forum. 2019.

129. Wehbe R, Harik R, Gurdal Z. In-plane tow deformations due to steering in automated fiber placement. in AIAA Scitech 2019 Forum. 2019.

130. Wehbe R, Harik R, Tatting B, Gurdal Z, Halbritter A, Wanthal S. Tow-Path Based Modeling of Wrinkling During the Automated Fiber Placement Process. The Composites and Advanced Materials Expo CAMX2017, 2017.

131. Albazzan M, Harik R, Tatting B, Gurdal Z. Efficient Design Optimization of Nonconventional Laminated Composites using Lamination Parameters: A State of the Art. Composite Structures, 209, pp 362-374

132. Sabido A, Bahamonde L, Harik R, Tooren M. Maturity assessment of the laminate variable stiffness design process. Composite Structures, 2017. 160: p. 804-812.

133. Bahamonde L, Bazzan M, Chevalier P, Gurdal Z, Tatting B, Harik R. Rapid tools for an AFP manufacturing defects assessment framework in SAMPE 2018 Conference \& Exhibition. 2018: Long Beach, California, US.

134. Harik R, Shi Y, Baek S. Shape Terra: mechanical feature recognition based on a persistent heat signature. Computer Aided Design and Applications, 2017. 14 (2) pp 206-218

135. Harik R. Spécifications de fonctions pour un système d'aide à la génération automatique de gamme d'usinage: application aux pièces aéronautiques de structure, prototype logiciel dans le cadre du projet RNTL USIQUICK. Université Henri Poincaré-Nancy I, 2007. 


\section{APPENDIX A}

\section{STANDARDIZATION FLOWCHARTS}

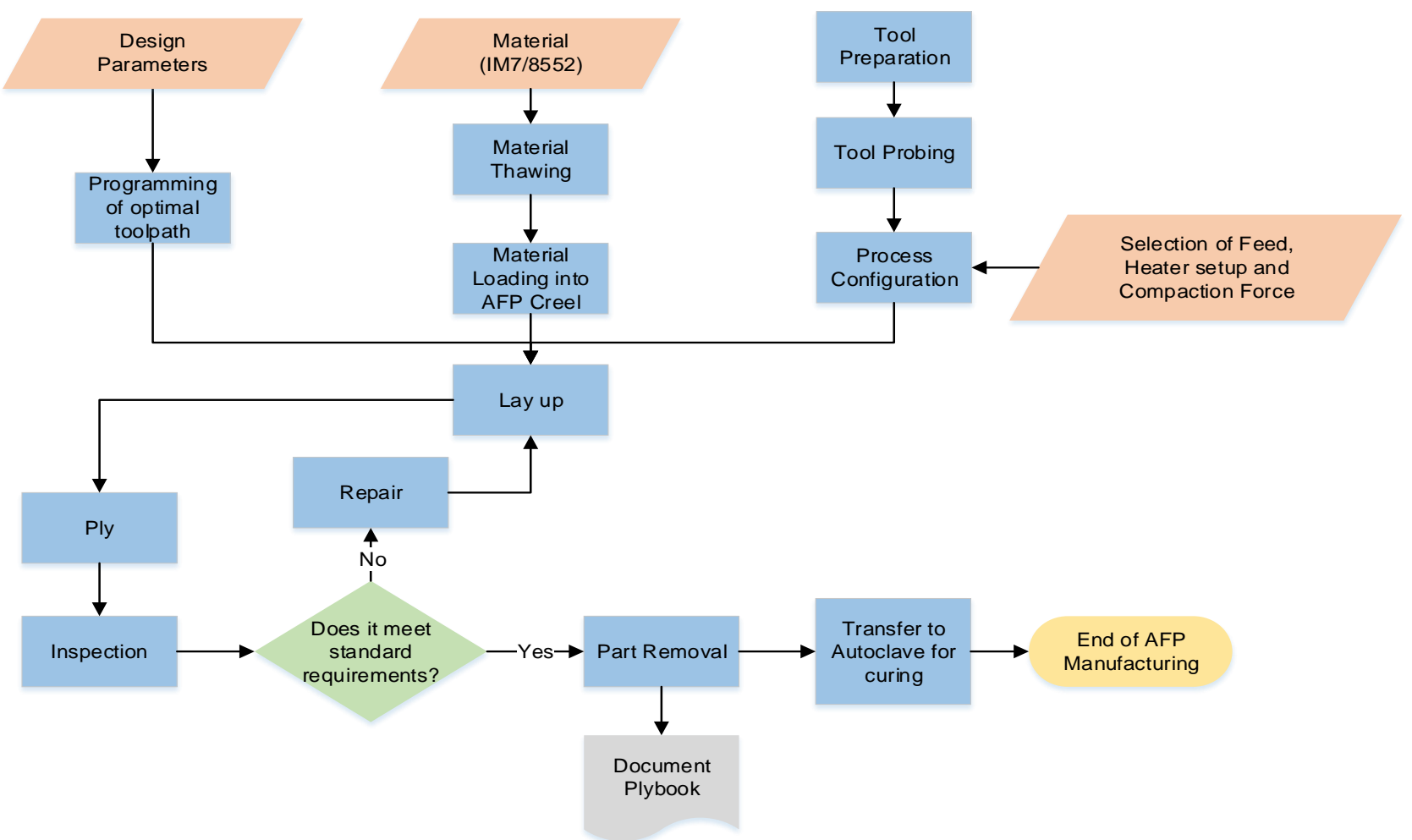

Figure A.1 AFP composite manufacturing flowchart 


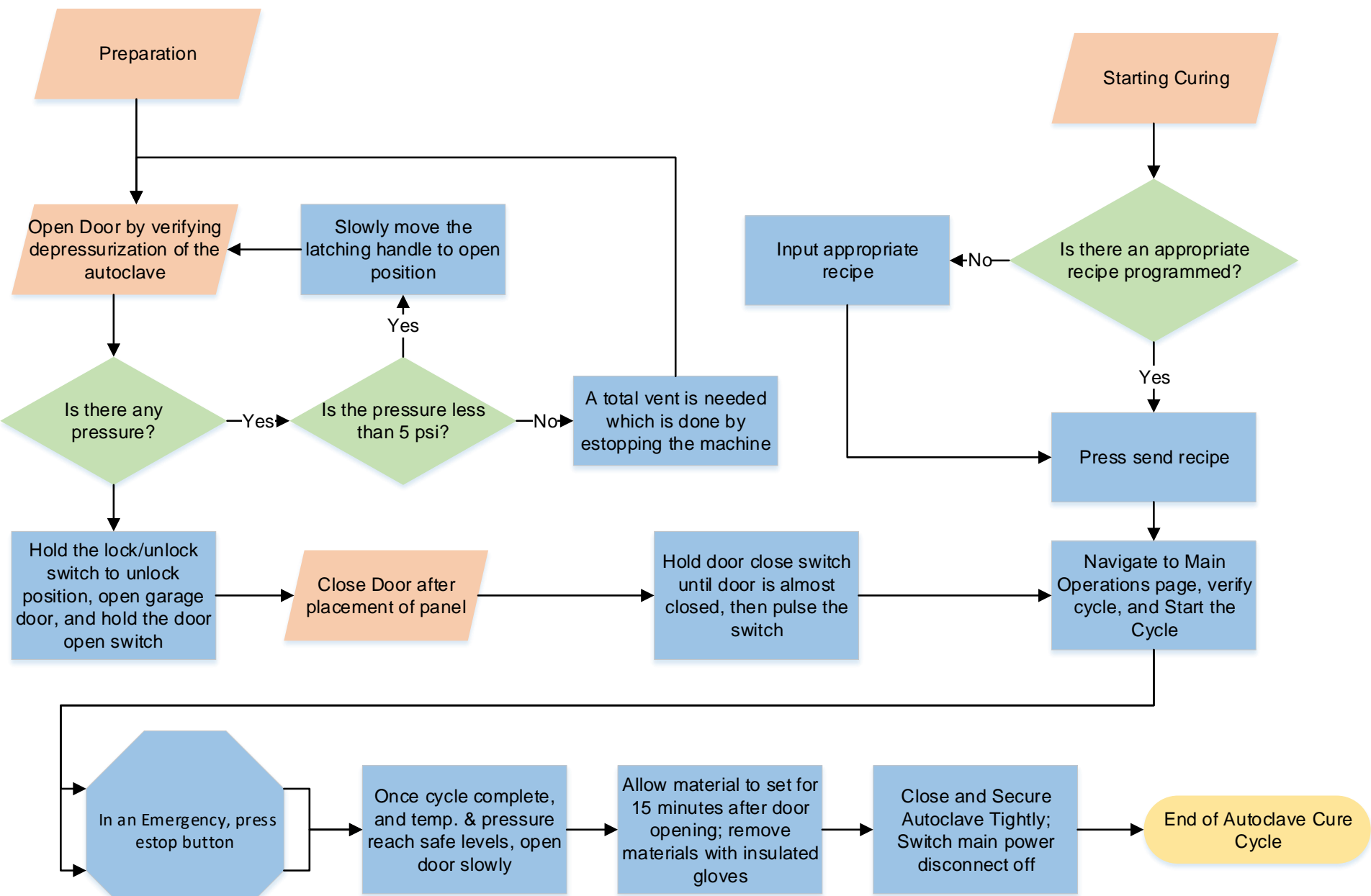

Figure A.2 Autoclave cure cycle flowchart 


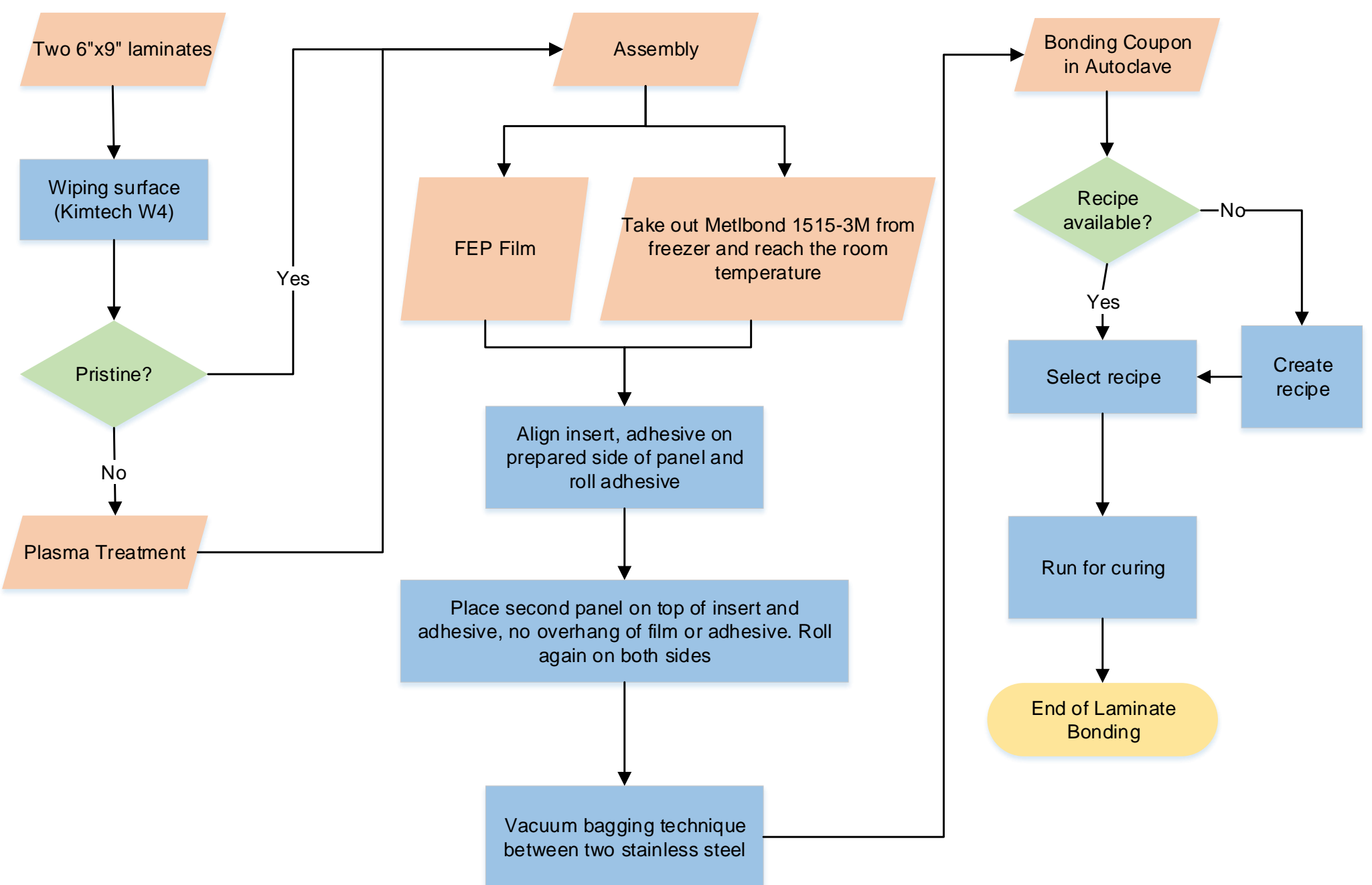

Figure A.3 Bonding laminate flowchart 


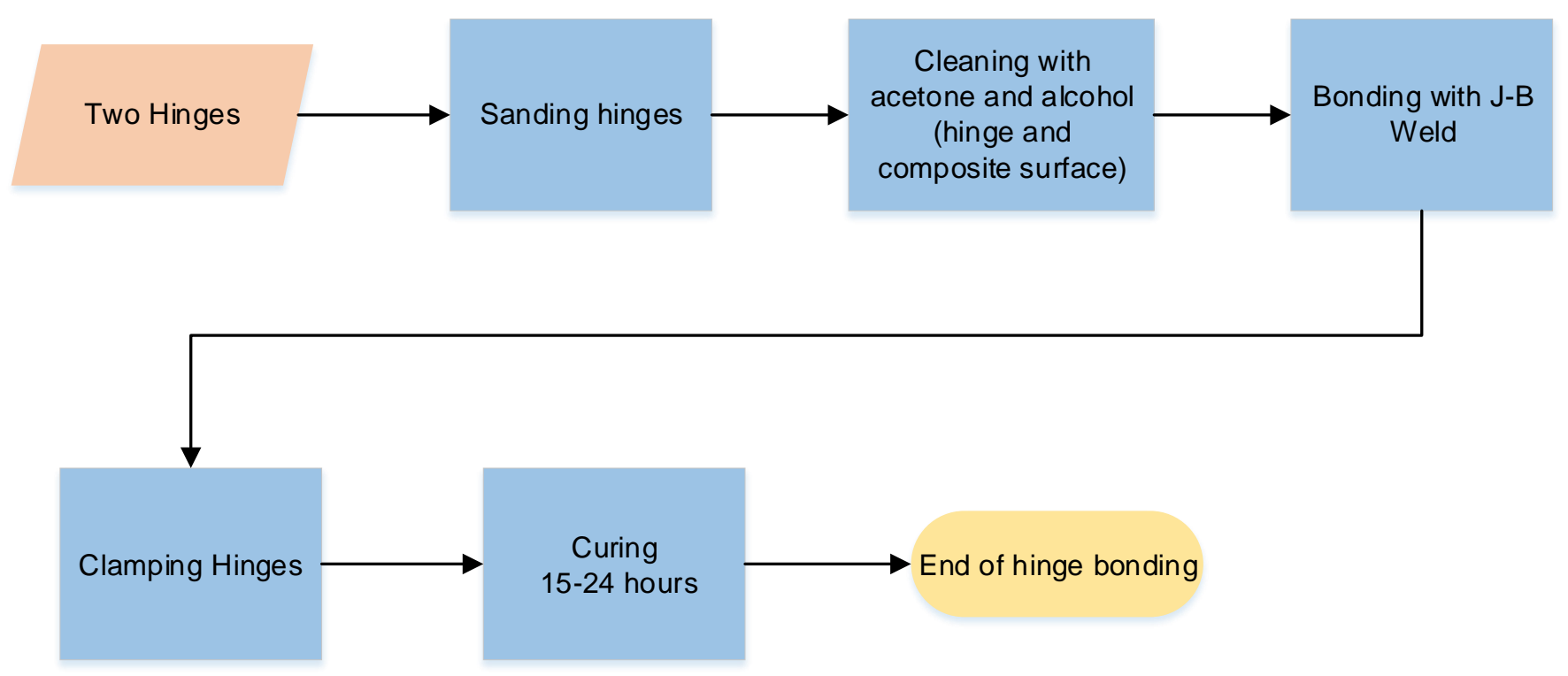

Figure A.4 Hinge bonding test flowchart 


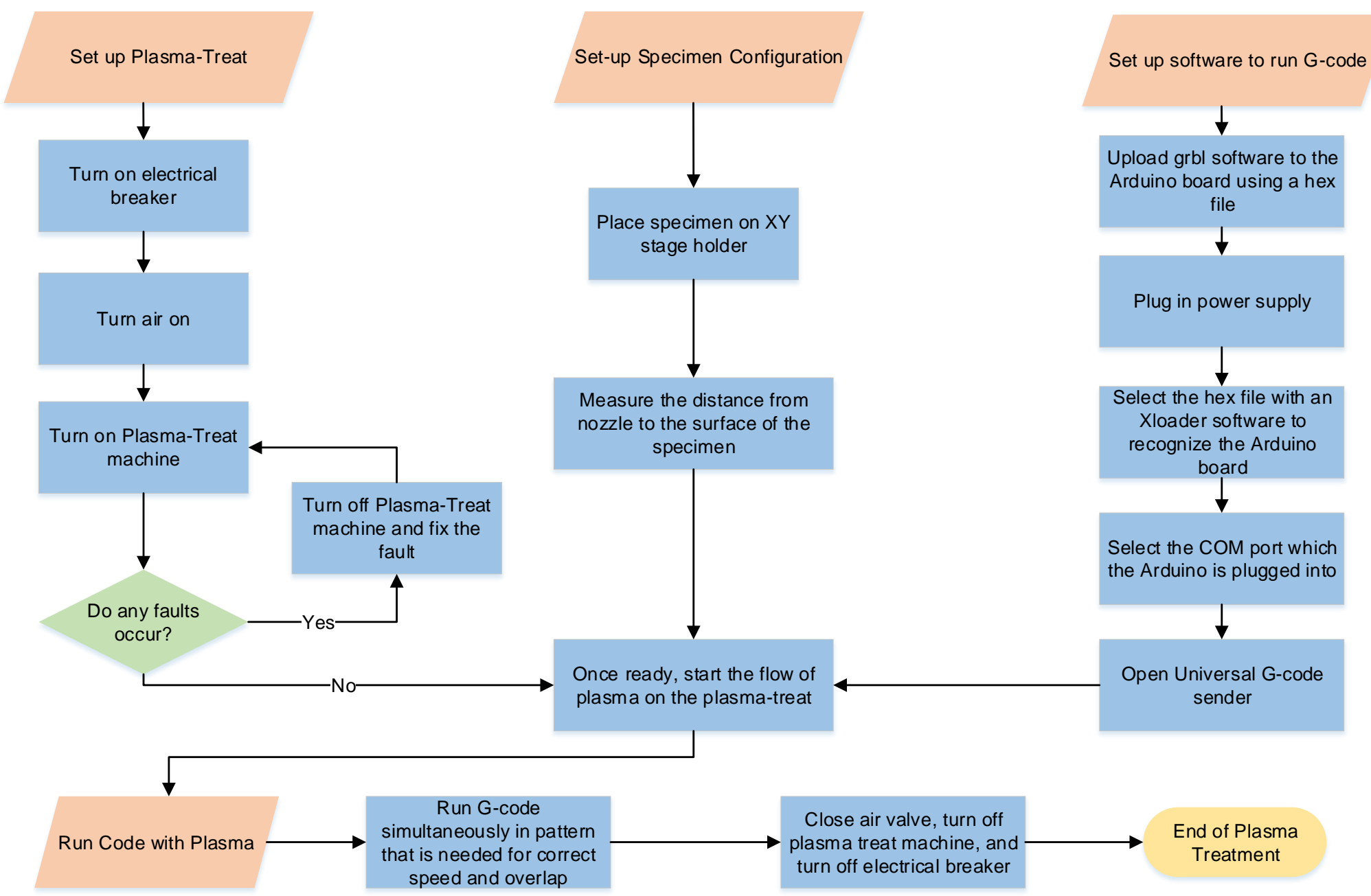

Figure A.5 Atmospheric pressure plasma treatment flowchart 


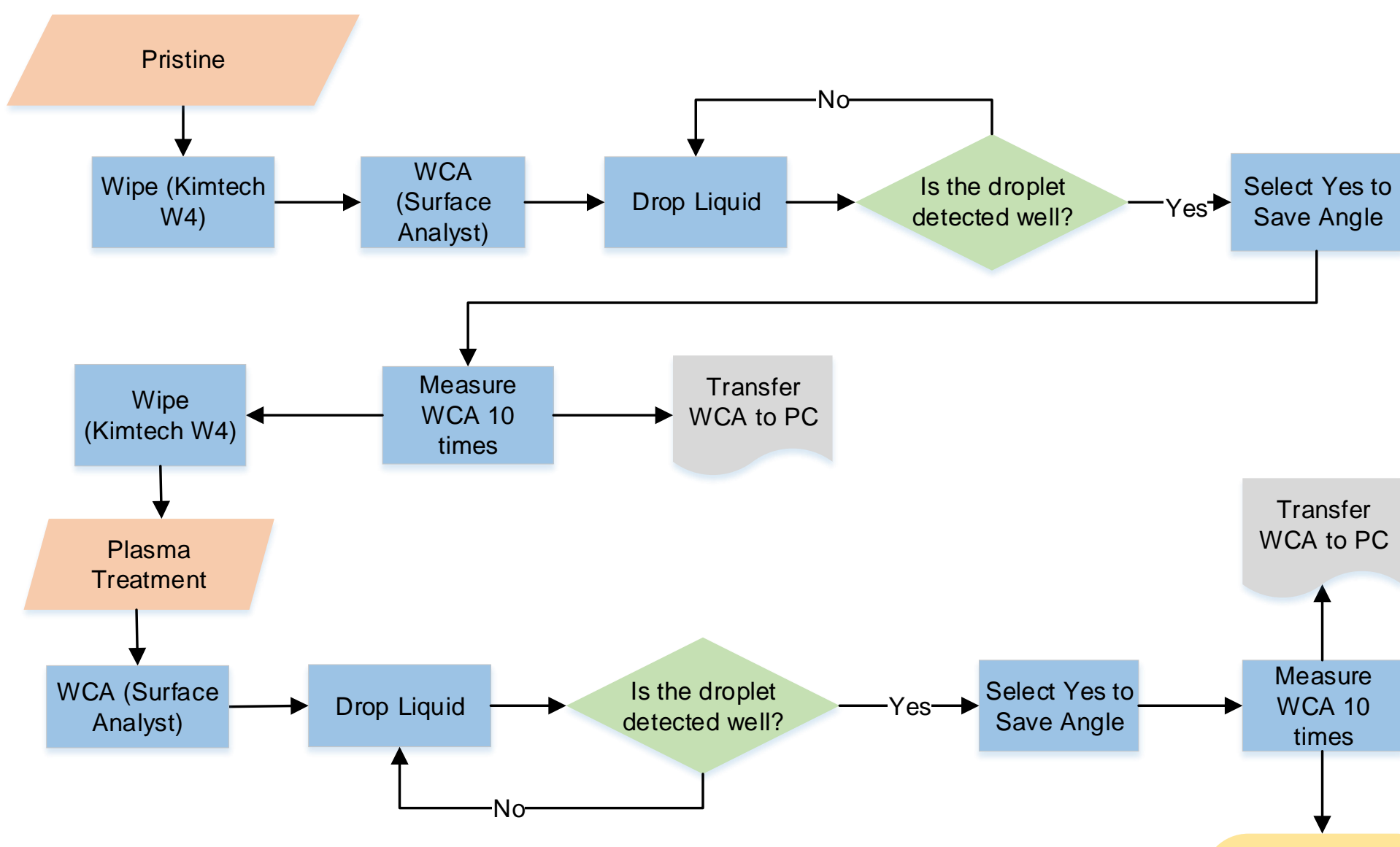

End of WCA Measurement

Figure A.6 Water contact angle measurement flowchart 


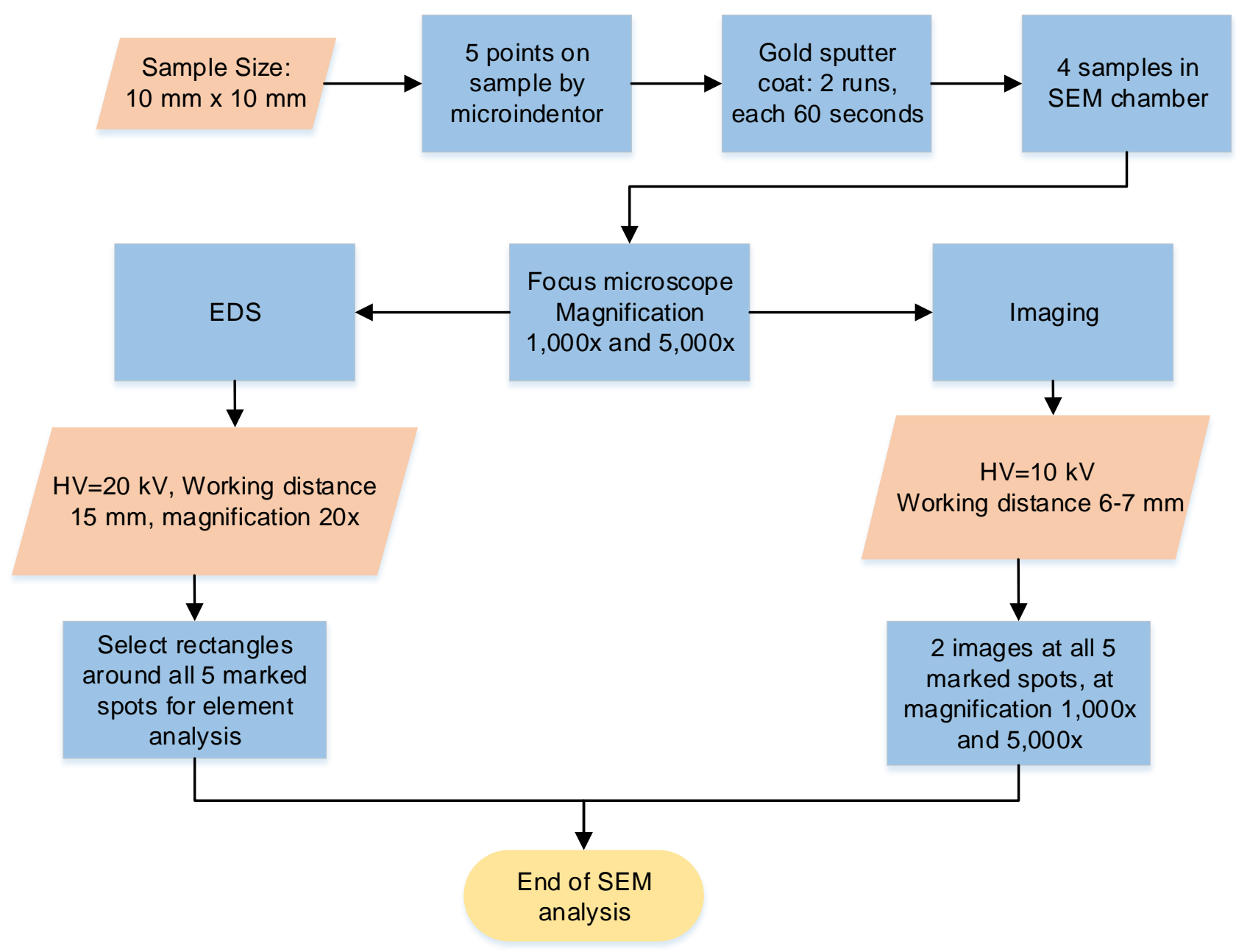

Figure A.7 SEM flowchart 


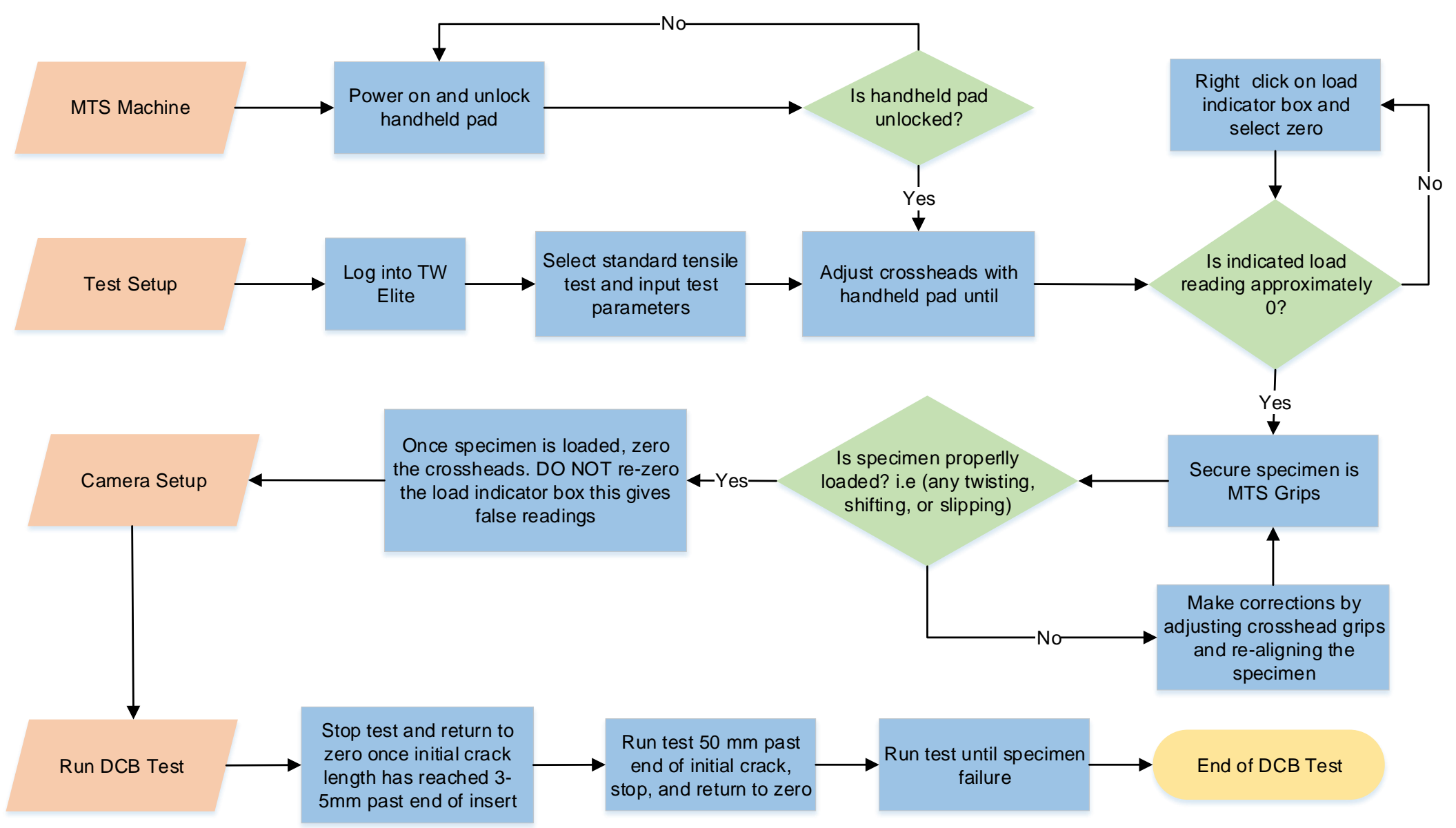

Figure A.8 Double cantilever beam test flowchart 